Universidad de Lima

Facultad de Ingeniería y Arquitectura

Carrera de Ingeniería Industrial

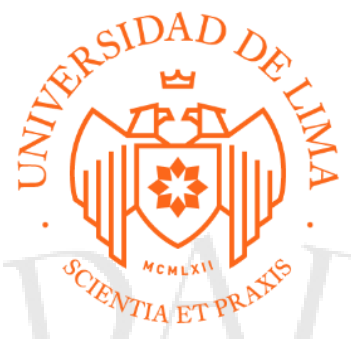

\title{
ESTUDIO DE LA REMOCIÓN DE ARSÉNICO EN AGUAS PARA RIEGO MEDIANTE LA ADICIÓN DE IONES FERRATO(VI)
}

Trabajo de investigación para optar el Título Profesional de Ingeniero Industrial

Patricia Mahela Prieto Veramendi

Código 20122098

\section{Asesor}

Javier Quino Favero, MSc

$$
\text { Lima - Perú }
$$

Setiembre de 2019 


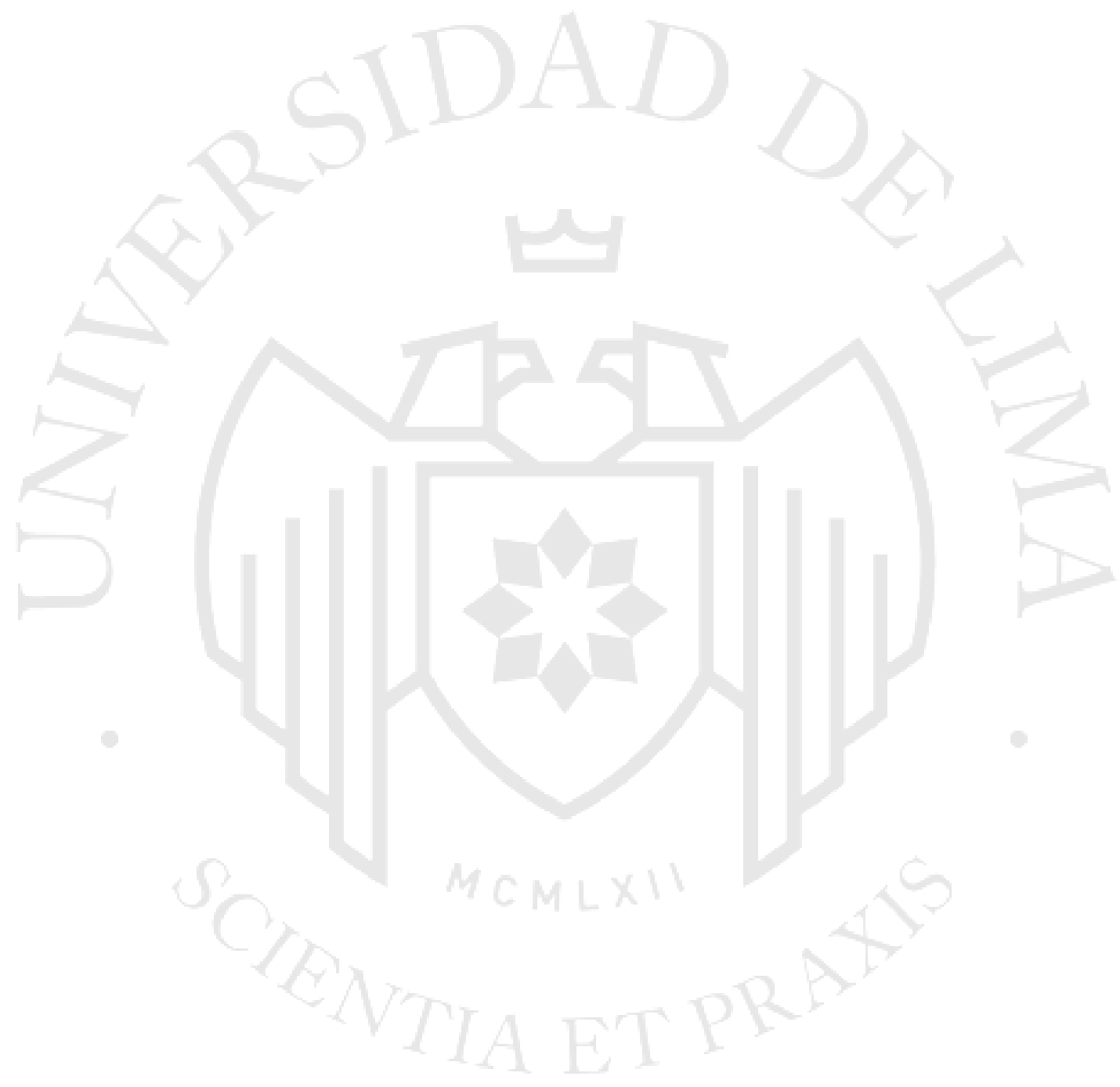




\section{STUDY OF ARSENIC REMOVAL FROM IRRIGATION WATER BY THE ADDITION OF FERRATE(VI) IONS}


1. RESUMEN ….................................................................................................

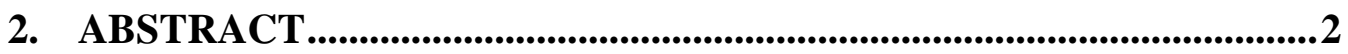

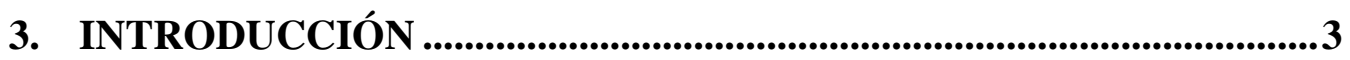

1. CAPÍTULO I. ASPECTOS GENERALES...............................................4

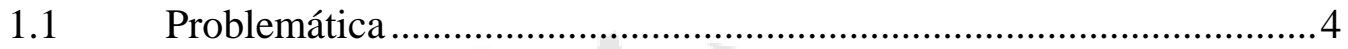

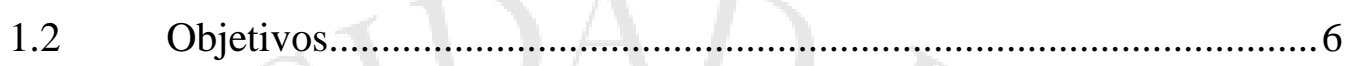

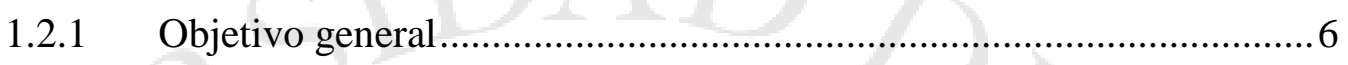

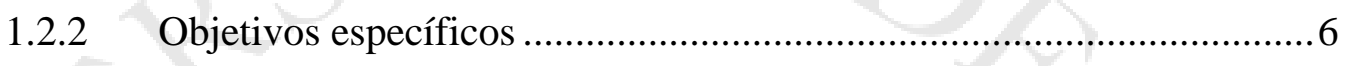

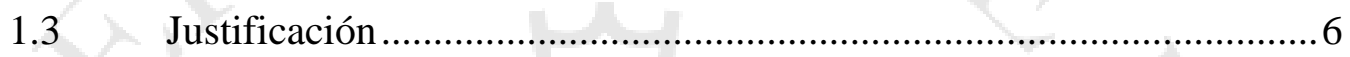

1.3.1 Justificación Técnica....................................................................6

1.3.2 Justificación Económica ………………………………………........

1.3.3 Justificación Social ........................................................................

$1.4 \quad$ Alcances y limitaciones ............................................................

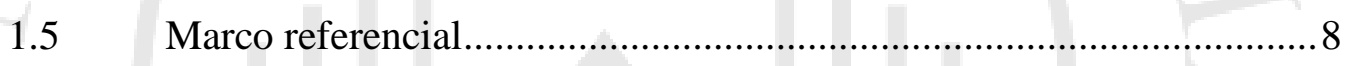

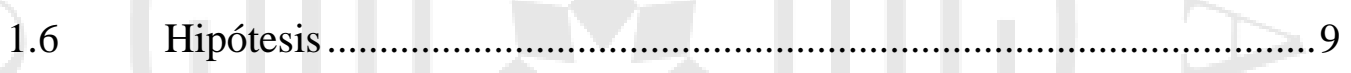

1.6.1 Variable dependiente .......................................................................

1.6.2 Variables independientes ...........................................................

1.6.3 Formulación de la hipótesis general ...................................................

1.6.4 Formulación de las hipótesis específicas ................................................

2. CAPÍTULO II. ASPECTOS TÉ́RICOS ............................................11

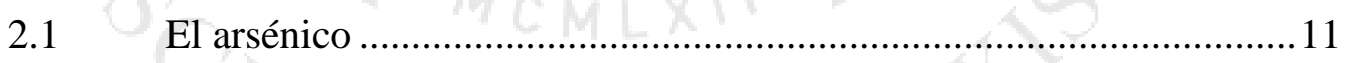

2.1.1 Formas de ocurrencia del arsénico.....................................................11

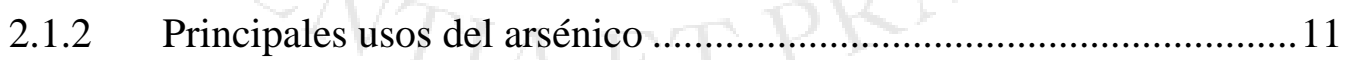

2.1.3 Presencia de arsénico en las aguas naturales ...................................... 12

2.1.4 Toxicidad del arsénico ................................................................... 13

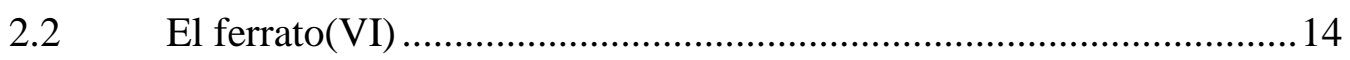

2.2.1 Propiedades físicas y químicas del ferrato(VI) ................................... 14

2.2.2 Uso del ferrato(VI) para el tratamiento de agua .................................. 15

2.2.3 Métodos de producción de ferrato(VI) .............................................. 16

2.3 La coagulación en el tratamiento de agua ............................................ 18

$2.4 \quad$ Filtración por membranas.................................................................. 19 
2.4.2 Fouling de la membrana ..............................................................22

2.5 Aspectos fisicoquímicos de la calidad del agua ...............................23

3. CAPÍTULO III. MATERIALES Y MÉTODOS .....................................29

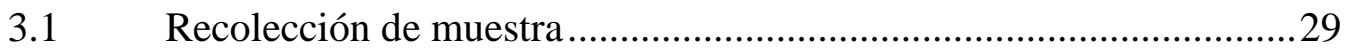

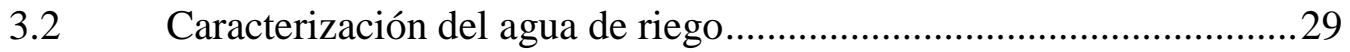

3.2.1 Medición de Alcalinidad .................................................................... 30

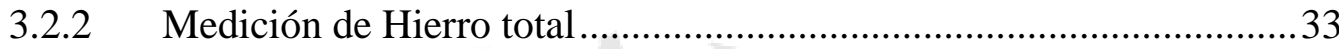

3.2.3 Medición de Sólidos Suspendidos Totales ..........................................35

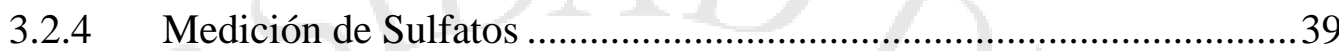

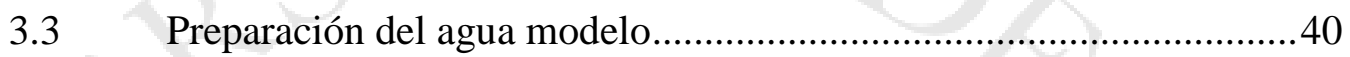

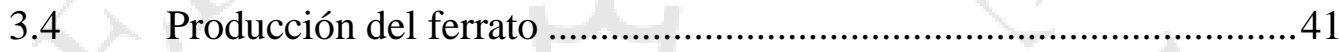

3.5 Medición de la concentración del ferrato(VI) ...................................42

3.6 Descripción de la prueba de jarras....................................................43

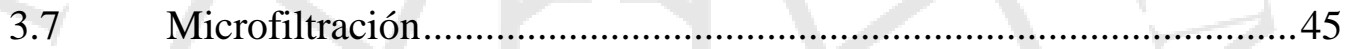

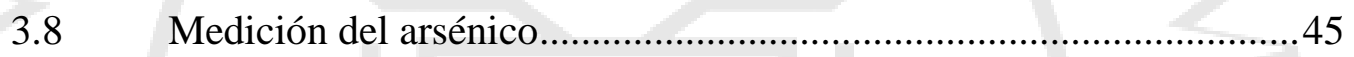

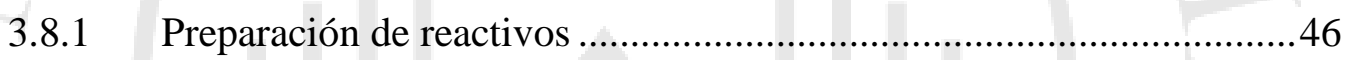

3.9 Evaluación del costo de tratamiento ..............................................4

4. CAPÍTULO IV. RESULTADOS.........................................................48

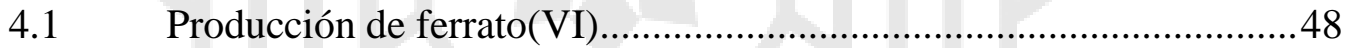

4.2 Resultados de la caracterización inicial............................................4 48

4.3 Resultados del tratamiento con iones ferrato(VI) y cloruro férrico ...51

4.4 Resultados de la caracterización final .............................................57

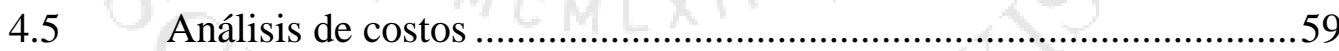

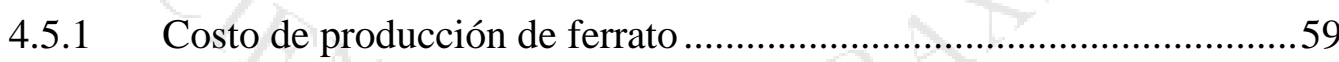

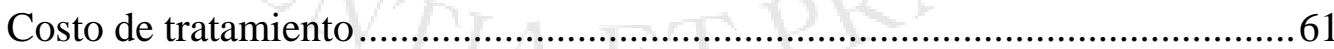

5. CAPÍTULO V. INGENIERÍA DEL PROYECTO..................................63

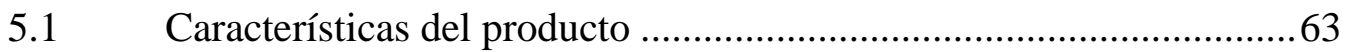

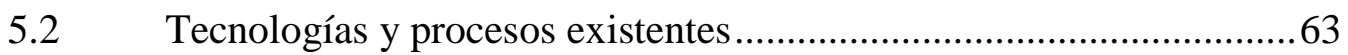

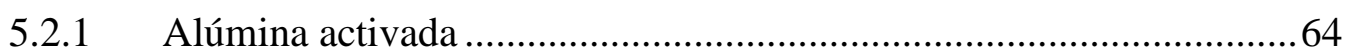

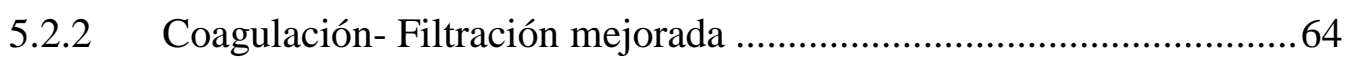

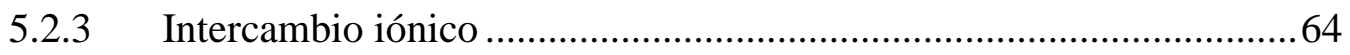

5.2.4 Ablandamiento con cal mejorado ..................................................65

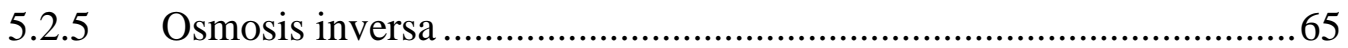




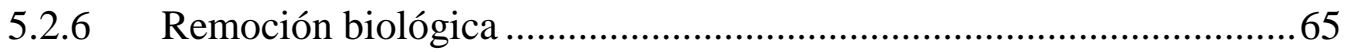

5.2.7 Selección de la tecnología.................................................................66

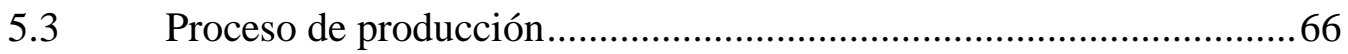

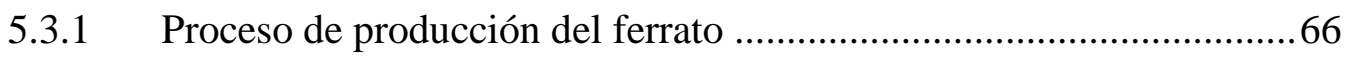

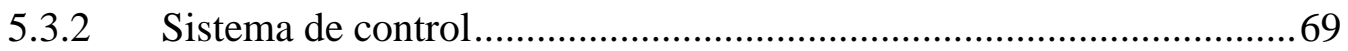

5.3.3 Proceso propuesto de tratamiento de agua para riego.........................69

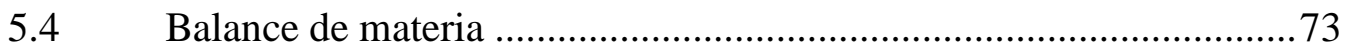

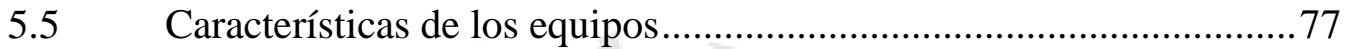

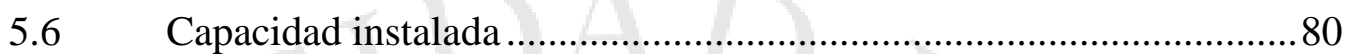

5.6.1 Cálculo del número de equipos y operarios requeridos .....................80

5.6.2 Cálculo de la capacidad instalada ................................................... 82

5.7 Identificación de los aspectos e impactos en el proceso.....................83

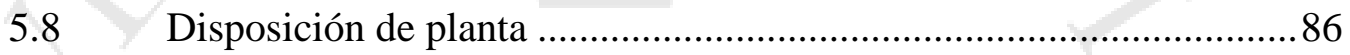

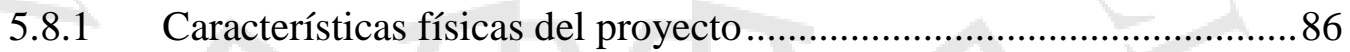

5.8.2 Determinación de las zonas físicas requeridas .................................. 86

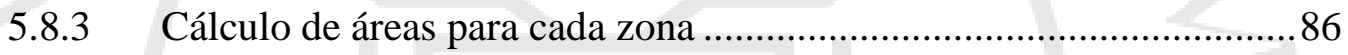

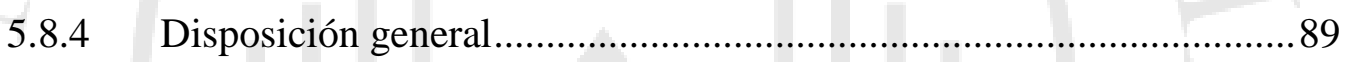

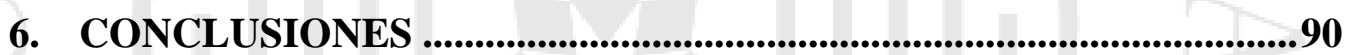

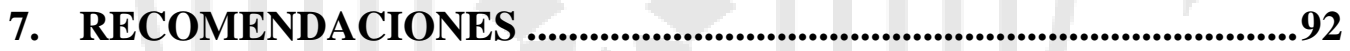

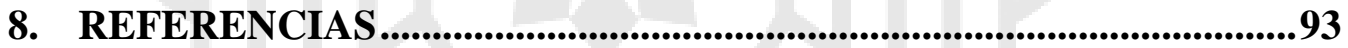

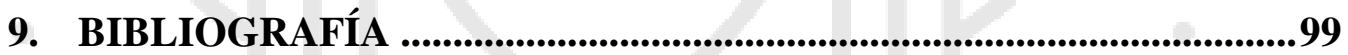

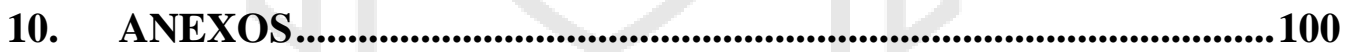




\section{ÍNDICE DE TABLAS}

Tabla 1.1 Disponibilidad hídrica a nivel nacional según vertiente, en $\mathrm{Hm}^{3}$.......4

Tabla 2.1 Potencial Redox para diferentes oxidantes utilizados en el tratamiento

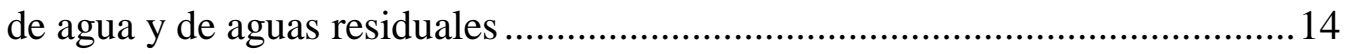

Tabla 2.2 Parámetros para agua destinada al riego de vegetales......................24

Tabla 3.1 Parámetros fisicoquímicos medidos en el punto de muestreo ..........29

Tabla 3.2 Parámetros fisicoquímicos a medir en laboratorio ............................30

Tabla 3.3 Reactivos empleados en la medición de arsénico total ....................45

Tabla 4.1 Resultados de los parámetros medidos en campo ..........................50

Tabla 4.2 Resultados de los parámetros medidos en laboratorio .....................50

Tabla 4.3 Dosificaciones con $\mathrm{Fe}(\mathrm{VI}) / \mathrm{Fe}(\mathrm{III})$ que remueven el arsénico a concentraciones menores a las que establece el ECA para agua de riego .........55

Tabla 4.4 Coeficientes de la regresión multivariable .....................................55

Tabla 4.5 Resumen del modelo de regresión...................................................56

Tabla 4.6 Resultados de la caracterización final ............................................57

Tabla 4.7 Energía consumida a corriente constante ......................................59

Tabla 4.8 Precios de consumibles para cada ciclo de producción.....................60

Tabla 4.9 Costo total de consumibles para cada ciclo de producción ...............61

Tabla 4.10 Costo de consumibles para un metro cúbico de agua.....................62

Tabla 5.1 Mejores tecnologías disponibles para la remoción de arsénico de agua potable

Tabla 5.2 Especificaciones de los equipos y dispositivos para la producción de ferrato.

Tabla 5.3 Especificaciones de los equipos e instrumentos para el tratamiento de

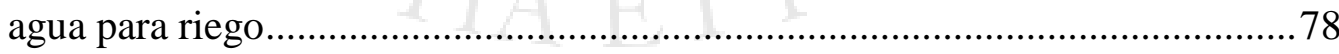

Tabla 5.4 Número de equipos requeridos para el tratamiento de agua..............80

Tabla 5.5 Número de equipos requeridos para la producción de ferrato..........81

Tabla 5.6 Capacidad instalada para la producción de ferrato...........................82

Tabla 5.7 Capacidad instalada para el tratamiento de agua.............................83

Tabla 5.8 Matriz de caracterización para la producción de ferrato ...................84

Tabla 5.9 Matriz de caracterización para el proceso de tratamiento de agua ... 85

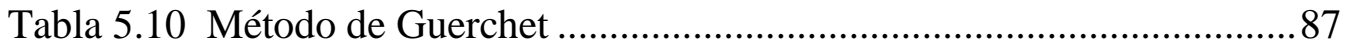




\section{ÍNDICE DE FIGURAS}

Figura 2.1 Especies de As(V) como función de $\mathrm{pH}$....................................... 12

Figura 2.2 Especies de As(III) como función de $\mathrm{pH}$...................................... 13

Figura 2.3 Esquema del proceso de separación a través de una membrana semipermeable. 20

Figura 2.4. Diagrama conceptual de las principales partículas rechazadas según el tipo de membrana 20

Figura 2.5 Filtración de flujo tangencial y filtración de punto muerto.............21

Figura 3.1 Instrumento, materiales y reactivos para medir alcalinidad ............31

Figura 3.2 Titulación para determinar alcalinidad............................................32

Figura 3.3 Coloración del punto final de la titulación para medir alcalinidad .33

Figura 3.4 Equipo, materiales y reactivos para medir Hierro total.................. 33

Figura 3.5 Ubicación de la celda en el colorímetro DR 890 ..........................34

Figura 3.6 Filtrado de muestra para determinación de SST .............................38

Figura 3.7 Secado y pesado de las muestras.................................................. 38

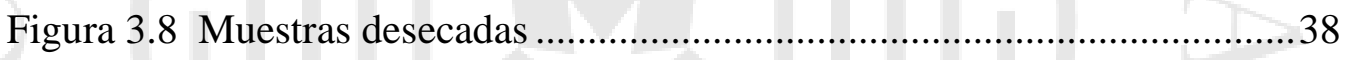

Figura 3.9 Equipo, materiales y reactivos para medir sulfatos.........................39

Figura 3.10 Configuración del reactor de ferrato(VI) .................................... 41

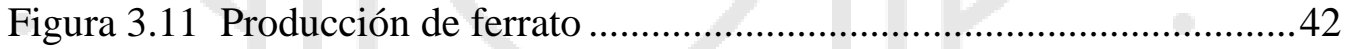

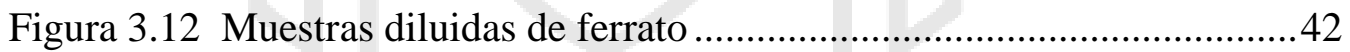

Figura 3.13 Configuración de la prueba de jarras .......................................... 44

Figura 4.1 Presencia de grasa en el reservorio del INIA ...............................49

Figura 4.2 Coloración que indica la presencia de algas .................................49

Figura 4.3 Cambio de color durante la reducción del ferrato(VI) .....................51

Figura 4.4 Concentración de arsénico remanente después del tratamiento con

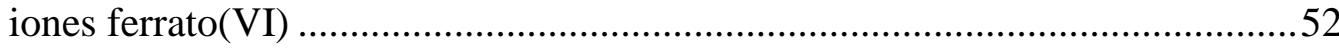

Figura 4.5 Concentración de arsénico remanente empleando iones ferrato(VI) y férrico

Figura 4.6 Concentración de arsénico remanente con otras dosis $\mathrm{Fe}(\mathrm{VI}) / \mathrm{Fe}(\mathrm{III})$

Figura 4.7 Remoción de algas luego del tratamiento ......................................58

Figura 4.8 Energía consumida durante la producción de ferrato(VI) ...............60 
Figura 5.1 Diagrama de operaciones y procesos para el armado del reactor electroquímico productor de ferrato(VI) .68

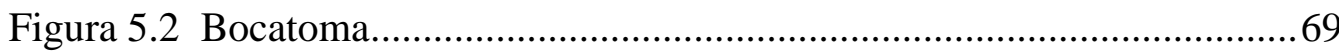

Figura 5.3 Filtro de rejas y sistema de inundación ........................................ 70

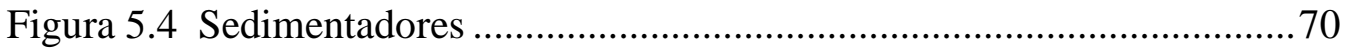

Figura 5.5 Disposición de filtros en la unidad de filtración tangencial ............71

Figura 5.6 Diagrama de flujo del proceso de tratamiento de agua para riego.. 72

Figura 5.7 Balance de materia del proceso de tratamiento de agua para riego 75

Figura 5.8 Balance de materia del proceso de producción de ferrato................76

Figura 5.9 Área total de terreno requerido .................................................. 88

Figura 5.10. Plano de planta propuesto ...................................................... 89 


\section{ÍNDICE DE ANEXOS}

Anexo 1: Decreto supremo $\mathrm{N}^{\circ}$ 004-2017-MINAM Estándares de calidad

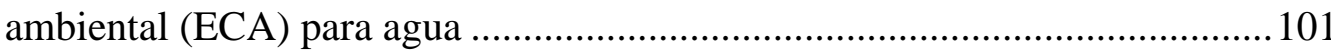

Anexo 2: Instrumentos, equipos materiales y reactivos ................................. 102

Anexo 3: Datos de ensayos de prueba de jarras ............................................. 105

Anexo 4: Datos de ensayos con otras dosis Fe(VI)/Fe(III) ............................ 106

Anexo 5: Cotización para el Hidróxido de sodio al 50\% ................................ 107

Anexo 6: Cotización para el cloruro férrico al 40\% ....................................... 108

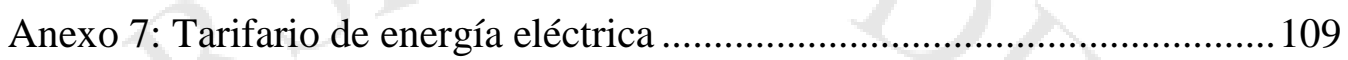




\section{RESUMEN}

Se informa acerca del estudio de una nueva tecnología para el tratamiento de agua de riego. Esta tecnología consiste en adicionar al agua iones ferrato(VI) seguidos de una solución de cloruro férrico $\left(\mathrm{FeCl}_{3}\right)$ como coagulante y culminar el proceso con una microfiltración. Las concentraciones evaluadas de los iones ferrato(VI) fueron 1, 2 y 3 $\mathrm{mg} / \mathrm{L}$; mientras que las concentraciones de los iones férricos $\left(\mathrm{Fe}^{3+}\right)$ fueron 3,6 y $9 \mathrm{mg} / \mathrm{L}$. $\mathrm{El} \mathrm{pH}$ final fue llevado a 7. Las pruebas y análisis realizados demuestran que al añadir iones ferrato(VI) a una concentración de $1 \mathrm{mg} / \mathrm{L}$ e iones férricos $\left(\mathrm{Fe}^{3+}\right)$ en concentración igual a $3 \mathrm{mg} / \mathrm{L}$, seguido de microfiltración, la concentración de arsénico disminuyó desde $500 \mu \mathrm{g} / \mathrm{L}$ hasta concentraciones inferiores de $100 \mu \mathrm{g} / \mathrm{L}$. Este resultado obtenido está de acuerdo con el valor Estándar Nacional de Calidad Ambiental (ECA) para agua destinada al riego de vegetales. Además, se evidenció que la adición de iones ferrato(VI) permite reducir la cantidad de coagulante empleado para alcanzar una concentración de arsénico por debajo de lo que indica el estándar, lo que permite una reducción del costo de tratamiento.

Palabras clave: ferrato, arsénico, agua para riego, microfiltración, coagulación 


\begin{abstract}
The study of a new technology for treatment of irrigation water is reported. This technology consists of adding ferrate(VI) ions to the water followed by a ferric chloride solution $\left(\mathrm{FeCl}_{3}\right)$ as a coagulant, and completing the process with microfiltration. The evaluated concentrations of ferrate(VI) ions were 1,2 and $3 \mathrm{mg} / \mathrm{L}$; while ferric $\left(\mathrm{Fe}^{3+}\right)$ ion concentrations were 3, 6 and $9 \mathrm{mg} / \mathrm{L}$. Final values of $\mathrm{pH}$ were adjusted to 7 . Results show that adding $1 \mathrm{mg} / \mathrm{L}$ of ferrate(VI) ions and $3 \mathrm{mg} / \mathrm{L}$ of ferric $\left(\mathrm{Fe}^{3+}\right)$ ions followed by microfiltration, decreased the arsenic initial concentration from $500 \mu \mathrm{g} / \mathrm{L}$ to concentrations below $100 \mu \mathrm{g} / \mathrm{L}$. This result complies with the National Standard for Environmental Quality (ECA) for water intended for vegetable irrigation. Furthermore, it was evidenced that the addition of ferrate(VI) ions allows to reduce the amount of coagulant used to reach an arsenic concentration below what the standard states, which makes it possible a reduction of treatment cost.
\end{abstract}

Keywords: ferrate, arsenic, irrigation water, microfiltration, coagulation 


\section{INTRODUCCIÓN}

Esta investigación evalúa el uso de ferrato(VI) como un agente a ser usado en el tratamiento de un agua modelo para riego con la finalidad de reducir la concentración de arsénico. El uso del ferrato(VI) permite tener un proceso más limpio, ya que se trata de una sustancia amigable con el medio ambiente. Asimismo, el ferrato(VI) puede desempeñar una doble función como oxidante y desinfectante; y a la vez forma un subproducto no tóxico que es el hierro(III) (Sharma, Anquandah, Kim, Jiang, \& Zboril, 2013). Se estudia el efecto de la adición de la solución de ferrato(VI) seguida de los procesos de coagulación y microfiltración.

Este trabajo ha sido desarrollado en cinco capítulos. El capítulo I presenta la problemática, los objetivos de la investigación, el alcance y la hipótesis. El capítulo II aborda conceptos relacionados al arsénico, el ferrato, la coagulación y la microfiltración; así como los aspectos fisicoquímicos de la calidad del agua. El capítulo III detalla la metodología a emplear para realizar los cálculos y para el desarrollo de los experimentos. El capítulo IV muestra los resultados de los experimentos, y el capítulo V propone la implementación de una planta de tratamiento de agua de riego que emplea la solución de ferrato(VI), los iones férricos y la microfiltración en sus procesos.

Finalmente, cabe mencionar que este trabajo de investigación es desarrollado en el marco del proyecto "Implementación del riego automatizado y mejora de la calidad de aguas no seguras para la agricultura mediante un sistema de tratamiento de aguas con iones ferrato(VI) en el Centro Experimental La Molina y la Estación Experimental Agraria Moquegua" del Programa Nacional de Innovación Agraria (PNIA) y el Instituto de Investigación Científica de la Universidad de Lima (IDIC). 


\section{CAPÍTULO I. ASPECTOS GENERALES}

\subsection{Problemática}

En el Perú, tal como se muestra en la Tabla 1.1, se dispone principalmente de aguas superficiales. Las aguas superficiales pueden ser destinadas al uso agrícola, al uso industrial, al consumo de la población o al desarrollo de otras actividades. La actividad agrícola cobra importancia no solo por suministrar variedad de alimentos a la población, sino también porque a ella se destina el $80 \%$ del total de agua superficial empleada (Autoridad Nacional del Agua [ANA], 2009). Por ello, el riego representa un factor determinante para el incremento de la seguridad alimentaria y el crecimiento agrícola y productivo (Ministerio de Economía y Finanzas [MEF], 2011).

Tabla 1.1

Disponibilidad hídrica a nivel nacional según vertiente, en $\mathrm{Hm}^{3}$

\begin{tabular}{l|rrrr}
\hline Vertiente & \multicolumn{1}{l}{ Pacifico } & \multicolumn{1}{l}{ Atlántico } & \multicolumn{1}{l}{ Titicaca } & \multicolumn{1}{l}{ Total } \\
\hline Superficial & 34,136 & $1,895,226$ & 6,259 & $1,935,621$ \\
Subterránea & 3,124 & 542,992 & 614 & 546,730 \\
\hline
\end{tabular}

Fuente: Instituto Nacional de Estadística e Informática (2015)

Elaboración propia

La calidad del agua para riego "[...] está determinada por la concentración o el grado de elementos, sustancias o parámetros físicos, químicos y biológicos que no representa riesgo significativo para la salud de las personas ni al ambiente" (Ministerio del Ambiente [MINAM], 2017). La calidad puede verse afectada por las condiciones naturales del entorno o por el desarrollo de actividades humanas alrededor de sus fuentes; por ello las descargas de los efluentes de las actividades productivas, de las aguas residuales domésticas y la escorrentía superficial de los campos de cultivo constituyen fuentes de contaminación de las aguas de riego. La contaminación se manifiesta a través de la presencia de sustancias indeseables tales como compuestos orgánicos, inorgánicos y microorganismos que afecten la calidad de los cultivos irrigados. Por este motivo, es necesario contar con fuentes de agua inocuas, ya sea de origen natural o a través de procesos de tratamiento de costo accesible para el productor agrícola. 
Según Henke (2009), uno de los contaminantes inorgánicos que puede presentar el agua para riego es el arsénico, cuya distribución y concentración está principalmente relacionada a las características mineralógicas, químicas y físicas de los suelos, sedimentos y rocas en contacto con el agua. Las personas que han estado expuestas durante periodos prolongados a este elemento presentan diversos daños a su salud, por esta razón el Instituto Nacional de Ciencias de la Salud Ambiental de los Estados Unidos reconoce al arsénico como cancerígeno, mientras que la Organización Mundial de la Salud lo considera una de las prioridades de investigación (The National Institute of Environmental Health Sciences, 2005).

En América Latina, la presencia de arsénico en aguas superficiales y subterráneas se relaciona principalmente al vulcanismo desarrollado en la Cordillera de Los Andes (Castro de Esparza M. L., 2015), mientras que Perú es ubicado como el tercer país de América del Sur en tener parte de su población expuesta al arsénico (Bernex, 2015). En consecuencia, se tiene casos como el de la región Tacna, donde se ha identificado “[...] una situación de descontrol en la cantidad de arsénico contenido en el agua tanto potable como de uso agropecuario" (Chávez, 2015).

Por otro lado, como señalan Howe, Hand, Crittenden, Trussell y Tchobanoglous (2016), mientras que la demanda de agua aumenta, cada vez son más exiguos los suministros de agua de alta calidad que sean disponibles localmente. Asimismo, la capacidad para detectar contaminantes ha adquirido un mayor nivel de complejidad y los efectos negativos sobre la salud de algunos de los componentes del agua son cada vez más evidentes; lo que conlleva a regulaciones más estrictas, por un lado, y por el otro, a demandas más enérgicas del consumidor por agua de más alta calidad. La creciente tendencia hacia el uso de fuentes de agua de baja calidad, aunada a estos efectos, ha estimulado una tendencia hacia tratamientos más avanzados que requieren más energía y recursos, lo que contribuye a una mayor contaminación y degradación del ambiente; por lo tanto, combinar la sostenibilidad y el consumo de energía en los procesos y prácticas de diseño contrarrestará esas tendencias y permitirá mayores niveles de tratamientos de agua sin efectos negativos (Howe et al., 2016). 


\subsection{Objetivos}

\subsubsection{Objetivo general}

Evaluar la efectividad de los iones ferrato(VI), producidos electroquímicamente, en la remoción de arsénico presente en aguas para riego obtenidas del Instituto Nacional de Innovación Agraria (INIA)- Centro Experimental La Molina.

\subsubsection{Objetivos específicos}

- Producir iones ferrato(VI) a través de la disolución anódica de un electrodo de hierro.

- Evaluar la remoción de arsénico de agua modelo para riego mediante la dosificación de una solución de ferrato(VI), seguido de un coagulante y microfiltración, para obtener agua de riego acorde a los Estándares Nacionales de Calidad Ambiental para Agua.

- Realizar una evaluación del costo del tratamiento del agua modelo para riego empleando las soluciones de ferrato(VI) y cloruro férrico.

\subsection{Justificación}

\subsubsection{Justificación Técnica}

La tecnología para la producción del ferrato ha sido evaluada anteriormente empleando diferentes métodos (oxidación seca, oxidación húmeda y el método electroquímico), en este proyecto se presenta una tecnología con que permite obtener los iones ferrato(VI) por el método electroquímico.

Los experimentos para validar la tecnología se realizarán en el laboratorio de investigación de la Facultad de Ingeniería y Arquitectura de la Universidad de Lima, por lo que se cuenta con materiales, reactivos y equipos necesarios. 


\subsubsection{Justificación Económica}

Actualmente, los sistemas de tratamiento de agua tradicionales pueden presentar costos elevados, mientras que el sistema que se evalúa en este trabajo se espera que tenga un costo bajo en los costos operativos, lo que la podría convertir en una propuesta interesante y atractiva para las empresas agroindustriales que pueden verla como una oportunidad para mejorar la calidad de agua que emplean para sus actividades.

\subsubsection{Justificación Social}

El calentamiento global agudiza los problemas relacionados al agua, ya que según Organización de las Naciones Unidas para la Educación, la Ciencia y la Cultura (UNESCO, 2003), un 20\% del incremento de la escasez mundial del agua obedecerá al cambio climático, el mismo que ocasionará que en las zonas húmedas probablemente las precipitaciones lluviosas aumenten, mientras que en muchas zonas disminuirán y serán más irregulares. Chávez (2015) señala que, ante inminentes cambios en la dinámica del transporte de las masas de agua "[...] es probable esperar que el descontrol de la concentración de arsénico se acentúe y aumente el riesgo de impactar negativamente en la salud de las personas". En relación a la importancia del agua en nuestra vida, la Organización de las Naciones Unidas (ONU) ha planteado un conjunto de Objetivos de Desarrollo Sostenible (ODS) que estan orientados a garantizar la disponibilidad de agua, su gestión sostenible y saneamiento (ODS6).

Seimer, Reinhart, Sharma y Austin (2007) señalan que los subproductos de la oxidación con ferrato no son biocidas, ni carcinogénicos y no impactan negativamente en la salud ni en el medio ambiente, por lo que no afectaría las especies vegetales irrigadas. Por esta razón, el uso de los iones ferrato para tratar las aguas de riego constituye una alternativa de solución para obtener productos agrícolas libres de agentes contaminantes.

La Organización de las Naciones Unidas para la agricultura y la alimentación (2002) afirma que contar con un mecanismo efectivo para remover el arsénico de aguas destinadas a la agricultura permitirá al sector agrario encontrarse mejor preparado para enfrentar los efectos del cambio climático; mientras que el suministro de alimentos inocuos y nutritivos permitiría incrementar la seguridad alimentaria para las personas. 


\subsection{Alcances y limitaciones}

Esta investigación evalúa la reducción de la concentración del arsénico del agua de riego, más no la reducción de concentración de otros contaminantes, si lo hubieren.

Uno de los objetivos del proyecto marco de esta investigación es evaluar la calidad del agua tratada con la unidad automatizada en el Centro Experimental La Molina y la Estación Experimental Agraria de Moquegua. Por ello, se evaluará la reducción de una concentración inicial de arsénico de $500 \mu \mathrm{g} / \mathrm{L}$ y se verificará si la concentración de arsénico remanente cumple con los $100 \mu \mathrm{g} / \mathrm{L}$ establecido por el Estándar Nacional de Calidad Ambiental-ECA para Agua, categoría 3, subcategoría D1 (Riego de cultivos de vegetales). La concentración inicial fue establecida tomando como referencia la concentración promedio de arsénico reportada en la literatura de los ríos Callazas y Salado, los que pertenecen a la cuenca del rio Locumba, en el sur de Perú; con concentraciones de arsénico de hasta 0.640 y $1.680 \mathrm{mg} \mathrm{As} / \mathrm{L}$, respectivamente (como se cita en McClintock y otros, 2012).

Debido a la complejidad de realizar un muestreo y el tiempo que demanda lograr que las muestras sean representativas, los ensayos se realizan tomando como modelo el agua del reservorio del Instituto Nacional de Innovación Agraria. Dicho reservorio almacena agua proveniente del río Rímac que ha recibido un pre-tratamiento. La Autoridad Nacional del Agua (ANA) clasifica al río Rímac en la Categoría 3, y el Ministerio del Ambiente señala que las aguas de esta categoría pueden ser destinadas al riego de vegetales y bebida de animales (Ministerio del Ambiente [MINAM], 2017).

\subsection{Marco referencial}

La especiación del arsénico en muestras de agua procedente de ríos incluye especies inorgánicas y orgánicas; siendo dominantes las primeras, que suelen presentarse como Arsénico(V) bajo la forma de arseniato $\mathrm{AsO}_{4}^{-3}$ y como Arsénico(III) bajo la forma de arsenito $\mathrm{AsO}_{3}{ }^{-3}$. La especie arsenito, por encontrarse sin carga eléctrica al $\mathrm{pH}$ de las aguas naturales, no se adsorbe a la mayoría de superficies minerales, lo que dificulta su remoción (Chavez, 2009).

En el Perú, se han encontrado concentraciones elevadas de arsénico en aguas superficiales, principalmente en las regiones de Lima, Moquegua y Tacna (Castro de Esparza, 2006). Por otro lado, se han realizado diversos estudios que confirman el 
impacto del empleo de aguas no seguras para los cultivos. Específicamente, se ha demostrado que la presencia de elevadas concentraciones de arsénico en el suelo y en las aguas de riego conducen a concentraciones elevadas de arsénico en los cultivos y por consiguiente constituyen un riesgo elevado para la seguridad de los alimentos, ya que muchos de los contaminantes, tales como los metales pesados, son absorbidos por los cultivos (Arora et al., 2008), persisten en el suelo (Khan, Cao, Zheng, Huang, \& Zhu, 2008) y terminan en el producto de consumo directo (Cabezas, 2014).

Asimismo, un equipo de investigadores de la Universidad de Valladolid y del Instituto de Recursos Naturales y Agrobiología de Salamanca, ha evaluado la bioacumulación del arsénico en plantaciones de patata, remolacha, zanahoria y trigo y ha encontrado que el arsénico almacenado en hojas y raíces es mayor cuando la concentración medida en el agua de riego es más alto (Moreno, 2009).

\subsection{Hipótesis}

\subsubsection{Variable dependiente}

Concentración final de arsénico total.

\subsubsection{Variables independientes}

Concentración de iones ferrato(VI), concentración de iones férricos.

\subsubsection{Formulación de la hipótesis general}

La aplicación de iones ferrato(VI) disminuye la cantidad de cloruro férrico utilizado como coagulante en el proceso de remoción de arsénico, logrando disminuir la concentración de arsénico en el agua para alcanzar un estándar de calidad de agua viable para riego.

\subsubsection{Formulación de las hipótesis específicas}

- La adición de iones ferrato(VI) al agua modelo para riego permite reducir la concentración inicial de arsénico. 
- La aplicación de iones ferrato(VI) seguido de iones férricos permite reducir la concentración del arsénico del agua hasta concentraciones menores a 100 $\mu \mathrm{g} / \mathrm{L}$.

- El empleo de iones ferrato(VI) permite reducir los costos de los consumibles para el tratamiento, en las condiciones evaluadas. 


\section{CAPÍTULO II. ASPECTOS TEÓRICOS}

\subsection{El arsénico}

\subsubsection{Formas de ocurrencia del arsénico}

El arsénico (As) es un semimetal, por lo que tiene varias, pero no todas las propiedades físicas y químicas de los metales. La abundancia promedio de arsénico en la corteza terrestre es de $1.8 \mathrm{mg} / \mathrm{L}$; en los suelos es de 5,5 a $13 \mathrm{mg} / \mathrm{L}$; en aguas superficiales es inferior a $2 \mu \mathrm{g} / \mathrm{L}$, y en aguas subterráneas generalmente es inferior a $100 \mu \mathrm{g} / \mathrm{L}$ (American Public Health Association, 1998).

Henke (2009) señala que el arsénico puede existir en los estados de oxidación 0 (elemental),+3 (trivalente, arsenitos) y +5 (pentavalente, arseniatos). Otro compuesto de arsénico con estado de oxidación -3 es la arsina, un gas incoloro que tiene varios usos industriales y es un agente hemolítico sumamente potente. En la mayoría de los casos y para propósitos toxicológicos, los estados de oxidación del arsénico más relevantes son las formas +3 y +5 , que también pueden ser identificadas como As(III) y As(V), respectivamente. La importancia toxicológica de estos dos estados de oxidación radica en que las formas trivalentes de arsénico, tanto orgánicas como inorgánicas, son generalmente más tóxicas que las formas pentavalentes.

\subsubsection{Principales usos del arsénico}

Durante siglos, los compuestos de arsénico han sido utilizados en una amplia variedad de productos, que incluyen pigmentos, medicinas, pesticidas, preservantes de madera, herbicidas, cristalería y como depilatorio en la manufactura de cuero. Asimismo, las propiedades tóxicas del arsénico son bien conocidas y han sido ampliamente usadas en agentes de guerra química y para cometer asesinato y suicidio desde tiempos antiguos (Henke, 2009). La Organización Mundial de la Salud (OMS, 2011) afirma que los compuestos de arsénico son usados en el ámbito comercial e industrial como agentes de aleación en la manufactura de transistores, láseres y semiconductores. 


\subsubsection{Presencia de arsénico en las aguas naturales}

El arsénico llega al agua a través de la disolución de rocas y minerales; de efluentes industriales, que incluyen desechos mineros y vía deposición atmosférica (OMS, 2011).

En aguas naturales, el arsénico puede existir como una o más especies disueltas; sin embargo, no se encuentra como iones $\mathrm{As}^{3+}$ o $\mathrm{As}^{5+}$ sino como oxianiones. El As(III) forma $\mathrm{H}_{3} \mathrm{AsO}_{3}$ y el $\mathrm{As}(\mathrm{V})$ forma $\mathrm{H}_{3} \mathrm{AsO}_{4}$. Debido a que son ácidos débiles, las moléculas de arsénico se ionizan poco para formar moléculas cargadas. Estas formas químicas del arsénico se forman en función del pH (Howe et al., 2016). Por lo tanto, como se observa en la Figura 2.1 y en la Figura 2.2, la especiación del arsénico disuelto en el agua dependerá del $\mathrm{pH}$, las condiciones redox y otras características químicas del agua, así como de la actividad biológica. Así, en aguas superficiales bien oxigenadas, generalmente está presente el arsénico(V); mientras que, en condiciones reductoras, como aquellas frecuentemente encontradas en aguas subterráneas o sedimentos profundos de lagos, la forma predominante es el arsénico(III).

Por otro lado, un incremento del pH podría incrementar la concentración del arsénico disuelto en el agua (OMS, 2011).

Figura 2.1

Especies de $\mathrm{As}(\mathrm{V})$ como función de $\mathrm{pH}$

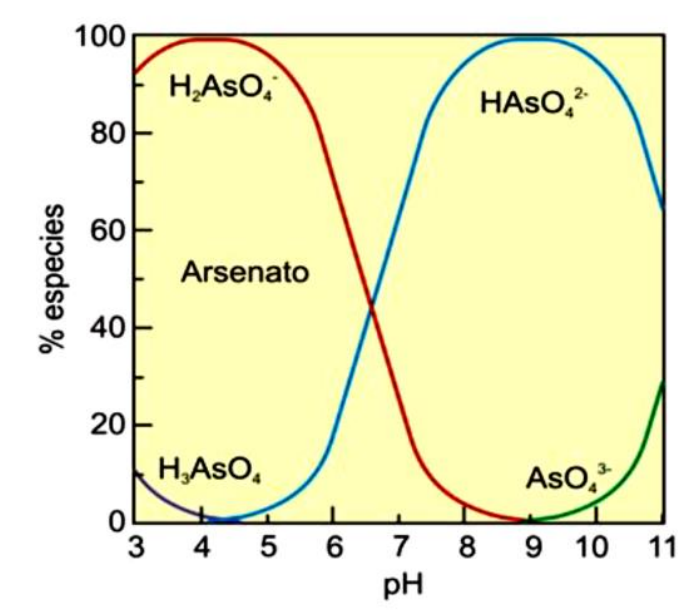

Fuente: Lillo, Javier (2008) 
Figura 2.2

Especies de As(III) como función de $\mathrm{pH}$

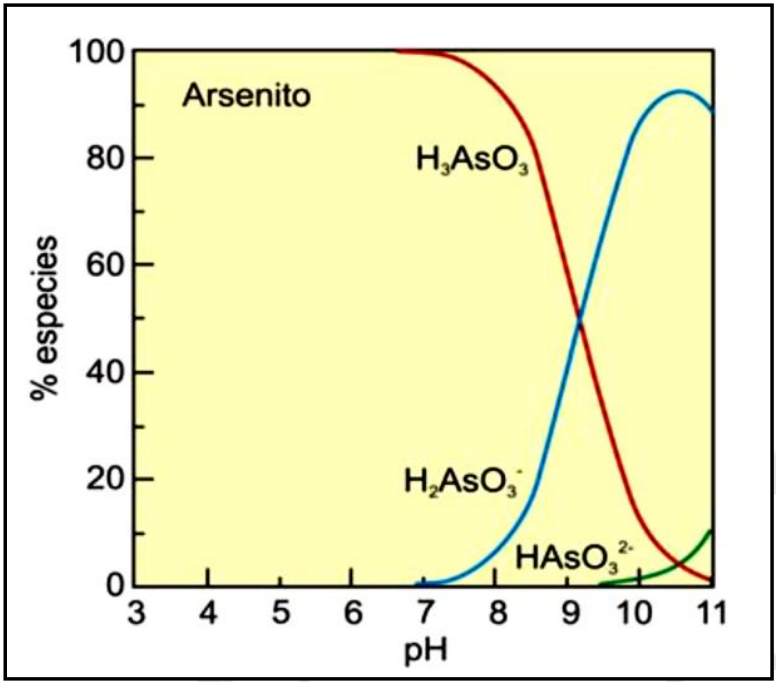

Fuente: Lillo, Javier (2008)

\subsubsection{Toxicidad del arsénico}

La exposición al arsénico puede resultar en una variedad de problemas a la salud, que incluyen varias formas de cáncer, enfermedades cardiovasculares y diabetes. Generalmente, tanto las formas inorgánicas y orgánicas del arsénico(III) tienden a ser más tóxicas para los humanos que las formas de arsénico(V). La exposición al arsénico puede ser a través de la inhalación, absorción por la piel e ingestión de comida y agua (Henke, 2009).

La intoxicación grave puede darse por la ingestión de una cantidad tan pequeña como 100 mg de trióxido de arsénico, mientras que los efectos crónicos pueden resultar de la acumulación de compuestos de arsénico en el cuerpo a bajos niveles de ingesta. Para la protección de la vida acuática, la concentración promedio de arsénico(III) en el agua no debe exceder de $72 \mu \mathrm{g} / \mathrm{L}$ y la concentración máxima no debe exceder de $140 \mu \mathrm{g} / \mathrm{L}$. La concentración máxima recomendada por Organización de las Naciones Unidas para la Alimentación y la Agricultura para las aguas de riego es de $100 \mu \mathrm{g} / \mathrm{L}$ (American Public Health Association, 1998). 


\subsection{El ferrato(VI)}

\subsubsection{Propiedades físicas y químicas del ferrato(VI)}

En la naturaleza, el hierro mayormente existe en los estados de oxidación +2 y +3 (ferroso, Fe(II) y férrico, Fe(III)) (Yates, Zboril, \& Sharma, 2014). Bajo condiciones fuertemente oxidantes se presentan estados de oxidación más altos como $+4,+5$ y +6 y +8 . Estos estados de valencia altos del hierro usualmente son generados como oxianiones de hierro, llamados ferratos, de los cuales el estado de valencia del más estable es el +6 , dicho compuesto se conoce como ferrato(VI), el cual tiene un color morado oscuro similar al permanganato $\left(\mathrm{MnO}_{4}{ }^{2-}\right)$ pero su comportamiento es diferente en todos los aspectos (Alsheyab, Jiang, \& Stanford, 2010).

$\mathrm{El}$ ion ferrato(VI) tiene la fórmula molecular $\mathrm{FeO}_{4}{ }^{2-}$ y es un fuerte oxidante, tal que, bajo condiciones ácidas tiene un potencial redox mayor que del cloro y del ozono, pudiendo llegar a potenciales de óxido-reducción de hasta 2,2 V, como se puede observar en la Tabla 2.1. Cabe resaltar que la velocidad de descomposición del ferrato(VI) es fuertemente dependiente del pH (Tiwari \& Lee, 2011). Se ha demostrado que, luego de evaluar un rango de $\mathrm{pH}$ de 7.7 - 12.2, la descomposición del ferrato en agua ocurre a una menor velocidad en el rango 9.4 - 9.7, lo que indicaría una región de alta estabilidad. Esto es corroborado por Mácová y otros (2009), quienes reportan haber encontrado una mayor estabilidad del ferrato(VI) en soluciones fuertemente alcalinas.

Tabla 2.1

Potencial Redox para diferentes oxidantes utilizados en el tratamiento de agua y de aguas residuales

\begin{tabular}{l|cc}
\hline \multicolumn{1}{c|}{ Oxidante } & Reacción & $\mathbf{E}^{\circ}$, Voltios \\
\hline Cloro & $\mathrm{Cl}_{2}(\mathrm{~g})+2 \mathrm{e}^{-} \rightleftharpoons 2 \mathrm{Cl}^{-}$ & 1,358 \\
& $\mathrm{ClO}^{-}+\mathrm{H}_{2} \mathrm{O}+2 \mathrm{e}^{-} \rightleftharpoons \mathrm{Cl}^{-}+2 \mathrm{OH}^{-}$ & 0,841 \\
Hipoclorito & $\mathrm{HClO}+\mathrm{H}^{+}+2 \mathrm{e}^{-} \rightleftharpoons \mathrm{Cl}^{-}+\mathrm{H}_{2} \mathrm{O}$ & 1,482 \\
Dióxido de cloro & $\mathrm{ClO}_{2}(\mathrm{ac})+\mathrm{e}^{-} \rightleftharpoons \mathrm{ClO}_{2}^{-}$ & 0,954 \\
Perclorato & $\mathrm{ClO}_{4}^{-}+8 \mathrm{H}^{+}+8 \mathrm{e}^{-} \rightleftharpoons \mathrm{Cl}^{-}+4 \mathrm{H}_{2} \mathrm{O}$ & 1,389 \\
Ozono & $\mathrm{O}_{3}+2 \mathrm{H}^{+}+2 \mathrm{e}^{-} \rightleftharpoons \mathrm{O}_{2}+\mathrm{H}_{2} \mathrm{O}$ & 2,076 \\
Peróxido de hidrógeno & $\mathrm{H}_{2} \mathrm{O}_{2}+2 \mathrm{H}^{+}+2 \mathrm{e}^{-} \rightleftharpoons 2 \mathrm{H}_{2} \mathrm{O}$ & 1,776 \\
Oxígeno disuelto & $\mathrm{O}_{2}+4 \mathrm{H}^{+}+4 \mathrm{e}^{-} \rightleftharpoons 2 \mathrm{H}_{2} \mathrm{O}$ & 1,229 \\
\hline
\end{tabular}

(continúa) 
(continuación)

\begin{tabular}{l|cc}
\hline Permanganato & $\mathrm{MnO}_{4}^{-}+4 \mathrm{H}^{+}+3 \mathrm{e}^{-} \rightleftharpoons \mathrm{MnO}_{2}+2 \mathrm{H}_{2} \mathrm{O}$ & 1,679 \\
Cromato & $\mathrm{MnO}_{4}{ }^{-}+8 \mathrm{H}^{+}+5 \mathrm{e}^{-} \rightleftharpoons \mathrm{Mn}^{2+}+4 \mathrm{H}_{2} \mathrm{O}$ & 1,507 \\
Ferrato(VI) & $\mathrm{Cr}_{2} \mathrm{O}_{7}^{2-}+14 \mathrm{H}^{+}+6 \mathrm{e}^{-} \rightleftharpoons 2 \mathrm{Cr}^{3+}+7 \mathrm{H}_{2} \mathrm{O}$ & 1,33 \\
& $\mathrm{FeO}_{4}{ }^{2-}+8 \mathrm{H}^{+}+3 \mathrm{e}^{-} \rightleftharpoons \mathrm{Fe}^{3+}+4 \mathrm{H}_{2} \mathrm{O}$ & 2,20 \\
& $\mathrm{FeO}_{4}^{2-}+4 \mathrm{H}_{2} \mathrm{O}+3 \mathrm{e}^{-} \rightleftharpoons \mathrm{Fe}(\mathrm{OH})_{3}+5 \mathrm{OH}^{-}$ & 0.72 \\
\hline
\end{tabular}

Fuente: Tiwari y Lee (2011) y Jiang, Durai, Winzenbacher, Petri y Seitz (2014)

\subsubsection{Uso del ferrato(VI) para el tratamiento de agua}

Debido a su fuerte propiedad oxidante, el ferrato(VI) es relativamente inestable en presencia del agua. Así, durante el proceso de oxidación, los iones ferrato(VI) se reducirán a iones férricos o hidróxidos férricos (Jian \& Lloyd, 2002), como se observa en la Tabla 2.1. Estos subproductos son recursos básicos para el proceso de coagulación (Jiang, Durai, Winzenbacher, Petri, \& Seitz, 2014). El Fe(III) producido luego de la reducción del ferrato(VI) es un buen coagulante/floculante, lo que convierte al ferrato(VI) en un producto químico de tratamiento de aguas multipropósito para la oxidación, coagulación y desinfección del agua (Tiwari \& Lee, 2011).

Por otro lado, la rápida reducción del ferrato(VI) a un oxido férrico ambientalmente benigno ha sido la base para sugerir el uso de ferrato como una alternativa más segura a la purificación del agua por cloración (Light \& Yu, 2005). Ya que "[...] el cloro favorece la generación de subproductos de desinfección" (disinfection by-products, DBPs por sus siglas en inglés) (Serrano, Montesinos, Cardador, Silva, \& Gallego, 2015) al reaccionar con la materia orgánica disuelta que se encuentra en todas las aguas. Los DBPs son sustancias tóxicas que pueden causar genotoxicidad (Liviac, Creus, \& Marcos, 2009).

La propiedad coagulante del ferrato(VI) también ha demostrado remoción eficiente de algunos metales tóxicos, nutrientes, radionúclidos y materia orgánica natural. Por lo que el ferrato puede ser aplicado en un proceso de pre-oxidación así como en el proceso de coagulación (Yates, Zboril, \& Sharma, 2014).

En cuanto al uso del ferrato(VI) para remover especies de arsénico del agua, se debe tener en cuenta que se requieren dos pasos: la oxidación y la posterior coagulación. Al respecto, Lee y otros (2003) consideran que el ferrato(VI) es el candidato ideal para 
la remoción de arsénico debido a su función dual como oxidante y coagulante. En su trabajo, sostienen que el proceso de oxidación del arsénico(III) se da por la transferencia del oxígeno; y propone la siguiente reacción para la oxidación del arsénico(III) por el ferrato(VI).

$$
2 \mathrm{HFeO}_{4}^{-}+3 \mathrm{H}_{3} \mathrm{AsO}_{3} \rightarrow 2 \mathrm{Fe}^{3+}+3 \mathrm{HAsO}_{4}^{2-}
$$

Asimismo, el ferrato(VI) ha llegado a ser considerado una sustancia química emergente para el tratamiento de agua al momento de abordar la preocupación de la formación de los DBPs asociados con las sustancias químicas que se usan actualmente, tales como el cloro libre, cloraminas y ozono. Por ejemplo, el ferrato no mostró reactividad con el ion bromuro, por lo tanto el ion bromato que es carcinogénico no se produce en el tratamiento de agua que contenga dicho ion (Yates, Zboril, \& Sharma, 2014). El ferrato(VI) no genera la aparición de bromato y hasta puede ser utilizado conjuntamente con el ozono por el efecto inhibidor que proporciona durante la formación del ion bromato (Han, Wang, Dong, Liu, \& Yin, 2013).

Además, el ferrrato(VI) tiene la capacidad de degradar un rango amplio de compuestos presentes en las aguas residuales y efluentes industriales; y más importante aún, puede oxidar contaminantes emergentes tales como estrógenos fenólicos, bisphenolA, sucralosa, antibióticos y medios de contraste de rayos X (Yates, Zboril, \& Sharma, 2014).

\subsubsection{Métodos de producción de ferrato(VI)}

El ferrato(VI) puede ser producido básicamente mediante dos métodos: químico y electroquímico. El método electroquímico es más prometedor que el método químico para la generación de ferrato en la medida que se trata de un proceso más simple y no requiere de reactivos químicos costosos (Alsheyab, Jiang, \& Stanford, 2010).

Entre las características más importantes a tener en cuenta, ante una posible síntesis práctica y uso del ferrato(VI), están la solubilidad y la estabilidad de las sales de ferrato(VI). La solubilidad indica cuan fácilmente la sal de ferrato(VI) puede ser transferida de una solución, donde es mayormente producida, al estado sólido. Mácová (2009) considera que el estado sólido es necesario para almacenar esta sal por largo tiempo, ya que la estabilidad del ferrato(VI) es influenciada negativamente por la 
humedad. Asimismo, propone el estado sólido para su uso en el tratamiento de agua, ya que la adición de ferrato(VI) disuelto, a diferencia del sólido, incrementaría el pH y la salinidad de la solución.

Los métodos para producir iones ferrato son: oxidación seca, oxidación húmeda y el método electroquímico (Sharma, Chen, \& Zboril, 2016).

\section{Oxidación seca}

En la oxidación seca, el ferrato se obtiene calentando una mezcla de óxidos de hierro con álcali y nitratos a altas temperaturas y presión. La mezcla final incluye las sales de ferrato, subproductos y reactantes sobrantes. Al sintetizar ferrato por este método ocurre la siguiente reacción:

$$
\mathrm{Fe}_{2} \mathrm{O}_{3_{(s)}}+3 \mathrm{Na}_{2} \mathrm{O}_{2_{(s)}} \rightarrow 2 \mathrm{Na}_{2} \mathrm{FeO}_{4_{(s)}}+\mathrm{Na}_{2} \mathrm{O}_{(\mathrm{S})}
$$

\section{Método húmedo}

El método húmedo incluye la oxidación de iones férricos por hipoclorito de sodio concentrado en presencia de hidróxido de sodio, obteniéndose ferrato de sodio. Luego de una recristalización con hidróxido de potasio se obtiene ferrato de potasio. Las reacciones que ocurren durante el proceso son:

$$
\begin{gathered}
2 \mathrm{Fe}(\mathrm{OH})_{3(a c)}+3 \mathrm{NaOCl}_{(a c)}+4 \mathrm{NaOH}_{(a c)} \rightarrow 2 \mathrm{Na}_{2} \mathrm{FeO}_{4(a c)}+3 \mathrm{NaCl}_{(a c)}+5 \mathrm{H}_{2} \mathrm{O}_{(l)} \\
\mathrm{Na}_{2} \mathrm{FeO}_{4_{(a c)}}+2 \mathrm{KOH}_{(a c)} \rightarrow \mathrm{K}_{2} \mathrm{FeO}_{4(s)}+2 \mathrm{NaOH}(a c)
\end{gathered}
$$

\section{Método electroquímico}

El método electroquímico tiene como principio básico la disolución del ánodo de hierro durante el proceso de electrólisis, teniendo como electrolito una solución fuertemente alcalina con una corriente eléctrica para oxidar el hierro a Fe(VI) (Alsheyab, Jiang, \& Stanford, 2010). Cabe indicar que este método permite obtener ferrato de alta pureza (Mácová et al., 2009). Las posibles reacciones anódicas y catódicas son las siguientes:

Reacción anódica: $\mathrm{Fe}+8 \mathrm{OH}^{-} \rightarrow \mathrm{FeO}_{4}{ }^{2-}+4 \mathrm{H}_{2} \mathrm{O}+6 e^{-}$

$$
\text { Reacción catódica: } 6 \mathrm{H}_{2} \mathrm{O}+6 \mathrm{e}^{-} \rightarrow 3 \mathrm{H}_{2}+6 \mathrm{H}^{-}
$$




$$
\begin{gathered}
\text { Reacción global: } \mathrm{Fe}+2 \mathrm{OH}^{-}+2 \mathrm{H}_{2} \mathrm{O} \rightarrow \mathrm{FeO}_{4}{ }^{2-}+3 \mathrm{H}_{2} \\
\mathrm{Y}: \mathrm{FeO}_{4}{ }^{2-}+2 \mathrm{Na}^{+} \rightarrow \mathrm{Na}_{2} \mathrm{FeO}_{4}
\end{gathered}
$$

Asimismo, en la cámara anódica también se produce el desprendimiento del gas oxígeno, el cual compite con la producción del ferrato (Mácová, Bouzek, \& Sharma, 2009). Mácová et al. (2009) señalan que la reacción es la siguiente:

$$
2 \mathrm{OH}^{-} \rightarrow \mathrm{H}_{2} \mathrm{O}_{(l)}+\frac{1}{2} \mathrm{O}_{2(g)}+2 e^{-}
$$

Los tres principales parámetros que influencian la producción de ferrato son la densidad de corriente, la concentración del electrolito y el contenido de carbono en el acero (Alsheyab, Jiang, \& Stanford, 2010).

\subsection{La coagulación en el tratamiento de agua}

El agua a tratar puede contener una variedad de impurezas solubles e insolubles; en estas últimas destacan las partículas coloidales, las sustancias húmicas y los microorganismos en general. Las impurezas coloidales presentan una carga superficial negativa, que impide que las partículas se aproximen unas a otras y que las lleva a permanecer en un medio que favorece su estabilidad (American Water Works Association, 2011).

Howe et al. (2016) señalan que la coagulación implica la adición de un químico coagulante con la finalidad de acondicionar la materia suspendida, coloidal y disuelta; y para crear condiciones que permitan la remoción posterior de la materia suspendida disuelta. Coagulantes como el sulfato de aluminio, el cloruro férrico y el sulfato férrico se hidrolizan con rapidez cuando se mezclan con agua. Cuando esos químicos se hidrolizan, forman precipitados insolubles que desestabilizan partículas, adsorben la superficie de las partículas y neutralizan su carga (reducen las fuerzas repulsivas). En consecuencia, la coagulación por la adición de químicos como las sales de aluminio o las sales de hierro puede implicar la desestabilización de materia coloidal y suspendida, la adsorción y reacción de porciones de materia orgánica natural coloidal y disuelta; y la creación de precipitados floculantes que se extienden por el agua atrapando todo el material suspendido, coloidal y disuelto en el momento en que se asienta. 
En algunos casos, dependiendo del proceso, la coagulación puede ser seguida por una etapa de floculación, la cual permite reunir las partículas desestabilizadas para formar aglomeraciones de mayor peso y tamaño que sedimenten con mayor eficiencia. La floculación “[...] implica agregar partículas desestabilizadas (carga eléctrica superficial reducida) y los productos de precipitación formados por la adición de coagulantes que los convierten en partículas más grandes conocidas como partículas floculantes (flóculos)". El flóculo agregado se puede eliminar posteriormente por sedimentación o filtración (Howe et al., 2016).

\subsection{Filtración por membranas}

Las membranas se utilizan en dos procesos fisicoquímicos específicos para el tratamiento de agua: el filtrado por membranas y la osmosis inversa. El filtrado por membranas es un proceso de separación impulsado por la presión o el vacío, en el cual las partículas son removidas de una suspensión a través del cribado a medida que el fluido pasa por el material poroso. Mientras que la ósmosis inversa es un proceso de separación por membranas impulsado por presión, en el que los elementos disueltos son separados de una solución (Howe et al., 2016).

En el filtrado por membranas, el material filtrante es una delgada película sintética, la cual contiene diminutos poros a través de los cuales puede pasar el agua (Howe et al., 2016). El mecanismo de filtración por membranas depende de la fuerza impulsora que se origina por la diferencia de presión para la separación y el proceso de filtrado (Al-Mashharawi, 2011).

Durante el filtrado, el agua pasa por los poros de la membrana semipermeable, pero las partículas quedan atrapadas en la superficie del material debido a su tamaño (Figura 2.3). El agua que atraviesa una membrana se llama agua por permeado (Howe et al., 2016). 
Figura 2.3

Esquema del proceso de separación a través de una membrana semipermeable

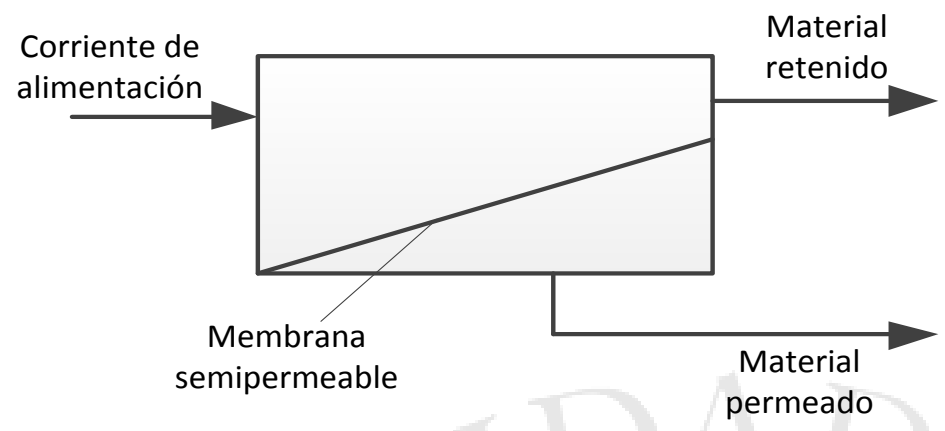

Fuente: Howe, Hand, Crittenden, Trussell, \& Tchobanoglous (2016)

Las membranas de filtración presentan diferentes tamaños de poros y según ello se dividen en 4 categorías que son: microfiltración (MF), ultrafiltración (UF), nanofiltración (NF) y osmosis inversa (OI). Las aplicaciones varían según el tamaño de poro, como se muestra en la Figura 2.4.

Figura 2.4.

Diagrama conceptual de las principales partículas rechazadas según el tipo de membrana

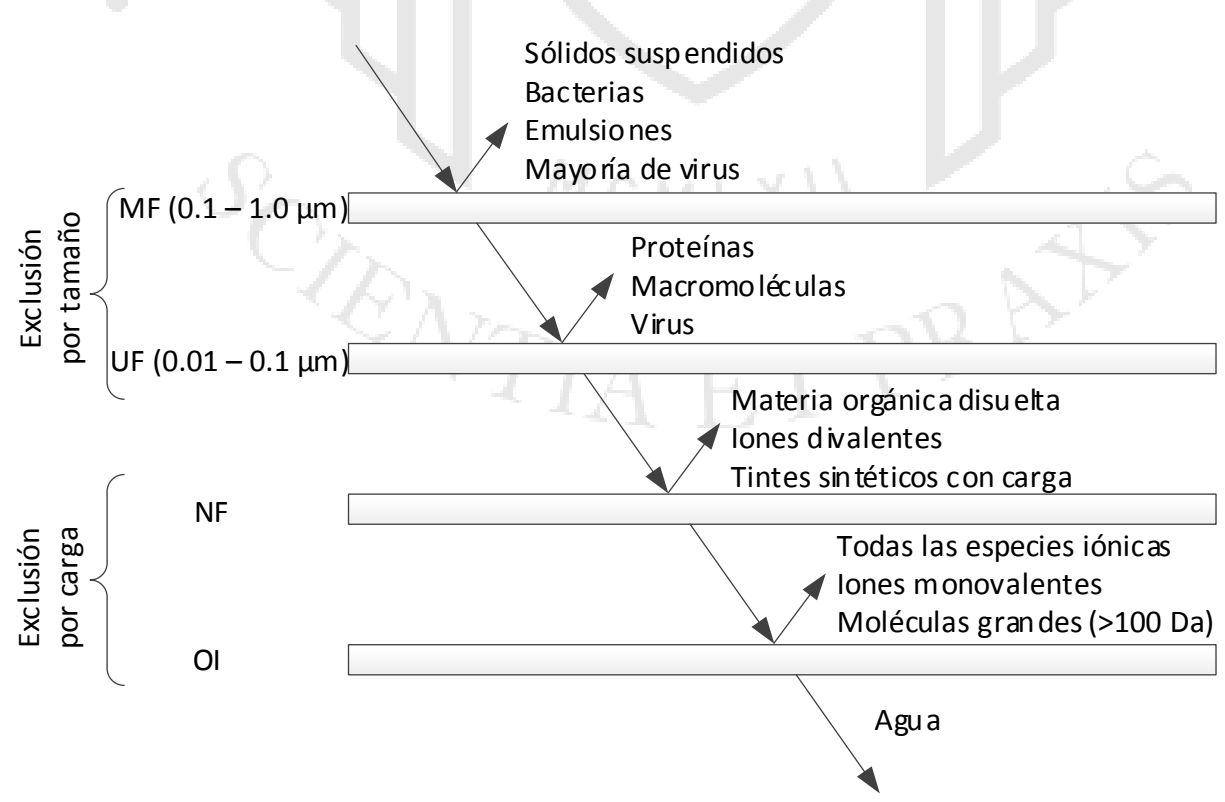

Fuente: Yoon, Seong-Hoon (2015) 


\subsubsection{Regímenes de flujo}

Se utilizan principalmente dos configuraciones del sistema de filtración: punto muerto y flujo transversal. La principal diferencia entre ellas es la relación entre la dirección del agua de alimentación y la superficie de la membrana, como se observa en la Figura 2.5. En consecuencia también difieren en la velocidad del filtrado, la recuperación, el flujo y la calidad del filtrado (Al-Mashharawi, 2011).

Figura 2.5

Filtración de flujo tangencial y filtración de punto muerto

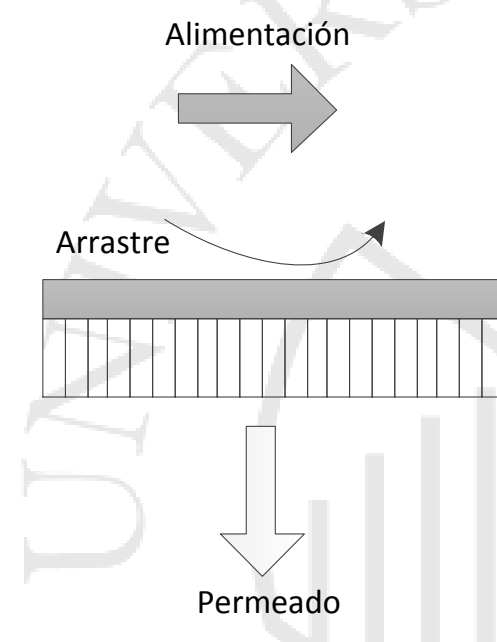

Flujo transversal

Fuente: Yoon, Seong-Hoon (2015)

\section{Regimen de punto muerto}

En esta configuración la recuperación es del 100\%, pero parte de esta porción se usa para el lavado a contracorriente. Por consiguiente, en el modo de punto muerto se tiene que el caudal de alimentación es igual al caudal de permeado.

En esta configuración la membrana opera sin una velocidad definida de flujo transversal continuo por lo que los sólidos se acumulan en ella durante todo el ciclo de filtrado. Esta mayor acumulación de sólidos puede generar valores menores de caudal promedio que los que se alcanzan con el filtrado de flujo transversal (Howe et al., 2016). En consecuencia, este modo requiere retrolavado con mayor frecuencia que las filtraciones de flujo cruzado. Además, después de un tiempo, la presión transmembrana se incrementa y el retrolavado se vuelve más difícil, lo que significa que necesita una 
limpieza adicional que se denomina retrolavado mejorado químicamente (AlMashharawi, 2011).

La mayoría de las plantas de desalinización que usan membranas de microfiltración o ultrafiltración utilizan el régimen de punto muerto porque requiere menos energía en comparación con la alta velocidad del agua de alimentación requerida en el flujo transversal para prevenir incrustaciones que resultan en una mayor pérdida de carga y consumo de energía (Al-Mashharawi, 2011).

\section{Regimen de flujo transversal}

Su denominación se debe a que la alimentación se mueve paralelamente a la superficie del filtro y el permeado fluye perpendicular al flujo de alimentación (Figura 2.5). En este caso, el caudal de alimentación es igual al caudal de permeado más el caudal de concentrado, el cual usualmente se recircula.

En la filtración de flujo transversal, el espesor de la capa de sólidos retenidos se puede controlar mediante el efecto de erosión/arrastre (scouring), pero se requiere energía adicional para mover el agua de alimentación lo suficientemente rápido. Si el efecto de arrastre y la deposición de partículas están equilibrados, la capa de sólidos apenas crece durante un período prolongado (Yoon, 2015).

El filtrado de flujo transversal requiere una recirculación sustancial del material retenido (el flujo de permeado suele ser del 15 al 20\% del flujo de alimentación) (Howe et al., 2016).

Generalmente, el modo de filtración de flujo cruzado se usa para agua con gran cantidad de sólidos suspendidos totales (SST), mientras que el modo de filtración de punto muerto es para agua con baja concentración de SST. Esto se debe a que la filtración en punto muerto no es sostenible sin eliminar los sólidos acumulados, para ello el filtro debe ser reemplazado o retrolavado periódicamente. La filtración en punto muerto puede ser energéticamente eficiente debido a la falta de flujo cruzado, pero propensa a pérdidas de rendimiento debido a la acumulación de sólidos (Yoon, 2015).

\subsubsection{Fouling de la membrana}

Al-Mashharawi (2011) señala que el fouling (ensuciamiento) está fuertemente relacionado con el flujo, ya sea disminuyendo el flujo en el caso de procesos de presión 
constante o aumentando la presión transmembrana en el caso de flujo constante. El fouling de la membrana se puede dar en dos fases:

- Fouling reversible: Se da por la acumulación de sólidos en la membrana durante un ciclo de filtración o entre intervalos de limpieza.

- Fouling irreversible: Se da durante la vida útil del módulo de membrana, Puede deberse a la acumulación de partículas o incrustaciones coloidales, incrustaciones orgánicas y biofouling (primero por fijación y luego por formación de una biopelícula).

\subsection{Aspectos fisicoquímicos de la calidad del agua}

La importancia de la calidad del agua para riego se debe a su impacto directo en los suelos y, en consecuencia, en los cultivos que se realizarán. Ello se debe a que el suelo recibe aporte de sales durante el riego, cuya concentración en el suelo puede incrementarse cuando el cultivo absorbe el agua y ocurre evaporación en la superficie. Los efectos de la calidad de agua empleada pueden variar de acuerdo a las características del suelo y del cultivo a regar, de las condiciones climáticas, de la intensidad y frecuencia del riego, del manejo de suelo y del cultivo; y del sistema de riego utilizado (Grupo de hidrología subterránea, 2018).

Los valores de los parámetros de calidad de agua para riego son establecidos por el decreto supremo $N^{\circ} 004$ - 2017 - MINAM Estándares Nacionales de Calidad Ambiental (ECA); el seguimiento está a cargo de la Autoridad Nacional del Agua. La Tabla 2.2 muestra los valores del ECA para los parámetros a tener en cuenta en este trabajo.

El Decreto Supremo mencionado se adjunta en el Anexo 1. 
Tabla 2.2

Parámetros para agua destinada al riego de vegetales

\begin{tabular}{|c|c|c|}
\hline \multirow{2}{*}{$\begin{aligned} \text { Parámetro } \\
\text { Físicos - Químicos }\end{aligned}$} & Unidad & ECA \\
\hline & & \\
\hline Conductividad & $\mu \mathrm{S} / \mathrm{cm}$ & 2500 \\
\hline Oxígeno Disuelto (valor mínimo) & $\mathrm{mg} / \mathrm{L}$ & 4 \\
\hline Potencial de Hidrógeno $(\mathrm{pH})$ & Unidad de $\mathrm{pH}$ & $6,5-8,5$ \\
\hline Sulfatos & $\mathrm{mg} / \mathrm{L}$ & 1000 \\
\hline Temperatura $^{1}$ & ${ }^{\circ} \mathrm{C}$ & $\Delta 3$ \\
\hline Nitritos $\left(\mathrm{NO}_{2}^{-}-\mathrm{N}\right)$ & $\mathrm{mg} / \mathrm{L}$ & 10 \\
\hline Inorgánicos & & \\
\hline Arsénico & & 0,1 \\
\hline Hierro & $\mathrm{mg} / \mathrm{L}$ & 5 \\
\hline
\end{tabular}

${ }^{1}$ Variación de 3 grados Celsius respecto al promedio mensual multianual del área evaluada. Fuente: Ministerio del Ambiente, MINAM (2015)

Elaboración propia

Adicionalmente, se medirá la cantidad de Solidos Suspendidos Totales (SST), la alcalinidad y la turbidez; por ser parámetros que se utilizan en la interpretación y el control de los procesos de tratamiento de agua y aguas residuales (American Public Health Association, 1998).

A continuación, se señala la importancia de la medición de cada parámetro.

\section{Conductividad}

La conductividad es una medida de la capacidad de una solución acuosa para transportar una corriente eléctrica. Esta habilidad depende de la concentración total de los iones presentes y de la temperatura de medida. Las soluciones de la mayoría de los compuestos inorgánicos son conductores relativamente buenos. Mientras que, las moléculas de compuestos orgánicos que no se disocian en solución acuosa conducen muy mal la corriente, si es que lo hacen (American Public Health Association, 1998).

El principal efecto de una elevada conductividad eléctrica del agua en la productividad de los cultivos es la incapacidad de la planta para competir por el agua con los iones en la solución del suelo. Cuanto más alta es la conductividad eléctrica, menos agua hay disponible para las plantas, aunque el suelo pueda parecer húmedo, debido a que las plantas solo pueden transpirar agua "pura", el agua que las plantas pueden utilizar de la solución del suelo disminuye dramáticamente a medida que aumenta la conductividad eléctrica (Bauder, Waskom, \& Davis, 2007). 


\section{Oxígeno Disuelto}

La concentración de oxígeno disuelto (OD) en las aguas naturales y residuales depende de las actividades físicas, químicas y bioquímicas en el cuerpo de agua; y su variación puede deberse al intercambio gaseoso a través de la superficie del agua, la producción fotosintética, el consumo respiratorio y otros procesos (Arroyo, 2012).

Según Arroyo (2012), el oxígeno disuelto es importante en los procesos de fotosíntesis, oxidación-reducción, solubilidad de minerales y la descomposición de materia orgánica. Sin embargo, existe una gran variedad de microorganismos (bacterias, hongos y protozoarios) para los cuales el oxígeno no es indispensable (anaerobios facultativos), otros no lo utilizan, siendo indiferentes a su presencia (aerotolerantes) e incluso, para algunos el oxígeno resulta ser tóxico o inhibitorio para el crecimiento (anaerobios estrictos).

La Asociación Americana de Salud Pública (American Public Health Association, 1998) señala que el análisis de la concentración de OD es una prueba clave en la contaminación del agua y el control del proceso de tratamiento de residuos.

\section{Potencial de Hidrógeno (pH)}

La prueba de $\mathrm{pH}$ mide el equilibrio entre los iones de hidrógeno positivos $\left(\mathrm{H}^{+}\right)$y los iones hidroxilo negativos $\left(\mathrm{OH}^{-}\right)$. Esto indica si el agua es alcalina $(\mathrm{pH}>7)$, neutra $(7)$ o ácida (<7) (DPI Agriculture Water and Irrigation Unit, 2016).

La Asociación Americana de Salud Pública (American Public Health Association, 1998) indica que la medición del pH es una de las pruebas más importantes y de uso frecuente en la química del agua. Esto se debe a que prácticamente todas las fases del suministro de agua y el tratamiento de aguas residuales dependen del $\mathrm{pH}$, por ejemplo, la neutralización ácido-base, el ablandamiento del agua, la precipitación, la coagulación, la desinfección y el control de la corrosión.

En el caso del agua para riego, un pH de 5.5 a 8.5 es adecuado para la mayoría de las plantas. Si el pH es mayor a 8, el calcio en el suelo puede precipitar y puede bloquear los equipos. Si el pH es menor a 6, puede comenzar la corrosión de las tuberías y accesorios de metal. Y si el pH es menor a 4, el agua puede contribuir a la acidez del suelo (DPI Agriculture Water and Irrigation Unit, 2016). 


\section{Sulfatos}

El sulfato $\left(\mathrm{SO}_{4}{ }^{2-}\right)$ está ampliamente distribuido en la naturaleza y puede estar presente en las aguas naturales en diferentes concentraciones (American Public Health Association, 1998). Las grandes concentraciones de sulfato tienen un efecto laxante en algunas personas y, en combinación con otros iones, dan al agua un sabor amargo (Driscoll, Carter, Williamson, \& Putnam, 2002). La toxicidad rara vez es un problema, excepto en concentraciones muy altas donde el sulfato alto puede interferir con la absorción de otros nutrientes. El sulfato en el agua de riego tiene beneficios de fertilidad (Bauder, Waskom, \& Davis, 2007).

\section{Temperatura}

La Asociación Americana de Salud Pública (American Public Health Association, 1998) señala que las lecturas de temperatura se utilizan en el cálculo de diversas formas de alcalinidad, en estudios de saturación y estabilidad con respecto al carbonato de calcio, en el cálculo de la salinidad y en las operaciones generales de laboratorio. Las plantas industriales a menudo requieren datos sobre la temperatura del agua para el uso del proceso o cálculos de transmisión de calor.

\section{Hierro}

El hierro $(\mathrm{Fe})$ es el cuarto elemento más abundante en la corteza terrestre. Se encuentra en hematites, magnetita y limonita; así como en componentes importantes para los seres vivos, como la hemoglobina. El hierro es ampliamente utilizado para la elaboración del acero y otras aleaciones.

Generalmente, en las aguas subterráneas el oxígeno disuelto está agotado, por ello cualquier hierro soluble se encuentra en estado ferroso; cuando es expuesto al aire o con la adición de oxidantes, el hierro ferroso se oxida al estado férrico $\left(\mathrm{Fe}^{3+}\right)$ y puede hidrolizarse para formar un óxido férrico hidratado, insoluble, rojo.

Las concentraciones elevadas de hierro en el agua pueden causar manchas en la plomería, lavandería y utensilios de cocina, y pueden impartir sabores y colores objetables a los alimentos. La concentración recomendada para las aguas de riego de la 
Organización de las Naciones Unidas para la Alimentación y la Agricultura es de 5 mg/L (American Public Health Association, 1998).

\section{Sólidos suspendidos totales (SST)}

Según el Instituto de Hidrología, Meteorología y Estudios Ambientales (2007):

Las aguas crudas naturales contienen tres tipos de sólidos no sedimentables: suspendidos, coloidales y disueltos. Los sólidos suspendidos son transportados gracias a la acción de arrastre y soporte del movimiento del agua; los más pequeños (menos de $0.01 \mathrm{~mm}$ ) no sedimentan rápidamente y se consideran sólidos no sedimentables, y los más grandes (mayores de $0.01 \mathrm{~mm}$ ) son generalmente sedimentables. Los sólidos coloidales consisten en limo fino, bacterias, partículas causantes de color, virus, etc., los cuales no sedimentan sino después de periodos razonables, y su efecto global se traduce en el color y la turbiedad de aguas sedimentadas sin coagulación. Los sólidos disueltos, materia orgánica e inorgánica, son invisibles por separado, no son sedimentables y globalmente causan diferentes problemas de olor, sabor, color y salud, a menos que sean precipitados y removidos mediante métodos físicos y químicos.

\section{Alcalinidad}

La alcalinidad es un indicador de la capacidad de neutralizar ácidos y una medida cuantitativa de los iones hidroxilo $\left(\mathrm{OH}^{-}\right)$totales o potenciales. La alcalinidad es una consecuencia de la presencia de bicarbonatos $\left(\mathrm{HCO}_{3}{ }^{-}\right)$y carbonatos $\left(\mathrm{CO}_{3}{ }^{2-}\right)$ en el agua. Se mide como mg/L de $\mathrm{CaCO}_{3}$ equivalente (DPI Agriculture Water and Irrigation Unit, 2016).

Según la Asociación Americana de Salud Pública (American Public Health Association, 1998), los valores medidos también pueden incluir contribuciones de boratos, fosfatos, silicatos u otras bases si están presentes. La alcalinidad en exceso de las concentraciones de metales alcalinotérreos es importante para determinar la idoneidad de un agua para el riego. 
Sin embargo, como los bicarbonatos suelen ser el principal contribuyente a la alcalinidad, las altas concentraciones pueden causar problemas que se mencionan a continuación (DPI Agriculture Water and Irrigation Unit, 2016):

- $\quad<90 \mathrm{mg} / \mathrm{L}$, bajo riesgo de problemas.

- 90 - $335 \mathrm{mg} / \mathrm{L}$, riesgo moderado de problemas del suelo y reducción del crecimiento de las plantas por el uso prolongado y la acumulación de incrustaciones blancas en plantas regadas por aspersión en climas de alta humedad.

- $\quad>335 \mathrm{mg} / \mathrm{L}$, alto riesgo de problemas del suelo y crecimiento reducido de la planta. Asimismo, se presenta acumulación de incrustaciones que bloquean las tuberías.

- $\quad 500 \mathrm{mg} / \mathrm{L}$, puede ser perjudicial para la salud humana. No obstante, el agua desarrolla un sabor desagradable mucho antes de esta concentración.

\section{Turbidez}

La turbidez es una expresión de la propiedad óptica que hace que la luz se disperse y absorba en lugar de transmitirse sin cambios en la dirección a través de la muestra (American Public Health Association, 1998). La turbidez en el agua es causada por materia suspendida y coloidal, como arcilla, limo, materia orgánica e inorgánica finamente dividida, plancton y otros organismos microscópicos. La unidad de medida de la turbidez es la unidad nefelométrica de turbidez o NTU por sus siglas en inglés (Nephelometric Turbidity Unit). 


\section{CAPÍTULO III. MATERIALES Y MÉTODOS}

\subsection{Recolección de muestra}

Se realizó un muestreo de tipo manual en el reservorio del Instituto Nacional de Innovación Agraria - Centro Experimental La Molina. Dicho reservorio almacena agua del río Rímac que ha recibido pre-tratamiento mediante un filtro de rejas y dos sedimentadores.

Las muestras de agua fueron recolectadas directamente con el envase, lo que permitió tomar nota de cualquier característica especial de la muestra de agua. Para el muestreo se empleó un envase opaco de polietileno que fue enjuagado tres veces con la misma muestra antes de ser llenado. Seguidamente, la muestra fue rotulada indicando la hora y lugar de muestreo; y se tomó nota de los parámetros medidos en campo (Tabla 3.1) de acuerdo a lo establecido en el procedimiento de operación estándar para muestreo de agua (Departament of Water, 2009).

\subsection{Caracterización del agua de riego}

Se evaluaron algunos parámetros fisicoquímicos del agua de riego del Instituto Nacional de Innovación Agraria (INIA). La medición en campo de los parámetros fisicoquímicos fue realizada mediante electrodos e instrumentos apropiados. Los equipos y métodos empleados para la medición en campo y en laboratorio se muestran en la Tabla 3.1 y Tabla 3.2, respectivamente.

Las especificaciones de los instrumentos y equipos empleados para los ensayos se encuentran en el Anexo 2.

Tabla 3.1

Parámetros fisicoquímicos medidos en el punto de muestreo

\begin{tabular}{l|cl}
\multicolumn{1}{c|}{ Parámetro } & Unidades & \multicolumn{1}{c}{ Instrumento de medición } \\
\hline Conductividad & $\mu \mathrm{S} / \mathrm{cm}$ & Conductivímetro \\
Oxígeno disuelto & $\%$ de saturación & Oxímetro \\
\hline
\end{tabular}

(continúa) 
(continuación)

\begin{tabular}{l|cc}
\hline $\mathrm{pH}$ & Unid. de $\mathrm{pH}$ & Sensor de $\mathrm{pH}$ \\
Temperatura & ${ }^{\circ} \mathrm{C}$ & Termómetro \\
Turbidez & NTU & Turbidímetro \\
\hline
\end{tabular}

Elaboración propia

Tabla 3.2

Parámetros fisicoquímicos a medir en laboratorio

\begin{tabular}{|c|c|c|c|}
\hline Parámetro & Unidades & Método & Equipo \\
\hline Alcalinid & $\mathrm{mg} / \mathrm{L} \mathrm{CaCO}_{3}$ & $\begin{array}{l}\text { Método fenolftaleína y } \\
\text { total }\end{array}$ & $\begin{array}{l}\text { Titulador Digital } \mathrm{HACH} \\
16900\end{array}$ \\
\hline Arsénico total & $\mathrm{mg} / \mathrm{L}$ As & $\begin{array}{l}\text { Generación de hidruros } \\
\text { y espectroscopia de } \\
\text { fluorescencia atómica }\end{array}$ & $\begin{array}{l}\text { Analizador de Arsénico } \\
\text { Millennium PSA }\end{array}$ \\
\hline Hierro total & $\mathrm{mg} / \mathrm{L} \mathrm{Fe}$ & Método FerroVer & $\begin{array}{l}\text { Colorímetro Hach } \\
\text { DR890 }\end{array}$ \\
\hline $\begin{array}{l}\text { Sólidos suspendidos } \\
\text { totales (SST) }\end{array}$ & $\mathrm{mg} / \mathrm{L}$ & $\begin{array}{l}\text { SST en agua secados a } \\
103-105^{\circ} \mathrm{C}\end{array}$ & $\begin{array}{l}\text { Horno digital, balanza } \\
\text { analítica, desecador }\end{array}$ \\
\hline Sulfatos & $\mathrm{mg} / \mathrm{L} \mathrm{SO}_{4}$ & Método SulfaVer 4 & $\begin{array}{l}\text { Colorímetro Hach } \\
\text { DR890 }\end{array}$ \\
\hline
\end{tabular}

Elaboración propia

\subsubsection{Medición de Alcalinidad}

Para medir este parámetro se empleó el método 8203 del manual del titulador digital método fenolftaleína y total (Hach Company, 2013). El instrumento, los reactivos y materiales empleados se muestran en la Figura 3.1. 
Figura 3.1

Instrumento, materiales y reactivos para medir alcalinidad

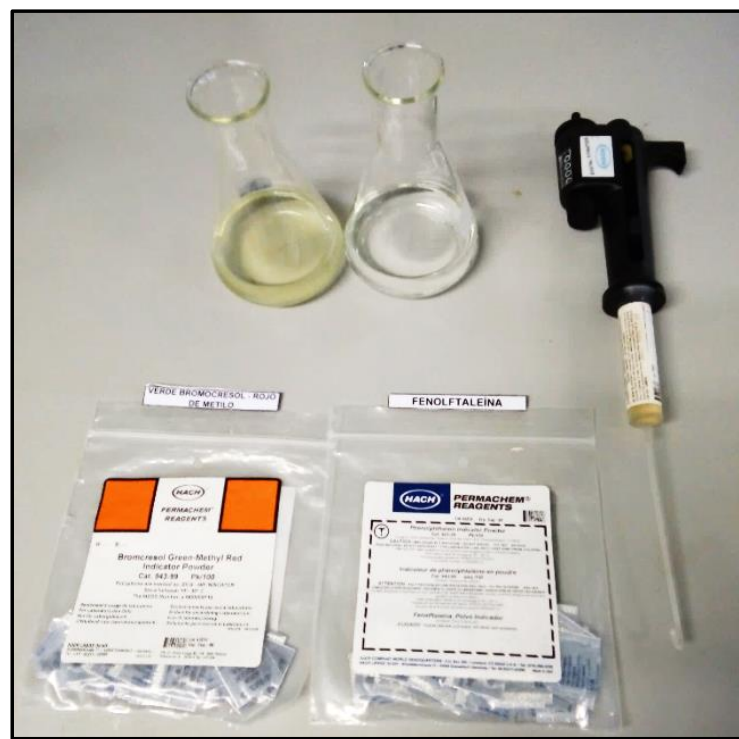

Elaboración propia

\section{Procedimiento}

1. Insertar un tubo de dosificación limpio en el cartucho de ácido sulfúrico 1.6 N y luego colocar el cartucho en el Titulador Digital HACH 16900.

2. Girar la perilla del titulador digital hasta expulsar unas cuantas gotas de solución valorada. Resetear el marcador a cero y limpiar la punta.

3. Usar una probeta graduada para separar $100 \mathrm{~mL}$ de muestra, luego transferir la muestra un matraz Erlenmeyer limpio de $250 \mathrm{~mL}$.

4. Añadir el contenido de una almohadilla de indicador fenolftaleína en polvo y agitar en círculos para mezclar

5. Si la solución se tiñe de rosado, titular hasta el punto final en que desaparece la coloración. Para ello, ubicar el tubo de dosificación en la solución y agitar el matraz mientras se titula con ácido sulfúrico (Figura 3.2). Anotar el número de dígitos requeridos. 
Figura 3.2

Titulación para determinar alcalinidad
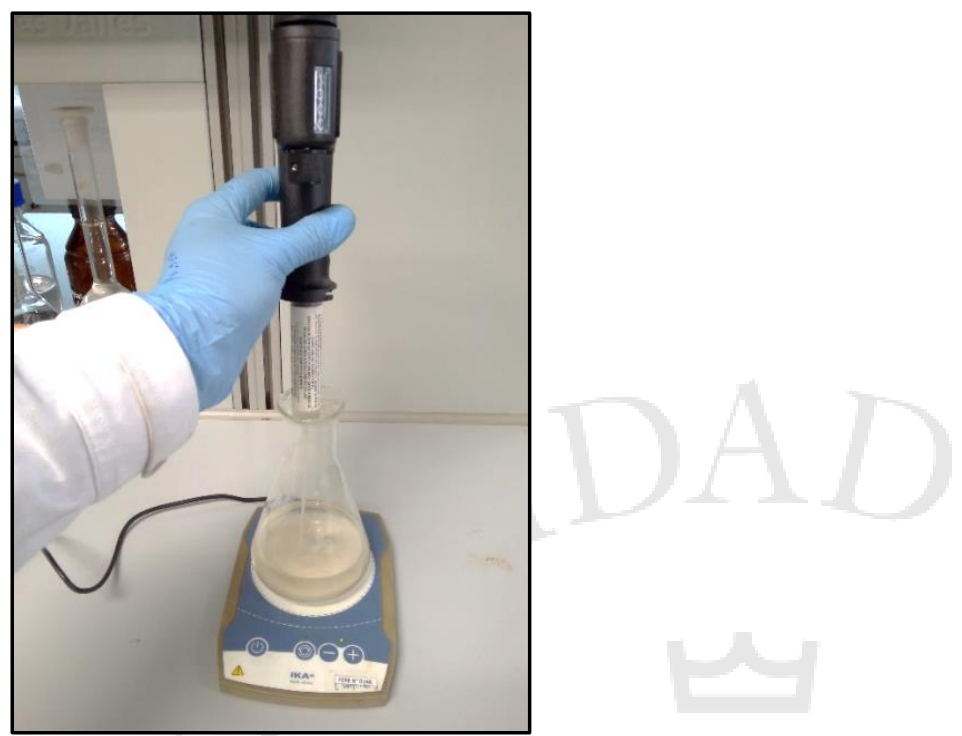

Elaboración propia

6. Si la solución es incolora antes de titular con ácido sulfúrico, la alcalinidad F es cero. Proseguir con el paso 7.

7. Equivalencia:

$$
\text { Dígitos requeridos }=\frac{m g}{L} \mathrm{CaCO}_{3}
$$

8. Añadir el contenido de una almohadilla de indicador Verde Bromocresol Rojo de Metilo al matraz y agitar en círculos para mezclar.

9. Continuar con la titulación con ácido sulfúrico hasta un color rosado claro (Figura 3.3). Anotar el número de dígitos requeridos

10. Equivalencia:

$$
\text { Dígitos requeridos }=\frac{m g}{L} \mathrm{CaCO}_{3} \text { Alcalinidad Total }
$$


Figura 3.3

Coloración del punto final de la titulación para medir alcalinidad

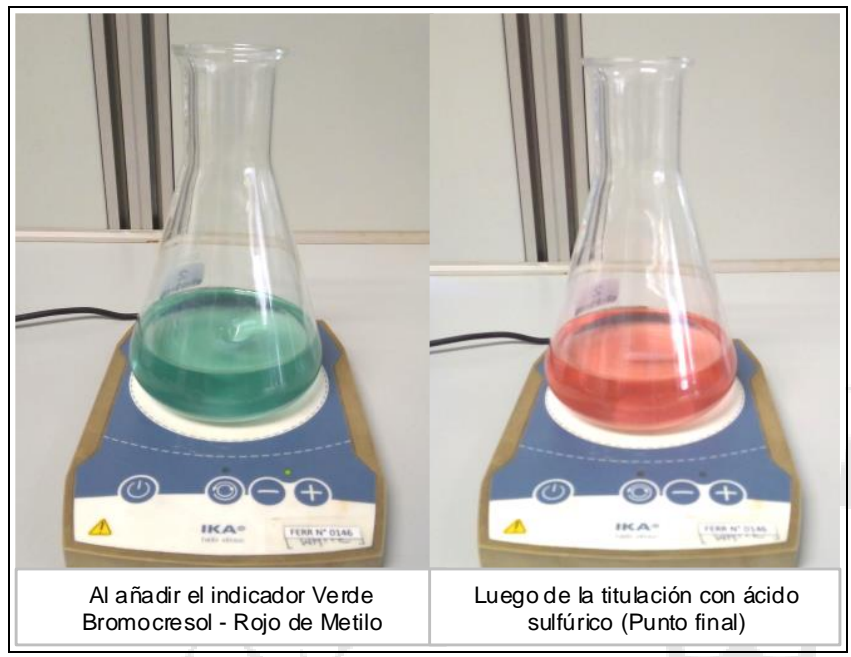

Elaboración propia

\subsubsection{Medición de Hierro total}

Para medir este parámetro se empleó el método 8008 del manual del colorímetro Hach DR 890 (Hach Company, 2013). Los reactivos a emplear se muestran en la Figura 3.4.

Figura 3.4

Equipo, materiales y reactivos para medir Hierro total

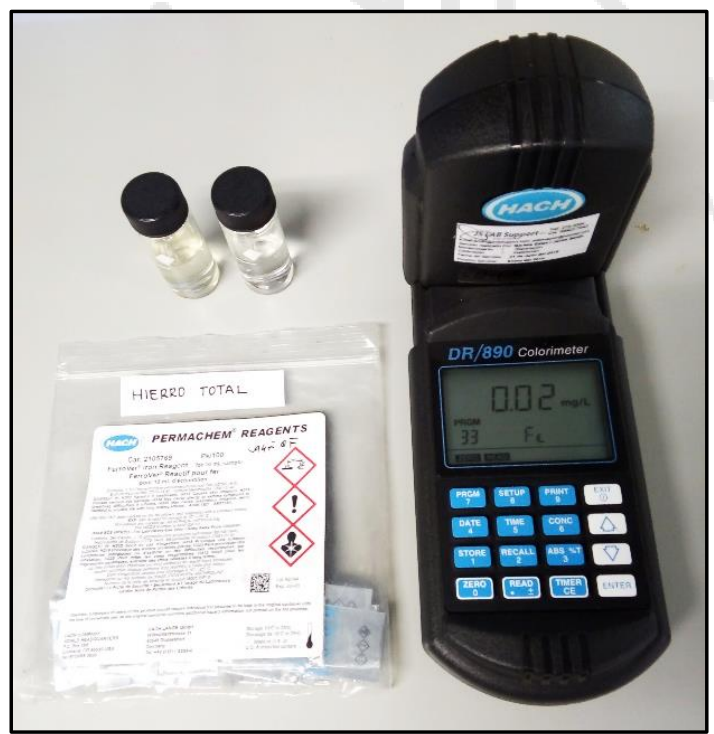

Elaboración propia 


\section{Procedimiento}

1. Presionar :33 ENTER. La pantalla mostrará mg/L Fe y el ícono ZERO.

2. Llenar una celda limpia de $10 \mathrm{~mL}$ con la muestra.

3. Ubicar el blanco en el soporte de la celda. Cubrir bien la celda de muestra con la tapa del instrumento (Figura 3.5).

Figura 3.5

Ubicación de la celda en el colorímetro DR 890

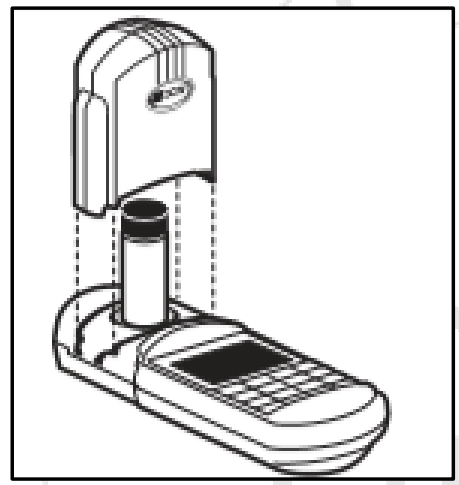

Fuente: Hach Company (2013)

4. Presionar: ZERO. El cursor se moverá a la derecha, luego la pantalla mostrará: $0 \mathrm{mg} / \mathrm{L} \mathrm{SO}_{4}$.

5. Llenar otra celda con $10 \mathrm{~mL}$ de muestra.

6. Añadir el contenido de una almohadilla de reactivo en polvo FerroVer a la celda de la muestra. Tapar la celda e invertir varias veces para mezclar. Se verá una coloración anaranjada si hay hierro en la muestra.

7. Presionar: TIMER ENTER. Comenzará un periodo de reacción de 3 minutos.

8. Ubicar la muestra preparada en el soporte de la celda. Cubra bien la celda de muestra con la tapa del instrumento (Figura 3.5). 
9. Presionar: READ. El cursor se moverá a la derecha, luego el resultado en $\mathrm{mg} / \mathrm{L}$ de hierro $(\mathrm{Fe})$ será mostrado.

\subsubsection{Medición de Sólidos Suspendidos Totales}

El método que se empleó es un método gravimétrico que se basa en la retención de las partículas sólidas en un filtro de fibra de vidrio a través del cual se hace pasar una muestra homogénea de agua; el residuo que queda retenido se seca a $103-105^{\circ} \mathrm{C}$. El incremento en el peso del filtro representa la cantidad de sólidos suspendidos totales (Instituto de Hidrología, Meteorología y Estudios Ambientales [IDEAM], 2007).

El método empleado es según el procedimiento indicado por el Instituto de Hidrología, Meteorología y Estudios Ambientales de Colombia, el cual se indica a continuación.

\section{Preparación de estándares de control de calidad}

En un vaso de $250 \mathrm{~mL}$ coloque alrededor de 10 gramos de caolín y séquelo a $103-105^{\circ} \mathrm{C}$ durante dos horas, como mínimo. Deje enfriar dentro de un desecador, hasta temperatura ambiente. Prepare las siguientes muestras como control de calidad:

- Estándar control de concentración $50 \mathrm{mg} / \mathrm{L}$ : En un vaso de $250 \mathrm{~mL}$, pese directamente $0.0050 \mathrm{~g}$ de caolín y adicione $100 \mathrm{~mL}$ de agua destilada medidos con una probeta. Agite para homogeneizar. Peso esperado de residuo seco: 5 $\mathrm{mg}$

- Estándar control de concentración 500 mg/L: Pesar 0,0500 g de caolín para preparar $100 \mathrm{~mL}$ de suspensión. Siga el procedimiento indicado anteriormente para el patrón de $50 \mathrm{mg} / \mathrm{L}$. Peso esperado de residuo seco: 50 mg.

\section{Preparación del filtro o disco de fibra de vidrio}

Siempre maneje el disco mediante pinzas metálicas y/o microespátula metálica. No manipule el filtro con la mano.

1. Marque cada cápsula de aluminio con un número, de forma consecutiva. 
2. Coloque el disco sobre el soporte, con el lado rugoso hacia arriba, aplique vacío.

3. Lave el disco con tres porciones sucesivas de $20 \mathrm{~mL}$ de agua destilada, medidos con probeta.

4. Deje el vacío durante 1 minuto adicional para secar el disco.

5. Cuidadosamente y con la ayuda de una microespátula o de unas pinzas, retire el disco y colóquelo dentro de la cápsula de aluminio correspondiente.

6. Seque el conjunto (cápsula de aluminio + disco) en el Horno precalentado a $105^{\circ} \mathrm{C}$ por $1 \mathrm{~h}$.

7. Lleve el conjunto a un desecador y deje enfriar aproximadamente por 15 minutos, hasta temperatura ambiente.

8. Pese y registre el peso del conjunto

9. Repita el ciclo de secado, enfriado y pesado. Registre el nuevo peso. Mantenga el conjunto en un desecador hasta que se vaya a utilizar.

10. La máxima variación aceptada en el peso del conjunto es de cinco unidades en la cuarta cifra decimal.

\section{Procesamiento de la muestra}

1. Retire del desecador el conjunto correspondiente a la muestra que va a procesar. Instale el disco en el equipo de filtración. Haga vacío en el sistema y fije el disco con una pequeña cantidad de agua destilada (Figura 3.6).

2. Agite invirtiendo el recipiente de la muestra varias veces. 
3. De la muestra recién agitada, tome rápidamente una alícuota medida con probeta, transfiera cuantitativamente al filtro y registre el volumen total filtrado.

4. Deje el vacío por un minuto adicional para retirar el exceso de humedad del filtro.

5. Retire cuidadosamente el disco con ayuda de una microespátula y colóquelo en la cápsula de aluminio correspondiente.

6. Seque el conjunto en el Horno a $103-105^{\circ} \mathrm{C}$, durante 1 hora.

7. Lleve el conjunto a un desecador y deje enfriar aproximadamente por 15 minutos, hasta temperatura ambiente (Figura 3.7 y Figura 3.8).

8. Pese y registre el peso del conjunto.

9. Repita el ciclo de secado, enfriado y pesado. Registre el nuevo peso.

10. La máxima variación aceptada en el peso del conjunto es de cinco unidades en la cuarta cifra decimal.

\section{Procesamiento de datos y cálculo de resultados}

1. Efectúe los cálculos por medio de la ecuación:

$$
S S T=\frac{(A-B) * 1000}{V}
$$

Donde:

SST: Sólidos Suspendidos Totales, en mg/L

A: Peso final del conjunto (disco + cápsula de aluminio) con el residuo seco, en mg.

B: Peso inicial del conjunto (disco + cápsula de aluminio), en mg. $\mathrm{V}$ : Volumen de muestra filtrada, en $\mathrm{mL}$. 
2. Registre los resultados, con dos cifras significativas.

Figura 3.6

Filtrado de muestra para determinación de SST

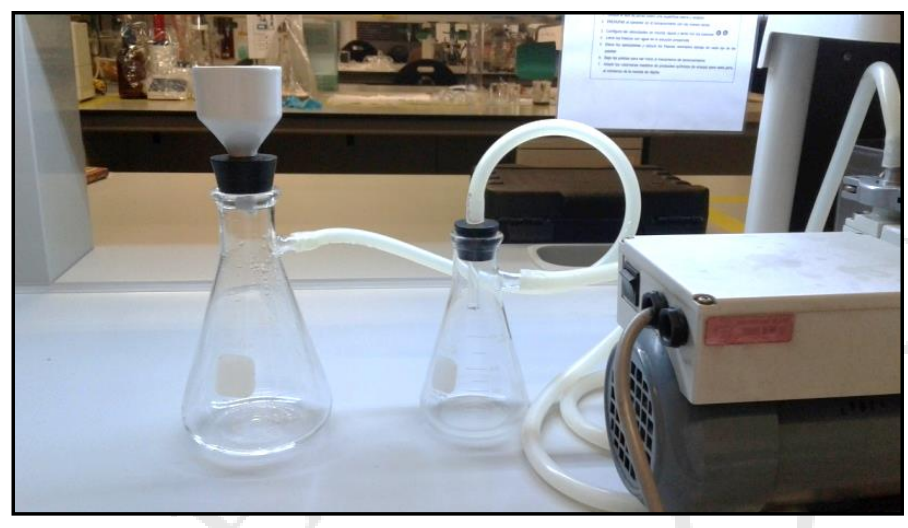

Elaboración propia

Figura 3.7

Secado y pesado de las muestras

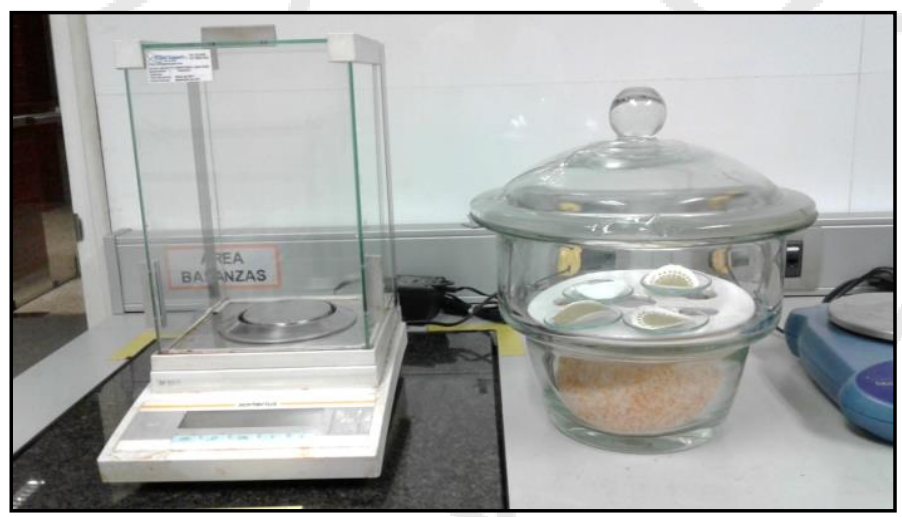

Elaboración propia

Figura 3.8

Muestras desecadas

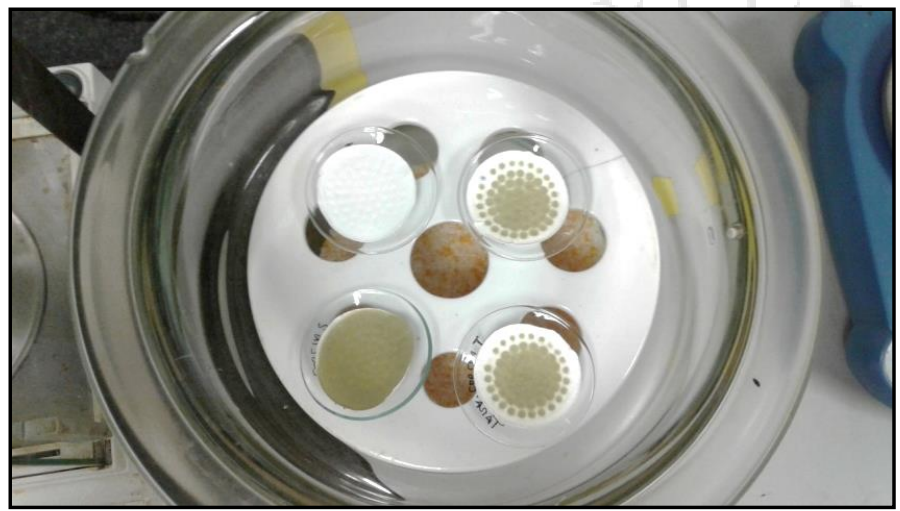

Elaboración propia 


\subsubsection{Medición de Sulfatos}

Para medir este parámetro se empleó el método 8051 (Método SulfaVer) del manual del colorímetro HACH DR 890 (Hach Company, 2013). Los reactivos a emplear se muestran en la Figura 3.9.

Figura 3.9

Equipo, materiales y reactivos para medir sulfatos

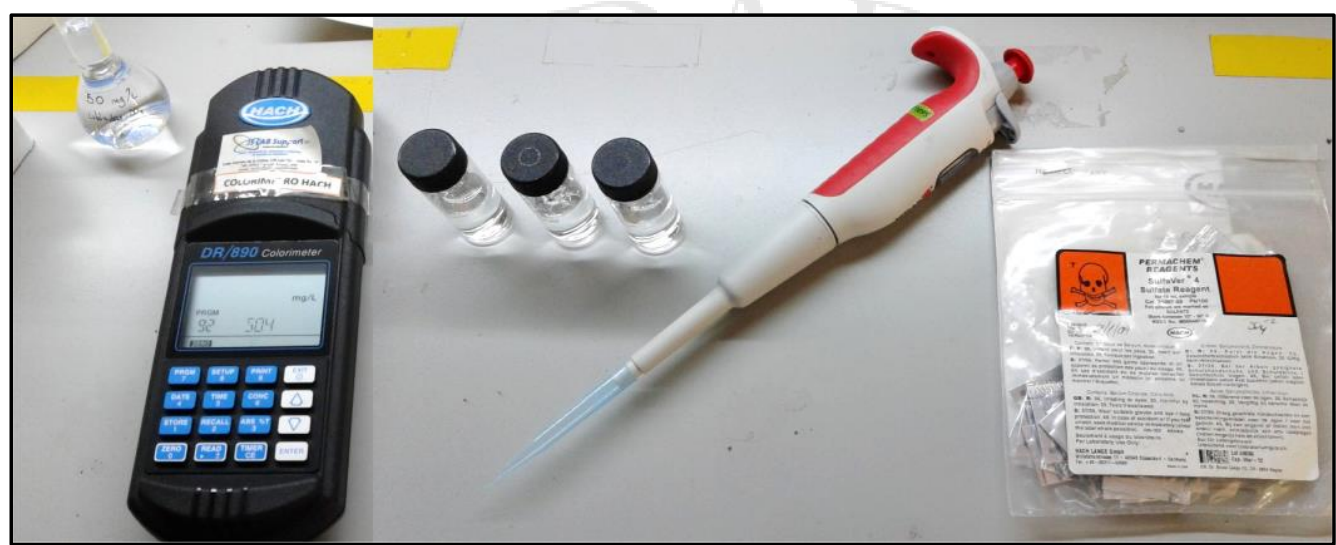

Elaboración propia

1. Presionar :91 ENTER. La pantalla mostrará $\mathrm{mg} / \mathrm{L} \mathrm{SO}_{4}{ }^{2-}$ y el ícono ZERO.

2. Llenar una celda limpia de $10 \mathrm{~mL}$ con la muestra. Filtrar muestras con alta turbidez o color, tanto para la muestra como para el blanco.

3. Añade el contenido de una almohadilla de reactivo en polvo SulfaVer a la celda de la muestra. Tapa la celda e invierte varias veces para mezclar. Se verá una turbidez blanca si hay sulfatos en la muestra. (Nota: La precisión no es afectada por el polvo no disuelto)

4. Presionar: TIMER ENTER. Comenzará un periodo de reacción de 5 minutos. Dejar reposar la celda. 
5. Luego de la alerta del temporizador, llena una segunda celda con $10 \mathrm{~mL}$ de muestra (el blanco).

6. Ubica el blanco en el soporte de la celda. Cubra bien la celda de muestra con la tapa del instrumento.

7. Presionar: ZERO. El cursor se moverá a la derecha, luego la pantalla mostrará: $0 \mathrm{mg} / \mathrm{L} \mathrm{SO}_{4}{ }^{2-}$.

8. Dentro de los 5 minutos siguientes a la alerta del temporizador, ubicar la muestra preparada en el soporte de la celda. Cubra bien la celda de muestra con la tapa del instrumento (Figura 3.5).

9. Presionar: READ. El cursor se moverá a la derecha, luego se mostrará el resultado en $\mathrm{mg} / \mathrm{L}$ de sulfato.

\subsection{Preparación del agua modelo}

El agua modelo fue preparada a partir de muestras tomadas del reservorio del Instituto Nacional de Innovación Agraria. Este reservorio almacena agua proveniente del río Rímac que ha recibido un pre-tratamiento. Durante la caracterización de la muestra se encontró que la concentración de arsénico total era de $19.6 \mu \mathrm{g} / \mathrm{L}$, por lo que iones de arsénico fueron añadidos para alcanzar una concentración de $500 \mu \mathrm{g} / \mathrm{L}$, similar a la concentración promedio de arsénico encontrada en la cuenca del rio Locumba (Castro de Esparza, 2006), ubicado en la zona sur del Perú. La adición de iones de arsénico a las muestras (spiking) hasta alcanzar la concentración deseada ha sido realizada en investigaciones similares por Hwang et al. (2002), Amy et al. (2000), Eaton et al. (1998) y Boerschke et al. (2002).

Para preparar el agua modelo, se añadió arsénico al agua muestreada hasta alcanzar una concentración de arsénico total de $500 \mu \mathrm{g} / \mathrm{L}$, constituida por $250 \mu \mathrm{g} / \mathrm{L}$ de cada especie de arsénico. El arsénico añadido fue una mezcla de una solución estándar 
de arseniato de Sodio (Merck 119773 trazable a SRM de NIST $\mathrm{H}_{3} \mathrm{AsO}_{4}$ en $\mathrm{HNO}_{3} 0.5$ mol/L) y una solución de arsenito de sodio (Merck 106277, preparado con trióxido de arsénico).

\subsection{Producción del ferrato}

En esta investigación se empleó el método electroquímico para la producción de ferrato. La solución de ferrato fue obtenida por medio de un reactor electroquímico, el cual posee dos cámaras separadas por una membrana de intercambio catiónico. Los electrodos fueron ubicados verticalmente y paralelos uno de otro (Figura 3.10). Se empleó un cátodo de grafito y un ánodo de acero dulce, soportadas en placas de polimetilmetacrilato (PMMA). Se usó una fuente de poder regulada (BK Precision 1740B) a corriente constante (Figura 3.11). En base a un estudio anterior que evaluó los parámetros de producción de ferrato (Quino-Favero, Eyzaguirre, Mogrovejo, Prieto, \& Del Pino, 2018) se consideraron los valores que se indican a continuación. La duración del proceso de electrólisis fue de 4 horas a una densidad de corriente de $100 \mathrm{~A} / \mathrm{m}^{2}$ y el electrolito usado fue una solución concentrada de hidróxido de sodio de $20 \mathrm{~mol} / \mathrm{L}$.

Figura 3.10

Configuración del reactor de ferrato(VI)

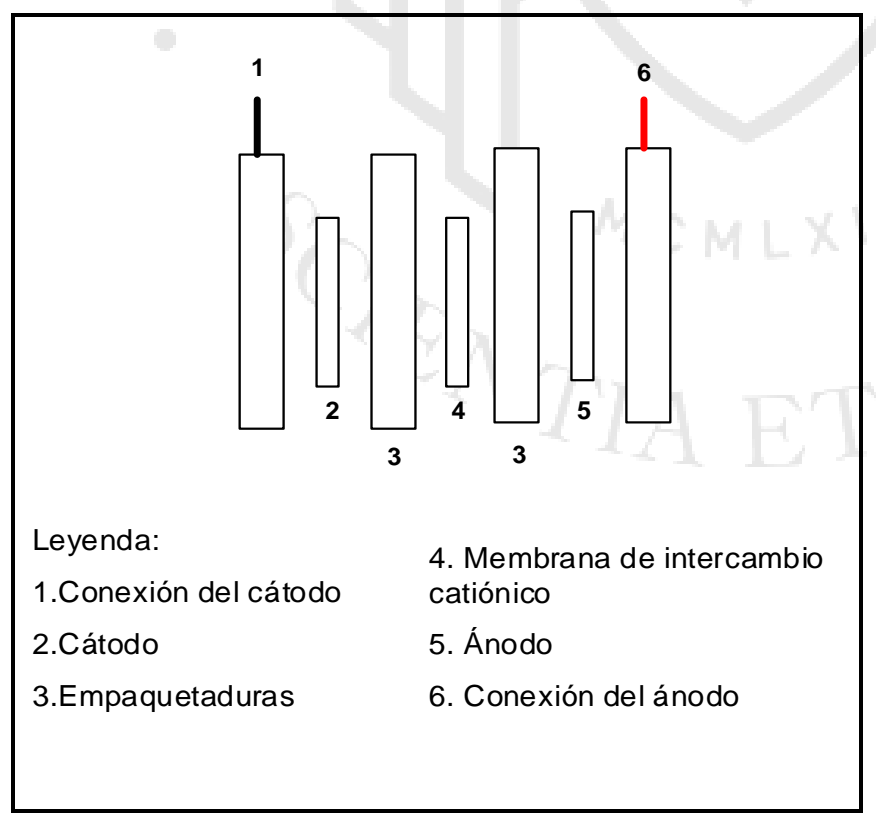

Fuente: Perú Patente No 8577 (2016)

Elaboración propia 
Figura 3.11

Producción de ferrato

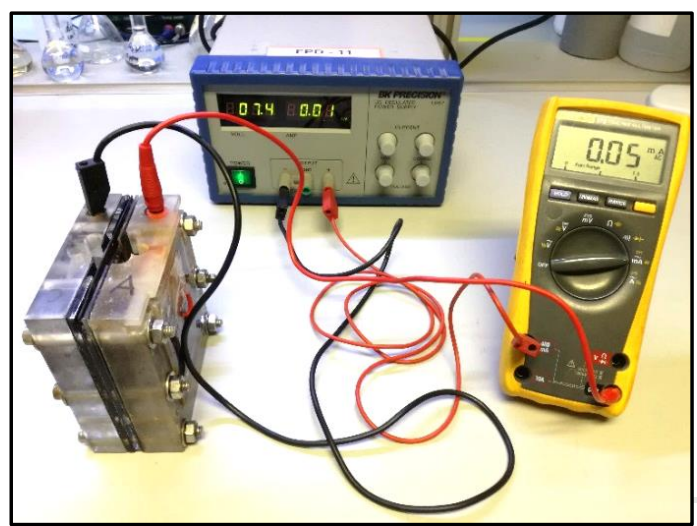

Elaboración propia

\subsection{Medición de la concentración del ferrato(VI)}

La concentración de la solución de ferrato producido(VI) se midió por medio de espectroscopia ultravioleta-visible usando un espectrofotómetro Perkin-Elmer Lambda $40 \mathrm{UV} / \mathrm{Vis}$.

Para obtener la concentración de iones de ferrato(VI) se empleó la siguiente relación:

$$
[F \operatorname{errato}(V I)]=\frac{\Delta A b s \cdot V_{\text {final }}}{\varepsilon \cdot L \cdot V_{\text {muestra }}}
$$

Donde $\Delta \mathrm{Abs}$ es la diferencia de extinción con el blanco medido a $505 \mathrm{~nm}, \mathrm{~V}_{\text {final }}$ es el volumen de la muestra $\left(\mathrm{V}_{\text {muestra }}\right)$ más el volumen de solución de hidróxido de sodio añadido para diluir (Figura 3.12), $\varepsilon$ es el coeficiente molar de extinción de ferrato reportado de $1050 \mathrm{M}^{-1} \mathrm{~cm}^{-1}$ (Stanford, Jiang, \& Alsheyab, 2009) y L es la longitud de la celda, en cm.

Figura 3.12

Muestras diluidas de ferrato

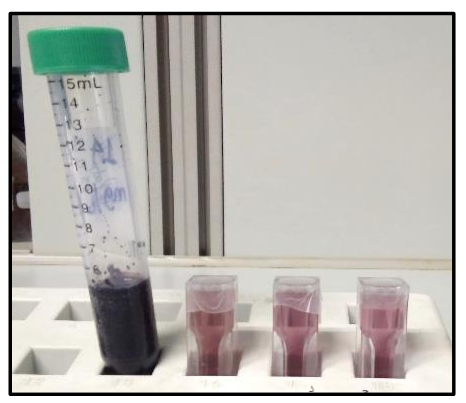

Elaboración propia 


\subsection{Descripción de la prueba de jarras}

La prueba de jarras se realiza para determinar los químicos, la dosificación y las condiciones requeridas para lograr resultados óptimos en los procesos de coagulaciónfloculación. Esta prueba permite evaluar variedad de contribuciones de coagulantes y floculantes usados en el tratamiento de agua y aguas residuales, considerando que todas las pruebas se realizan con la misma agua y las mismas condiciones experimentales. Asimismo, esta prueba sirve para evaluar los efectos de las concentraciones de los coagulantes y floculantes; y el orden en que son añadidos (American Society for Testing and Materials, 2013).

Para la prueba de jarras se emplea un agitador múltiple con variación continua de velocidad (Figura 3.13). Las paletas de agitación deben ser de un material resistente a la corrosión y todas deben tener la misma configuración y tamaño. La base iluminada es útil para observar la formación de flocs. Todas las jarras son de la misma forma y tamaño (American Society for Testing and Materials, 2013). El uso de recipientes cuadrados limita la formación de flujos de vórtices en los que las partículas rotarían en la misma posición en relación con las demás (Howe et al., 2016).

\section{Procedimiento}

1. Medir volúmenes iguales de $1000 \mathrm{~mL}$ de muestra en cada uno de las jarras. Ubicar los vasos de manera que las paletas queden centradas. Se utilizó un agitador (Jar Tester Platypus) para realizar las mezclas.

2. Arrancar el agitador múltiple a la velocidad de "mezcla rápida" de 200 rpm. Agregar la solución de oxidante y coagulante, según la concentración y secuencia definidos previamente. Mezcla instantánea durante 1 minuto después de las adiciones de productos químicos.

3. Luego, reducir la velocidad según sea necesario al mínimo requerido para mantener las partículas de floc uniformemente suspendidas durante el período de "mezcla lenta". La mezcla lenta dura 15 minutos. Si se usan coagulantes, la velocidad de mezcla es crítica porque la agitación excesiva tiende a romper la formación temprana de flóculos y pueden redispersarse (American Society for Testing and Materials, 2013). 
4. Después del periodo de agitación lenta, retirar las paletas y proceder con la microfiltración. Luego, medir turbidez, pH y otros parámetros.

Figura 3.13

Configuración de la prueba de jarras

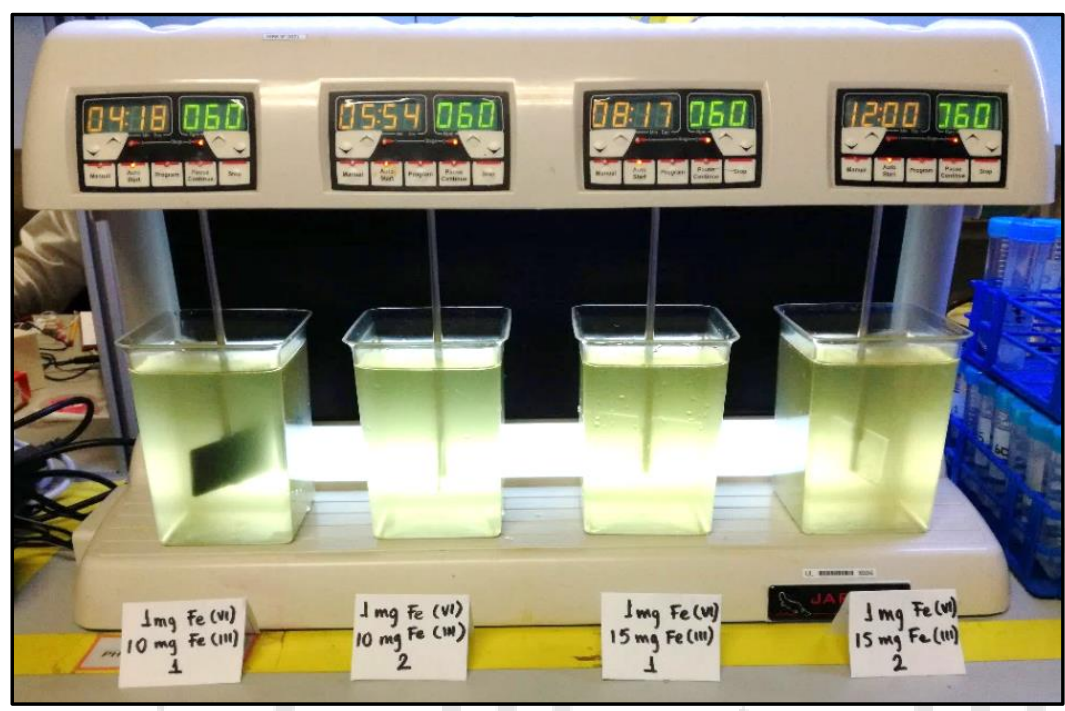

Elaboración propia

Las concentraciones de reactivos para cada jarra fueron 1,2 y $3 \mathrm{mg} / \mathrm{L}$ de ferrato(VI). El ferrato(VI) se encuentra como ion $\mathrm{FeO}_{4}{ }^{2-}$ (Light \& Yu, 2005). Para añadir $1 \mathrm{mg}$ de ferrato(VI) a un litro de agua se añadió $0.0217 \mathrm{~mL}$ de la solución de ferrato(VI) obtenida en la cámara anódica del reactor, dicho volumen a añadir fue calculado como sigue:

$$
10^{-3} \mathrm{~g} \mathrm{FeO}_{4}^{2-} \times \frac{1 \mathrm{~mol} \mathrm{FeO}_{4}^{2-}}{119.843 \mathrm{~g}} \times \frac{L_{\text {solución }}}{0.384 \mathrm{~mol} \mathrm{FeO}_{4}^{2-}} \times \frac{10^{3} \mathrm{~mL}}{L}=0.0217 \mathrm{~mL} \text { de solución }
$$

La solución de ferrato(VI) fue añadida al comienzo de la prueba en una mezcla rápida a $200 \mathrm{rpm}$ durante 1 minuto (gradiente de velocidad de $726 \mathrm{~s}^{-1}$ ), luego se continuó con una mezcla lenta a $60 \mathrm{rpm}$ durante 15 minutos (gradiente de velocidad de $119.9 \mathrm{~s}^{-1}$ ), con el objeto de permitir las colisiones entre las partículas coloidales.

Como coagulante se empleó una solución de cloruro férrico $\left(\mathrm{FeCl}_{3}\right)$, el cual "es uno de los agentes coagulantes ampliamente usado en el tratamiento de agua para 
consumo y aguas residuales" (Jian \& Lloyd, 2002). Para los cálculos se consideraron los iones férricos, los cuales fueron añadidos 5 segundos después de añadir el ferrato(VI). Las concentraciones de iones férricos fueron 3, 6 y $9 \mathrm{mg} / \mathrm{L}$.

Finalmente, para evaluar la remoción de arsénico en las mismas condiciones de $\mathrm{pH}$, en todas las jarras se ajustó el pH a 7 con ácido clorhídrico.

Todas las pruebas de jarra se realizaron por duplicado.

\subsection{Microfiltración}

Todas las pruebas de microfiltración se realizaron "en línea", es decir, se omitió la etapa de sedimentación. Konieczny y otros (2009) señalan que realizar la filtración "en línea" permite reducir la dosis del coagulante y la duración del tratamiento del agua. Esto es de especial importancia en el caso de pequeñas estaciones de tratamiento de agua, ya que la superficie requerida por la instalación puede reducirse a un mínimo.

Luego de la mezcla con el ferrato(VI) y el coagulante, se hizo pasar la muestra a través de unos filtros de $0.45 \mu \mathrm{m}$ de $47 \mathrm{~mm}$ de diámetro, empleando para ello una bomba de vacío. En seguida se colectó $12.5 \mathrm{~mL}$ del filtrado para analizar la concentración de arsénico remanente. Cada prueba se realizó por duplicado.

\subsection{Medición del arsénico}

Para medir el arsénico total remanente se empleó el equipo PSA Millennium Excalibur que se basa en la generación de hidruros y espectroscopía de fluorescencia atómica. El detalle de los reactivos requeridos para el análisis se muestra en la Tabla 3.3.

Tabla 3.3

Reactivos empleados en la medición de arsénico total

\begin{tabular}{l|l}
\hline \multicolumn{1}{c|}{ Reactivo } & \multicolumn{1}{c}{ Características } \\
\hline Solución reductora & $0.7 \% \mathrm{NaBH}_{4}(\mathrm{~m} / \mathrm{v})$ en $0.4 \% \mathrm{NaOH}(\mathrm{m} / \mathrm{v})$ \\
Blanco/Carrier & $\mathrm{HCl} 25 \%(\mathrm{v} / \mathrm{v})$ con KI y ácido ascórbico \\
Gas para secado & Aire comprimido \\
Carrier gas & Argón \\
\hline
\end{tabular}

Elaboración propia 


\subsubsection{Preparación de reactivos}

\section{Solución reductora}

Disolver $7.0 \mathrm{~g}$ de borohidruro de sodio $\left(\mathrm{NaBH}_{4}\right)$ en $500 \mathrm{~mL}$ de agua ultrapura y añadir 4 g de hidróxido de sodio $(\mathrm{NaOH})$. Enrasar con agua ultrapura a $1 \mathrm{~L}$.

\section{Solución yoduro de potasio/ácido ascórbico}

Disolver $25 \mathrm{~g}$ de yoduro de potasio (KI) y $5 \mathrm{~g}$ de ácido ascórbico $\left(\mathrm{C}_{6} \mathrm{H}_{8} \mathrm{O}_{6}\right)$ en aproximadamente $40 \mathrm{~mL}$ de agua ultrapura y enrasar a $50 \mathrm{~mL}$.

\section{Blanco/Carrier}

Para cada $1000 \mathrm{~mL}$ añadir $250 \mathrm{~mL}$ de ácido clorhídrico concentrado y $20 \mathrm{~mL}$ de la solución yoduro de potasio/ácido ascórbico, enrasar con agua ultrapura.

\section{Preparación de estándares y muestras}

Se prepararon estándares de 25, 50, 75, 100 y $125 \mu \mathrm{g} / \mathrm{L}$ de una mezcla de As(III) y As(V) en proporción 1:1. Se emplea una solución estándar de arseniato de Sodio (Merck 119773 trazable a SRM de NIST $\mathrm{H}_{3} \mathrm{AsO}_{4}$ en $\mathrm{HNO}_{3} 0.5 \mathrm{~mol} / \mathrm{l}$ ) y una solución estándar preparada de arsenito.

El estándar para arsenito se preparó de un estándar primario de trióxido de arsénico. Para ello, se disolvió $989.2 \mathrm{mg}$ de $\mathrm{As}_{2} \mathrm{O}_{3}$ (base de metal traza 99.995\%, Aldrich) con unos cuantos pellets de $\mathrm{NaOH}$ en aproximadamente $100 \mathrm{~mL}$ de agua ultrapura, luego se neutralizó la solución usando $\mathrm{HCl}$ y un electrodo de vidrio; se enrasó a un volumen de $1000 \mathrm{~mL}$ para obtener una solución $0.01 \mathrm{~mol} / \mathrm{L}$ As(III).

Las muestras a analizar se diluyeron 1:4, para ello se añadió $6.25 \mathrm{~mL}$ del agua proveniente del test de jarras, $12.5 \mathrm{~mL}$ de $\mathrm{HCl}$ concentrado, $0.5 \mathrm{~mL}$ de la solución yoduro de potasio/ácido ascórbico, se mezcló y se dejó reposar durante 30 minutos. Finalmente, se enrasó a $25 \mathrm{~mL}$ con agua ultrapura.

Para la curva de calibración los estándares fueron leídos tres veces cada uno, mientras que las muestras fueron leídas dos veces. 
La eficiencia de remoción del arsénico del agua fue calculada con la siguiente fórmula:

$$
\text { Eficiencia de remoción }(\%)=\frac{\left(\text { Concentración }_{\text {inicial }}-\text { Concentración }_{\text {final }}\right)}{\text { Concentración }_{\text {inicial }}}
$$

\subsection{Evaluación del costo de tratamiento}

Como se mencionó en el punto 3.5, el tratamiento empleado consta de tres etapas secuenciales: la adición de ferrato, la coagulación con cloruro férrico y la microfiltración. El costo de consumibles para la producción del ferrato fue calculado, mientras que el precio del cloruro férrico fue obtenido del precio de mercado a través de una cotización (Anexo 6). El costo de la microfiltración considera el consumo de energía eléctrica es realizado por la electrobomba que alimenta a la unidad de filtración tangencial. A partir de esos costos, se calculó el costo de tratamiento de $1 \mathrm{~m}^{3}$ de agua, tomando como modelo el agua pre-tratada proveniente del reservorio del INIA - Centro Experimental La Molina.

Para la producción de ferrato, los consumibles empleados son el Hidróxido de Sodio $20 \mathrm{~mol} / \mathrm{L}$, la placa de hierro y la energía eléctrica. Se calculó primero la cantidad requerida de cada consumible para producir un kilogramo de ferrato. Para determinar los costos de los consumibles, se determinó el consumo de cada uno durante el ciclo de producción de 4 horas a $250 \mathrm{~mA}$ de corriente constante.

El consumo del electrolito (hidróxido de sodio) durante un ciclo de producción está determinado por el volumen de la cámara anódica que es constante. El consumo de hierro se calculó empleando la Ley de Faraday según la siguiente fórmula:

$$
\text { Consumo de Fe }(g)=\frac{M I t}{z F}
$$

Donde $\mathrm{M}$ es la masa molar del hierro ( $\mathrm{g} / \mathrm{mol})$, I es la corriente aplicada (A), t es el tiempo (s), z es el número de electrones transferidos (igual a 2, considerando el mínimo número de electrones que se desprenden del ánodo) y F es la constante de Faraday igual a $96485 \mathrm{C} / \mathrm{mol}$.

El consumo de energía eléctrica se calculó empleando las mediciones de voltaje realizadas cada hora durante el ciclo de producción de 4 horas. Para ello, se calculó primero la energía consumida en kWh mediante la integración del área debajo de la curva Watt-hora. 


\section{CAPÍTULO IV. RESULTADOS}

\subsection{Producción de ferrato(VI)}

\section{Cálculo de la concentración de ferrato}

Luego de leer la muestra diluida de la solución de ferrato obtenida en el reactor, se tuvo que los valores promedio de absorbancia netos medidos a $505 \mathrm{~nm}$ fueron de $1.6415 \mathrm{y}$ 1.5725 para el primer y segundo ciclo de producción, respectivamente. La dilución empleada, en ambos casos fue de 10:2510. De la ecuación descrita en el apartado 3.4, se tiene para el cálculo de la concentración de la solución de ferrato del primer ciclo de producción:

$$
[\text { Ferrato }(V I)]=\frac{\Delta \text { Abs.V } V_{\text {final }}}{\varepsilon \cdot L . V_{\text {muestra }}}=\frac{1.6415 \times 2510 \mu L}{1050 M^{-1} \mathrm{~cm}^{-1} \times 1 \mathrm{~cm} \times 10 \mu L}=0.392 \mathrm{M}
$$

Se realizaron dos ciclos de producción de ferrato. Luego de una electrólisis de 4 horas a una densidad de corriente de $100 \mathrm{~A} / \mathrm{m}^{2}$, la concentración obtenida de ferrato(VI) fue de $0.392 \mathrm{~mol} / \mathrm{L}$ y $0.376 \mathrm{~mol} / \mathrm{L}$ en el primer y segundo ciclo, respectivamente. La concentración de ferrato promedio fue de $0,384 \mathrm{~mol} / \mathrm{L}$.

\subsection{Resultados de la caracterización inicial}

Se realizaron las mediciones según la metodología previa. Los resultados de los parámetros medidos en campo se muestran en la Tabla 4.1. La temperatura del agua muestreada fue de $20.8^{\circ} \mathrm{C}$.

Durante el muestreo se tomó nota de las características de la fuente de agua. Se observó que había presencia de grasa en los contornos del reservorio, como puede observarse en la Figura 4.1. Asimismo, se observó una coloración verdosa del agua, debido a la presencia de algas (Figura 4.2). 
Figura 4.1

Presencia de grasa en el reservorio del INIA

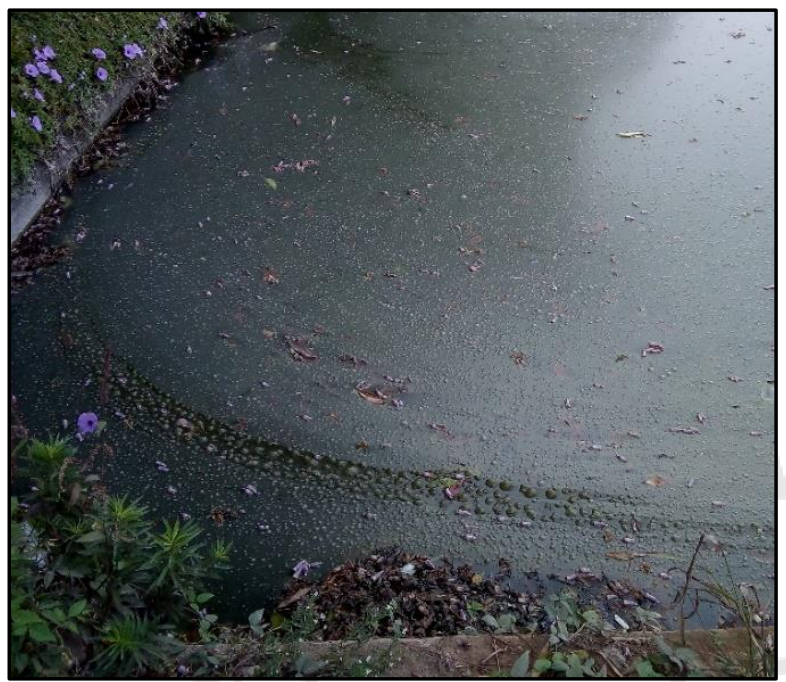

Elaboración propia

Figura 4.2

Coloración que indica la presencia de algas

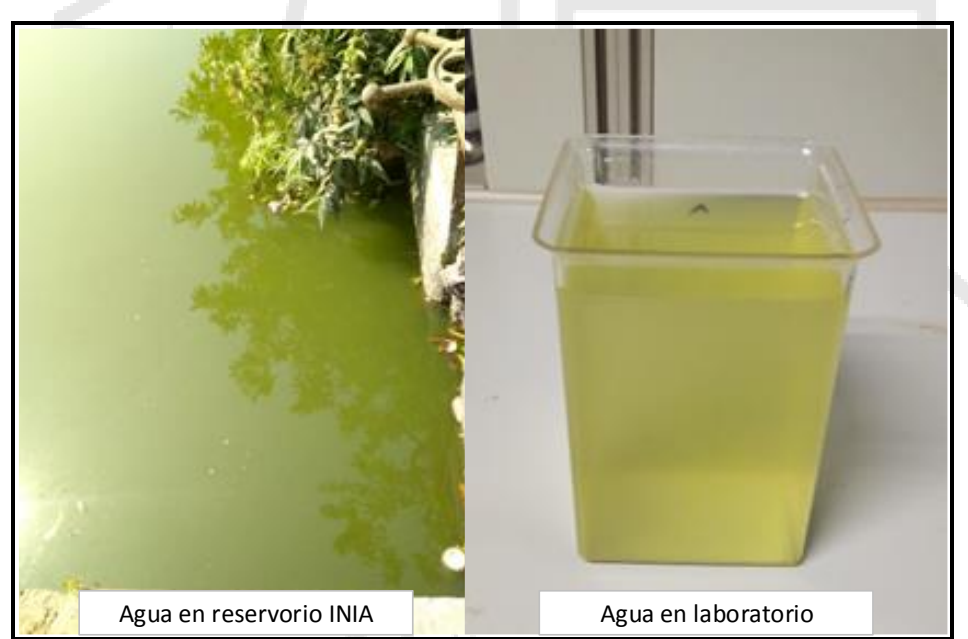

Elaboración propia

De lo observado en la Figura 4.2, cabe mencionar que la eutrofización del agua de superficie es un problema mundial, y su significancia se está incrementando. La eutrofización es causada por un ingreso excesivo de nutrientes, especialmente fosforo, que estimula el indeseable crecimiento de algas. El masivo crecimiento de algas puede ser causa de olores y sabores desagradables, algunos tipos de alga causan obstrucción de los filtros e incluso pueden penetrar el filtro, lo que conlleva al deterioro de la calidad del agua. Asimismo, las algas son precursoras de los subproductos de desinfección y su 
remoción del proceso de tratamiento de agua es difícil debido a su pequeño tamaño y baja gravedad específica (Ma \& Liu, 2002).

\section{Tabla 4.1}

Resultados de los parámetros medidos en campo

\begin{tabular}{c|ccc}
\hline Parámetro & Valor medido & ECA-Categoría 3 & Unidades \\
\hline $\mathrm{pH}$ & 9.84 & $6,5-8,5$ & Unid. de $\mathrm{pH}$ \\
Oxígeno disuelto & 8.32 & 4 & $\mathrm{mg} / \mathrm{L}$ \\
Conductividad & 504 & 2500 & $\mu \mathrm{S} / \mathrm{cm}$ \\
Turbidez & 41,53 & No indica & $\mathrm{NTU}$ \\
\hline
\end{tabular}

Fuente: Ministerio del Ambiente (2015)

Elaboración propia

La Tabla 4.1, muestra que un valor del $\mathrm{pH}$ ligeramente alcalino y es superior al valor que indica el Estándar Nacional de Calidad Ambiental-ECA para Agua, categoría 3, subcategoría D1 (Riego de vegetales). Mientras que los demás parámetros sí están dentro de los estándares.

Los resultados de los parámetros medidos en laboratorio se muestran en la Tabla 4.2, en la que se observa los parámetros cumplen con los valores del estándar mencionado.

Tabla 4.2

Resultados de los parámetros medidos en laboratorio

\begin{tabular}{c|ccc}
\hline Parámetro & Valor & ECA - Categoría 3 & Unidades \\
\hline Sólidos suspendidos totales & 50 & No indica & $\mathrm{mg} / \mathrm{L}$ \\
Sulfatos & 179.7 & 1000 & $\mathrm{mg} / \mathrm{L} \mathrm{SO}_{4}$ \\
Alcalinidad & 27 & No indica & $\mathrm{mg} / \mathrm{L} \mathrm{CaCO}_{3}$ \\
Hierro total & 0.02 & 5 & $\mathrm{mg} / \mathrm{L} \mathrm{Fe}$ \\
Arsénico total & 19,6 & 100 & $\mu \mathrm{g} / \mathrm{L}$ \\
\hline
\end{tabular}

Fuente: Ministerio del Ambiente (2015)

Elaboración propia 


\subsection{Resultados del tratamiento con iones ferrato(VI) y cloruro férrico}

Se evaluó el desempeño del ferrato(VI) como coagulante, ya que luego de actuar como oxidante, se reduce a óxidos o hidróxidos férricos. El proceso de coagulación permite eliminar el As(V) inorgánico disuelto en el agua mediante la adsorción y co-precipitación del $\mathrm{As}(\mathrm{V})$ a un precipitado de hidróxido férrico. El proceso de reducción del ferrato(VI) se observa en la Figura 4.3, en ella puede apreciarse que la solución de ferrato(VI) era inicialmente de color púrpura, la cual rápidamente se volvió amarillenta a medida que el ferrato(VI) se descompone. Asimismo, se observa la formación de algunos precipitados amarillos en el fondo del vaso de precipitados.

Figura 4.3

Cambio de color durante la reducción del ferrato(VI)

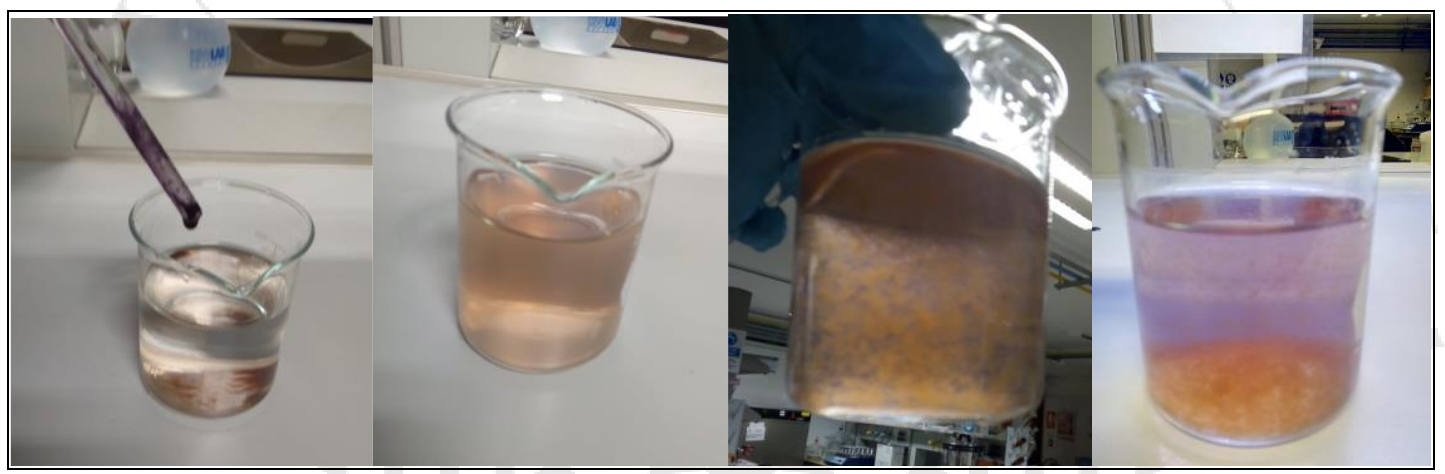

Elaboración propia

Luego de que el ferrato(VI) haya cumplido su función oxidante/coagulante, es necesario retener los flóculos formados para poder usar el agua en el riego, esta separación se realizó mediante la microfiltración.

Se investigó la remoción de la mezcla de As(V) y As(III), con una concentración inicial de arsénico total de $500 \mu \mathrm{g} / \mathrm{L}$, es decir $250 \mu \mathrm{g} / \mathrm{L}$ de cada especie de arsénico. El tratamiento empleado estuvo conformado de tres etapas secuenciales: la oxidación con ferrato, la coagulación con cloruro férrico y la microfiltración en $0.45 \mu \mathrm{m}$.

Inicialmente, solo se añadieron iones ferrato(VI) en solución a las muestras de agua a procesar en las pruebas de jarras seguidas de microfiltración. La solución de ferrato(VI) fue añadida al agua de riego en tres concentraciones distintas 1, 2 y 3 mg/L. No se evaluaron mayores concentraciones de ferrato debido al incremento del $\mathrm{pH}$ del agua, considerando además que el $\mathrm{pH}$ inicial del agua ya era alcalino ( $\mathrm{pH} 8.9$ ). Los 
resultados de la remoción de arsénico empleando solamente iones ferrato(VI) en solución se muestran en la Figura 4.4. Se observa que a medida que se incrementa la concentración del ferrato(VI) añadido, se incrementa la remoción de arsénico. Sin embargo, la concentración de arsénico remanente para la mayor dosis de ferrato $(224.8 \pm 28.1 \mu \mathrm{g} / \mathrm{L}$ As) no cumple con los estándares de calidad ambiental para agua de riego, que establece $100 \mu \mathrm{g} / \mathrm{L}$ As.

Los resultados detallados del experimento se encuentran en el Anexo 3.

Figura 4.4

Concentración de arsénico remanente después del tratamiento con iones ferrato(VI)

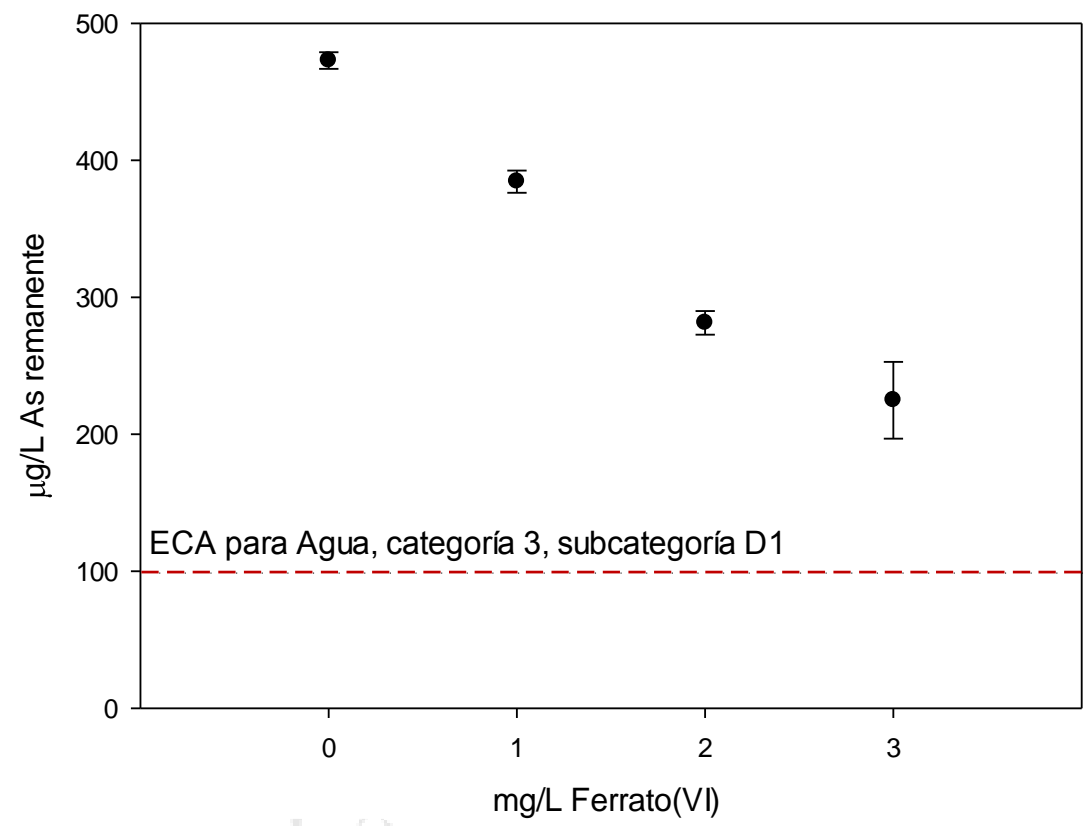

Elaboración propia

Posteriormente, con la finalidad de mejorar el proceso de coagulación, además de los iones ferrato se añadieron iones férricos en solución en diferentes concentraciones (3, 6 y $9 \mathrm{mg} / \mathrm{L}$ ). Para la adición de los iones férricos, se tuvo en cuenta que Halder y otros (2018) encontraron que se logró una remoción del 90\% de arsénico cuando emplearon la relación molar Fe:As de 12:1. En esta investigación, la relación molar Fe:As para la mayor dosis $\mathrm{Fe}(\mathrm{VI}) / \mathrm{Fe}(\mathrm{III})$ fue de 27:1, mientras que para la menor dosis fue de 9:1.

Los resultados del arsénico remanente luego de añadir $\mathrm{Fe}(\mathrm{VI})$ y $\mathrm{Fe}(\mathrm{III})$ al agua de riego se muestran en la Figura 4.5. Se encontró que cuando solamente se emplean los 
iones férricos, luego de añadir la mayor dosis que corresponde a $9 \mathrm{mg} / \mathrm{L} \mathrm{Fe(III),} \mathrm{la}$ concentración del arsénico remanente (109.8 $\pm 6.5 \mu \mathrm{g} / \mathrm{L}$ As) sigue siendo mayor al ECA de agua para riego. Sin embargo, cuando los iones férricos son añadidos luego de los iones ferrato, en todos los casos se consigue reducir la concentración de arsénico por debajo del ECA para la categoría 3.

\section{Figura 4.5}

Concentración de arsénico remanente empleando iones ferrato(VI) y férrico

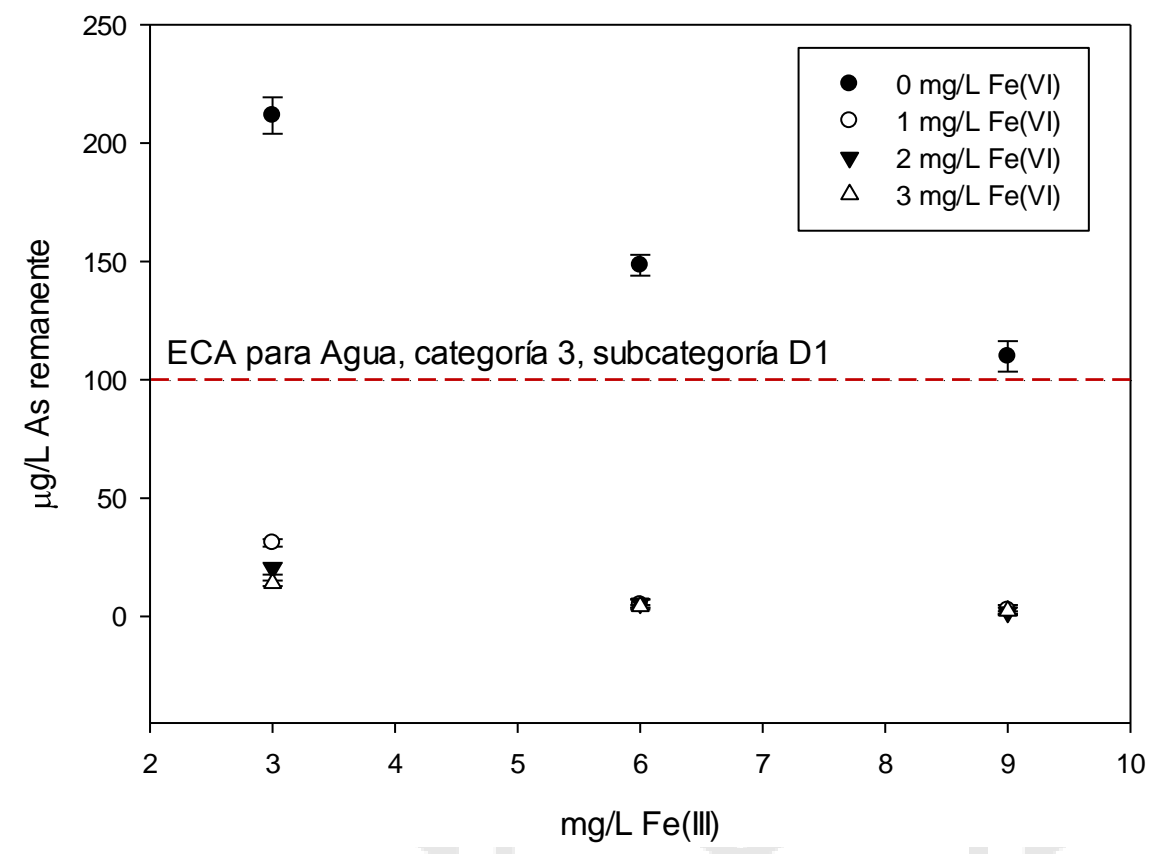

Elaboración propia

En la Figura 4.5 se observa que el uso de ferrato seguido de cualquier dosificación de iones férricos permite alcanzar el ECA en todos los ensayos.

Se encontró que cuando solamente se añaden iones férricos en las dosis de 3, 6 y 9 mg/L Fe(III), el arsénico remanente luego de la microfiltración es de 211.6 \pm 7.7, 148.4 \pm 4.4 y $109.8 \pm 6.5 \mu \mathrm{g} / \mathrm{L}$, respectivamente. Siendo estas concentraciones mayores a las que establece el ECA para Agua, categoría 3, subcategoría D1 (Agua para riego de vegetales).

Sin embargo, al añadir $1 \mathrm{mg} / \mathrm{L}$ de ferrato seguido de iones férricos $\mathrm{y}$ microfiltración se consigue reducir la concentración de arsénico a $31.1 \pm 1.6,5 \pm 2.1$ y $2.7 \pm 2.2 \mu \mathrm{g} / \mathrm{L}$, para cada dosificación de iones férricos. Todas estas concentraciones 
están dentro de lo que establece el ECA. Esta mejora en la remoción de arsénico empleando iones ferrato se debe principalmente a la oxidación del arsénico por el ferrato, lo que produce que el arsénico oxidado este presente como un anión facilitando la combinación con los cationes férricos para formar arseniato ferroso poco soluble. Asimismo, después de la reducción del ferrato a férrico; la hidrólisis de los iones férricos produce oxihidróxidos a escala nanopartícula cuya superficie actúa como adsorbente mejorado del As(V) (Prucek et al., 2013). Por otro lado, la oxidación por ferrato podría cambiar las propiedades de la superficie de los sólidos suspendidos y del arsénico, haciendo que sean fáciles de remover a través de coagulación y precipitación (Jiang, Durai, Winzenbacher, Petri, \& Seitz, 2014).

Luego de comparar las combinaciones de dosis $\mathrm{Fe}(\mathrm{VI}) / \mathrm{Fe}(\mathrm{III})$ en las que se consigue obtener una concentración de arsénico remanente menor a $100 \mu \mathrm{g} / \mathrm{L}$, se considera la adición de $1 \mathrm{mg} / \mathrm{L} \mathrm{Fe}(\mathrm{VI})$ seguida de $3 \mathrm{mg} / \mathrm{L} \mathrm{Fe}(\mathrm{III})$ como la dosificación más apropiada (Tabla 4.3), con la que se obtiene una concentración de arsénico remanente de $31.1 \pm 1.6 \mu \mathrm{g} / \mathrm{L}$.

Esta dosificación permite añadir la menor cantidad de iones de hierro al agua, mientras se añade la menor dosis de ferrato. Utilizar una menor dosificación de iones ferrato(VI) es importante debido a la naturaleza fuertemente alcalina de la solución que los contiene y que tiene como efecto no deseable el aumento excesivo del $\mathrm{pH}$ del agua.

Aunque es preferible remover el arsénico a concentraciones mucho menores de lo que establece el ECA, ya que el arsénico se acumula y persiste en el suelo (Khan, Cao, Zheng, Huang, \& Zhu, 2008), esto requiere mayores dosificaciones $\mathrm{Fe}(\mathrm{VI}) / \mathrm{Fe}(\mathrm{III})$ lo que conduce a un aumento de los iones (sodio y hierro) que originalmente contenía el agua.

Asimismo, con esta dosis, la cantidad de hierro total añadido es de 3,466 mg/L. Esta dosificación permite añadir la menor cantidad iones al agua mientras se consigue una mejor remoción que con otra dosificación con hierro total comparable que no emplea el ferrato. La concentración de hierro que establece el ECA es de $5 \mathrm{mg} / \mathrm{L}$, dato que se debe tener en cuenta si se considera añadir mayores concentraciones de ferrato y férrico, ya que posteriormente los iones añadidos han de ser retirados. Jiang et al. (2014) considera que la obtención de buenos resultados a bajas dosis debería atraer el interés de las industrias del agua, ya que esto primero reduce el consumo de químicos, en segundo lugar, reduce la producción de lodos; y finalmente, reduce los costos operativos. 


\section{Tabla 4.3}

Dosificaciones con $\mathrm{Fe}(\mathrm{VI}) / \mathrm{Fe}(\mathrm{III})$ que remueven el arsénico a concentraciones menores a las que establece el ECA para agua de riego

\begin{tabular}{cc|ccccc}
\hline $\begin{array}{c}\mathbf{F e}(\mathbf{V I}) \\
\mathbf{m g} / \mathbf{L}\end{array}$ & $\begin{array}{c}\mathbf{F e}(\mathbf{I I I}) \\
\mathbf{m g} / \mathbf{L}\end{array}$ & $\begin{array}{c}\text { Promedio } \\
\text { Arsénico } \\
\text { remanente } \\
\boldsymbol{\mu g} / \mathbf{L}\end{array}$ & $\begin{array}{c}\mathbf{m g} / \mathbf{L} \mathbf{F e} \\
\text { Total }\end{array}$ & $\begin{array}{c}\text { mmol/L Fe } \\
\text { Total }\end{array}$ & $\begin{array}{c}\text { Ratio molar } \\
\mathbf{F e}: \text { As }\end{array}$ & $\begin{array}{c}\text { Eficiencia de } \\
\text { remoción } \\
\mathbf{\%}\end{array}$ \\
\hline 1 & 3 & $31.1 \pm 1.6$ & 3,466 & 0,062 & 9 & 93,9 \\
2 & 3 & $20.1 \pm 2.5$ & 3,932 & 0,070 & 10 & 96,0 \\
3 & 3 & $14 \pm 1.2$ & 4,398 & 0,079 & 12 & 97,2 \\
1 & 6 & $5 \pm 2.1$ & 6,466 & 0,116 & 17 & 99,0 \\
2 & 6 & $5.5 \pm 1.8$ & 6,932 & 0,124 & 18 & 98,9 \\
3 & 6 & $4.2 \pm 0.6$ & 7,398 & 0,132 & 20 & 99,2 \\
1 & 9 & $2.7 \pm 2.2$ & 9,466 & 0,170 & 25 & 99,5 \\
2 & 9 & $1.7 \pm 0.5$ & 9,932 & 0,178 & 26 & 99,7 \\
3 & 9 & $2.3 \pm 1.4$ & 10,398 & 0,186 & 27 & 99,5 \\
\hline
\end{tabular}

Elaboración propia

Para verificar estadísticamente si la dosificación de iones ferrato(VI) y de iones férricos (variables independientes) explican la cantidad de arsénico remanente (variable dependiente) se empleó una regresión multivariable, cuyos coeficientes se muestran en la Tabla 4.4. Según los valores de significancia para t-test, en ambos casos, menor a 0.05, se tiene que cada variable independiente se relaciona de forma significativa con la variable dependiente. Por otro lado, de la Tabla 4.5 se observa que según el valor del indicador Durbin-Watson, hay un efecto en el hecho de que la repetición de los ensayos haya sido realizado en momentos distintos, lo que podría ser explicado por el uso de diferente material, la variación de la temperatura y el muestreo del agua.

Tabla 4.4

Coeficientes de la regresión multivariable

\begin{tabular}{c|ccccc}
\hline \multirow{2}{*}{ Modelo } & \multicolumn{2}{|c}{$\begin{array}{c}\text { Coeficientes no } \\
\text { estandarizados } \\
\text { B }\end{array}$} & \multicolumn{1}{c}{$\begin{array}{c}\text { Coeficientes } \\
\text { Destandarizados } \\
\text { Beta }\end{array}$} & $\mathbf{t}$ & Sig. \\
\hline (Constante) & 347,250 & 48,086 & & 7,221 & 0,000 \\
$\mathrm{mg} / \mathrm{L} \mathrm{Fe}(\mathrm{VI})$ & $-55,200$ & 20,053 & $-0,417$ & $-2,753$ & 0,016 \\
$\mathrm{mg} / \mathrm{L} \mathrm{Fe}(\mathrm{III})$ & $-32,100$ & 6,684 & $-0,727$ & $-4,802$ & 0,000 \\
\hline
\end{tabular}


Tabla 4.5

Resumen del modelo de regresión

\begin{tabular}{ccccc}
\hline $\mathbf{R}$ & R cuadrado & $\begin{array}{c}\text { R cuadrado } \\
\text { ajustado }\end{array}$ & $\begin{array}{c}\text { Error estándar de la } \\
\text { estimación }\end{array}$ & Durbin-Watson \\
\hline 0,838 & 0,702 & 0,656 & 89,68123 & 0,558 \\
\hline
\end{tabular}

Elaboración propia

Se realizaron pruebas adicionales para evaluar la reducción de concentración de arsénico del agua modelo para riego. Las dosis empleadas de ferrato fueron de 0.5 y 1 $\mathrm{mg} / \mathrm{L}$, mientras que las dosis evaluadas de férrico fueron 10 y $15 \mathrm{mg} / \mathrm{L}$ (Anexo 4). Los resultados se muestran en la Figura 4.6. A partir de este experimento, se demuestra que es posible alcanzar concentraciones de arsénico remanente por debajo de lo que establece el ECA de interés solamente empleando iones férricos, pero es necesario utilizar mayores concentraciones de los mismos; con lo que se confirma la importancia del uso de iones ferrato para reducir el uso de iones férricos en el proceso de coagulación. A su vez, a menor cantidad de coagulante añadido se reduciría la generación de lodos en esta etapa del tratamiento.

Figura 4.6

Concentración de arsénico remanente con otras dosis $\mathrm{Fe}(\mathrm{VI}) / \mathrm{Fe}(\mathrm{III})$

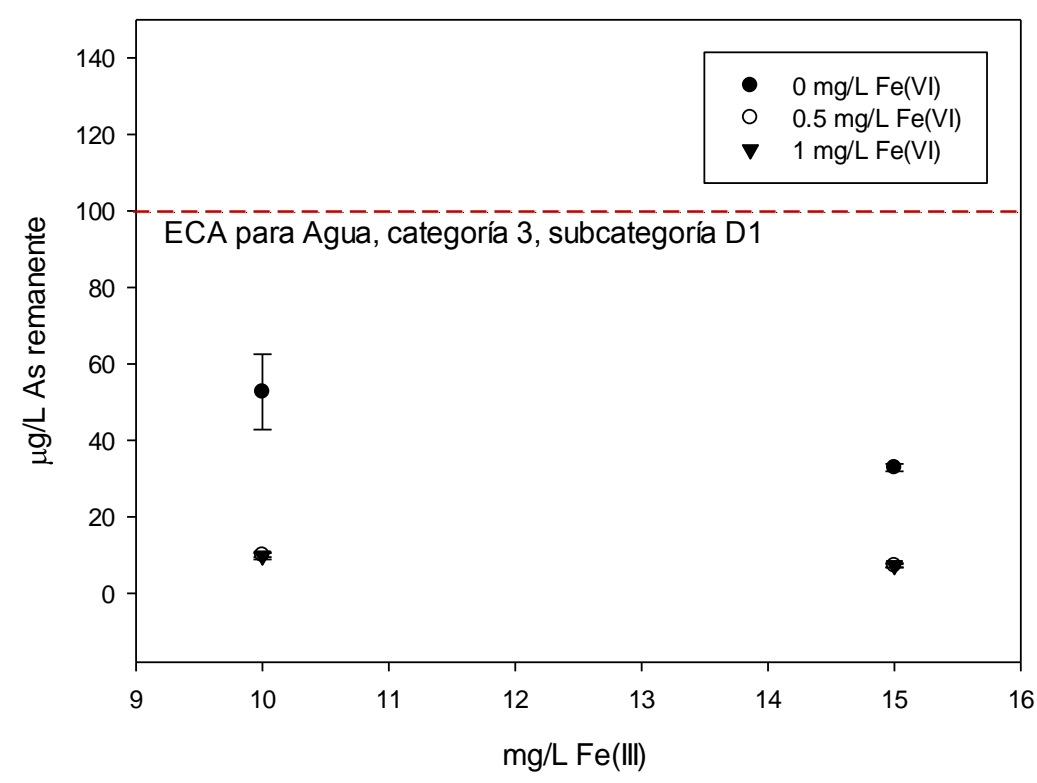

Elaboración propia 


\subsection{Resultados de la caracterización final}

Para realizar la caracterización del agua luego del tratamiento, se consideró solamente el agua de la jarra con la mejor dosis encontrada, es decir, aquella a la que se añadió $1 \mathrm{mg} / \mathrm{L}$ $\mathrm{Fe}(\mathrm{VI})$, seguido de $3 \mathrm{mg} / \mathrm{L}$ de $\mathrm{Fe}(\mathrm{III})$ y microfiltración. Los resultados de la caracterización final se muestran en la Tabla 4.6

Tabla 4.6

Resultados de la caracterización final

\begin{tabular}{c|ccc}
\hline Parámetro & Valor & ECA - Categoría 3 & Unidades \\
\hline $\mathrm{pH}$ & 7.07 & $6,5-8,5$ & Unid. de $\mathrm{pH}$ \\
Oxígeno disuelto & 5.21 & 4 & $\mathrm{mg} / \mathrm{L}$ \\
Conductividad & 633 & 2500 & $\mu \mathrm{S} / \mathrm{cm}$ \\
Turbidez & $<0.1$ & No indica & $\mathrm{NTU}$ \\
Sulfatos & 178.4 & 1000 & $\mathrm{mg} / \mathrm{L} \mathrm{SO}_{4}$ \\
Alcalinidad & 22 & $\mathrm{No} \mathrm{indica}$ & $\mathrm{mg} / \mathrm{L} \mathrm{CaCO}_{3}$ \\
\hline Hierro total & 0.04 & 5 & $\mathrm{mg} / \mathrm{L} \mathrm{Fe}$ \\
\hline
\end{tabular}

Elaboración propia

Se observa que los valores de los parámetros se han reducido respecto a los valores medidos en la caracterización inicial. En todos los casos se cumple con el Estándar Nacional de Calidad Ambiental-ECA para Agua, categoría 3, subcategoría D1 (Riego de cultivos de vegetales). Para el oxígeno disuelto, la norma establece $4 \mathrm{mg} / \mathrm{L}$ como valor mínimo, por lo que también se estaría cumpliendo con ese parámetro.

Por otro lado, luego del tratamiento se observa que la turbidez se reduce notoriamente (Figura 4.7). Así, luego del tratamiento empleado se encontró que el valor de la turbidez es menor a 0.1 NTU. Como comparación se puede tomar en cuenta el valor aceptable para agua potable que debe ser inferior a 5 NTU.

Se ha encontrado que el pretratamiento con oxidantes puede mejorar el proceso de coagulación y específicamente la remoción de algas y otro material particulado en las subsiguientes etapas del tratamiento. Se sugiere que el mecanismo común para la remoción de algas mediante un oxidante es la destrucción de la estructura de las algas en diversas formas a través de diferentes formas de oxidación. Una investigación fue 
realizada para evaluar la efectividad de la pre oxidación con ferrato(VI) en la remoción de algas, encontraron que el tratamiento previo con ferrato(VI) dio como resultado una reducción de la dosis de alumbre requerida para causar una coagulación eficiente para la eliminación de algas. Tras la oxidación con ferrato(VI), las células se inactivaron y algunos componentes intracelulares y extracelulares se liberaron en el agua, lo que puede ser útil para la coagulación mediante un efecto puente (Ma \& Liu, 2002).

Figura 4.7

Remoción de algas luego del tratamiento

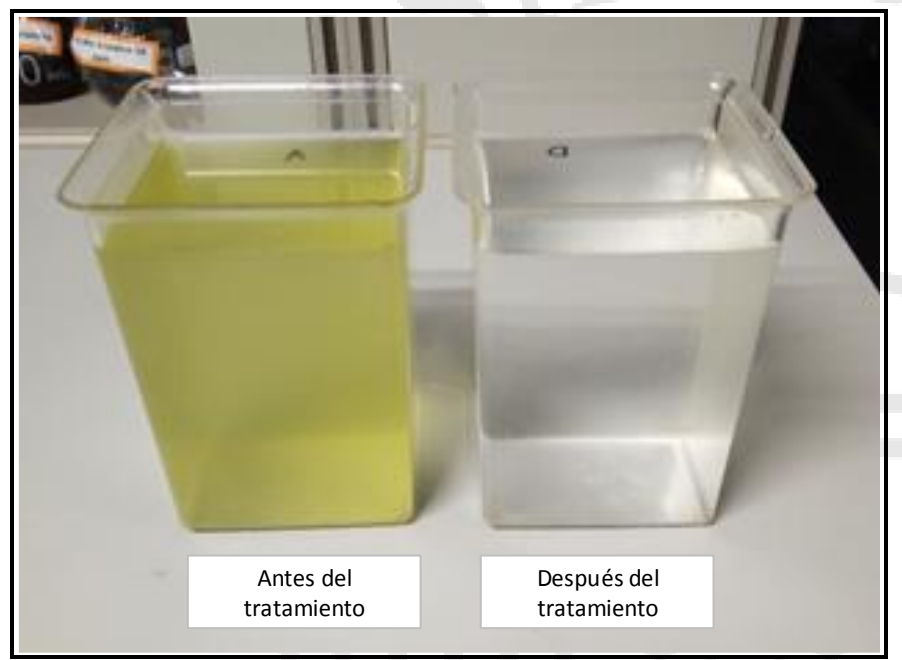

Elaboración propia

Jiang et al. (2014) reportaron que el ferrato(VI) se desempeñaba mejor que otros coagulantes para reducir la turbidez. Ellos demostraron que usar dosis muy bajas de ferrato $(0.2 \mathrm{mg} / \mathrm{L}$ como $\mathrm{Fe})$ puede tener un desempeño superior a otros coagulantes. Mencionan que solo el alto potencial redox no podría explicar el desempeño superior del ferrato(VI), y que debe haber otras razones detrás de ese fenómeno. Primero, la oxidación por ferrato(VI) puede que cambie las propiedades de la superficie de los sólidos suspendidos y contaminantes orgánicos haciendo que queden listos para ser removidos mediante coagulación y precipitación. En segundo lugar, los subproductos de la oxidación del ferrato(VI) son iones férricos o hidróxidos férricos que son recursos coagulante básicos. Por lo tanto, el ferrato(VI) también desempeña coagulación después de degradar la materia orgánica y los microorganismos (Jiang et al., 2014). 


\subsection{Análisis de costos}

\subsubsection{Costo de producción de ferrato}

\section{Electrolito}

El consumo de electrolito para un ciclo de producción está determinado por el volumen de la cámara anódica de $7.5 \mathrm{~mL}$. La presentación comercial para el electrolito es de Hidróxido de Sodio al 50\%.

Consumo de electrolito $=7.5 \mathrm{~mL} \mathrm{NaOHx} \frac{1.52 \mathrm{~g}}{m L}=11.4 \mathrm{~g}$ de $\mathrm{NaOH}$ al $50 \%$

\section{Placa de hierro}

El consumo del ánodo de hierro durante la electrólisis del ciclo de producción fue calculado mediante la Ley de Faraday. Se calculó el consumo de hierro en gramos durante el ciclo de producción a corriente constante de $250 \mathrm{~mA}$ durante cuatro horas.

$$
\text { Consumo de hierro }=\frac{\frac{55.845 \mathrm{gFe}}{\mathrm{mol} \mathrm{Fe}} \times 0.250 \mathrm{~A} \times 14400 \mathrm{~s}}{2 \times \frac{96485 \mathrm{C}}{\mathrm{mol}}}=1.042 \mathrm{gFe}
$$

\section{Energía eléctrica}

El reactor de ferrato trabaja por lotes a corriente constante de $250 \mathrm{~mA}$ durante cuatro horas. La energía consumida que fue medida cada hora y se muestra en la Tabla 4.7. El cálculo de watts consumidos se realizó respecto al voltaje promedio.

Por otro lado, de la Figura 4.8 puede calcularse el área debajo de la curva que representa el total de energía consumida en kWh.

Tabla 4.7

Energía consumida a corriente constante

\begin{tabular}{c|ccccc}
\hline Hora & $\begin{array}{c}\text { Ciclo 1 } \\
\text { Voltaje(V) }\end{array}$ & $\begin{array}{c}\text { Ciclo 2 } \\
\text { Voltaje(V) }\end{array}$ & $\begin{array}{c}\text { Promedio } \\
\text { Voltaje(V) }\end{array}$ & $\begin{array}{c}\text { Intensidad } \\
(\mathbf{A})\end{array}$ & Watt (W) \\
\hline 0 & 16.20 & 14.60 & 15,40 & 0,25 & 3,85 \\
1 & 11.9 & 13.2 & 12,55 & 0,25 & 3,14 \\
2 & 11 & 12.9 & 11,95 & 0,25 & 2,99 \\
3 & 10.7 & 9.8 & 10,25 & 0,25 & 2,56 \\
4 & 10.5 & 9.8 & 10,15 & 0,25 & 2,54 \\
\hline
\end{tabular}

Elaboración propia 
Figura 4.8

Energía consumida durante la producción de ferrato(VI)

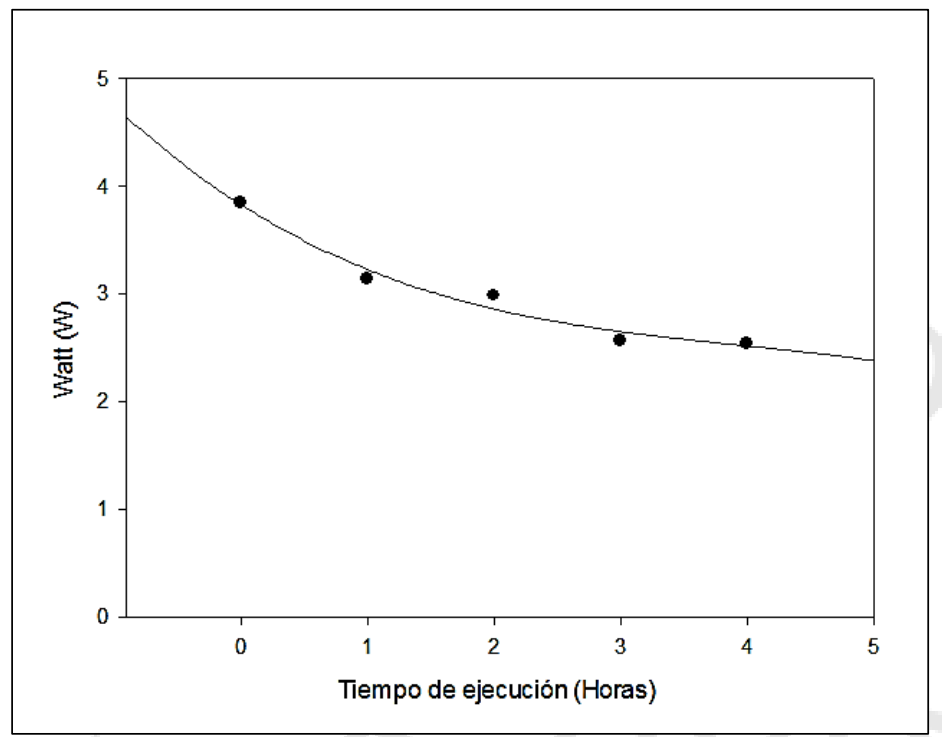

Elaboración propia

La ecuación de la curva obtenida tiene un $\mathrm{R}^{2}$ de 0.9715 , y es como sigue:

$$
y=-0,0135 x^{3}+0,1598 x^{2}-0,7507 x+3,8284
$$

Se integra el área bajo la curva de dicha ecuación y se obtiene que se consumieron en promedio $0,0119 \mathrm{kWh}$ durante las cuatro horas de producción.

\section{Costo total de consumibles}

Con la información anterior del consumo de cada consumible y la información de los precios de cada consumible que se muestran en la Tabla 4.8, se calculó el costo total de los consumibles para la producción de ferrato (Tabla 4.9).

\section{Tabla 4.8}

Precios de consumibles para cada ciclo de producción

\begin{tabular}{l|cc}
\hline \multicolumn{1}{c|}{ Consumible } & Precio S/. & Unidad \\
\hline $\mathrm{NaOH}$ al 50\% & 2.47 & $\mathrm{~S} / \mathrm{kg} \mathrm{NaOH}$ \\
Acero A36 & 2,81 & $\mathrm{~S} / \mathrm{kg}$ \\
Energía eléctrica & 0,2705 & $\mathrm{~S} / \mathrm{kWh}$ \\
\hline
\end{tabular}

Elaboración propia 
Tabla 4.9

Costo total de consumibles para cada ciclo de producción

\begin{tabular}{cccc}
\hline NaOH S/. & Energia S/. & Hierro S/. & Costo Total S/. \\
\cline { 1 - 4 } 0,0282 & 0,0032 & 0,0029 & 0,0343
\end{tabular}

Elaboración propia

\section{Costo por kilogramo de ferrato}

Teniendo en cuenta que la concentración promedio de ferrato obtenida en la cámara anódica $(7.5 \mathrm{~mL})$ es de $0,384 \mathrm{~mol} / \mathrm{L}$, se calculará el costo por kilogramo de ferrato.

$$
\frac{0.384 \mathrm{~mol} \mathrm{FeO}_{4}^{2-}}{\mathrm{L}} \times 7.5 \times 10^{-3} \mathrm{~L} \times \frac{119.843 \mathrm{~g} \mathrm{FeO}_{4}^{2-}}{\mathrm{mol} \mathrm{FeO}_{4}^{2-}}=0.3451 \mathrm{~g} \mathrm{FeO}_{4}^{2-}
$$

Por lo tanto, el costo total por kilogramo es:

$$
\frac{0.0343 \mathrm{~S} / .}{0.3451 \mathrm{~g} \mathrm{FeO}_{4}^{2-}} \times \frac{1000 \mathrm{~g}}{1 \mathrm{~kg}}=99.49 \frac{\mathrm{S} / .}{\mathrm{kg}}
$$

\section{Costo de tratamiento}

Se calculó el costo de tratamiento para un metro cúbico de agua. Se empleó agua pretratada que fue tomada del reservorio del INIA-Centro Experimental La Molina. Las etapas de tratamiento consideradas para el análisis de costo fueron la oxidación con ferrato, la coagulación con cloruro férrico y la microfiltración, empleando para esta última operación una unidad de flujo transversal. Los cálculos se realizaron teniendo en cuenta que las mejores dosis encontradas para las condiciones de estudio son de $1 \mathrm{mg}$ de ferrato(VI) seguido de $3 \mathrm{mg}$ de hierro como cloruro férrico y microfiltración para un litro de agua.

Se calculó primero la cantidad requerida de los consumibles: ferrato, cloruro férrico al $40 \%$ y energía eléctrica.

\section{Energía eléctrica}

El consumo de energía eléctrica es realizado por la electrobomba que alimenta a la unidad de filtración tangencial, por lo que se calculará cuánto tiempo de funcionamiento se 
requiere para tratar un metro cúbico de agua. El caudal del filtrado, según las especificaciones del filtro de membrana, su caudal es de $1.014 \mathrm{~m}^{3} / \mathrm{h}$.

Tiempo de funcionamiento de electrobomba $=1 \mathrm{~m}^{3} \times \frac{h}{1.014 \mathrm{~m}^{3}}=0.986 \mathrm{~h}$

Será necesario que la electrobomba, que alimenta al filtro de membrana, trabaje 0.986 horas para obtener un $\mathrm{m}^{3}$ de permeado. Según las características del motor de la bomba que se muestran en la Tabla 5.3, se calculó el consumo de energía requerido.

$$
0.5 H P \times 745.9 \frac{W}{H P} \times \frac{1 k W}{1000 W} \times 0.986 h=0.368 k W h
$$

\section{Cálculo del costo de tratamiento para un metro cúbico de agua}

El costo de los consumibles necesarios para tratar un metro cúbico de agua se muestran en la Tabla 4.10. El costo del ferrato se calculó en el punto anterior, el precio del cloruro férrico al $40 \%$ está indicado en una cotización adjunta en el Anexo 6 y el costo de la energía eléctrica proviene del tarifario adjunto en Anexo 7.

De los cálculos realizados para el balance de materia tenemos que, para tratar $1 \mathrm{~L}$ de agua, se requiere $1 \mathrm{mg}$ de ferrato y $1.524 \times 10^{-5} \mathrm{~L} \mathrm{FeCl}_{3}$ al $40 \%$.

Tabla 4.10

Costo de consumibles para un metro cúbico de agua

\begin{tabular}{c|cccccc}
\hline Consumible & $\begin{array}{c}\text { Cantidad } \\
\text { requerida }\end{array}$ & $\begin{array}{c}\text { Unidad de } \\
\text { cantidad }\end{array}$ & Precio & $\begin{array}{c}\text { Unidad } \\
\text { de precio }\end{array}$ & $\begin{array}{c}\text { Costo } \\
\text { Total S/. }\end{array}$ \\
\hline Ferrato(VI) & 1 & $\mathrm{~g}$ & 99,49 & $\mathrm{~S} / / \mathrm{kg}$ & 0,10 \\
Cloruro férrico al 40\% & 15,24 & $\mathrm{~mL}$ & 4,851 & $\mathrm{~S} / / \mathrm{L}$ & 0,07 \\
Energía eléctrica bomba & 0,368 & $\mathrm{kWh}$ & 0,2705 & $\mathrm{~S} / / / \mathrm{kWh}$ & 0,10 \\
& & & & & & $\mathbf{0 , 2 7}$ \\
\hline
\end{tabular}

Elaboración propia

Se tiene que el costo total de consumibles para tratar un metro cúbico de agua es de S/.0,27, el cual comprende a las etapas de oxidación con ferrato, la coagulación con cloruro férrico y la microfiltración. 


\section{CAPÍTULO V. INGENIERÍA DEL PROYECTO}

\subsection{Características del producto}

Las características deseables que se buscan obtener con el tratamiento del agua se muestran en la Tabla 2.2 y están acorde al Estándar Nacional de Calidad Ambiental-ECA para Agua, categoría 3, subcategoría D1 (Riego de vegetales).

\subsection{Tecnologías y procesos existentes}

Una variedad de procesos de tratamiento para remover el arsénico del agua han sido desarrollados, de estos, las tecnologías que se muestran en la Tabla 5.1 han sido identificadas como las mejores tecnologías disponibles para remover el arsénico basado en la demostración de la eficacia bajo condiciones de campo y considerando el costo, sin embargo todas estas tecnologías son para remover As(V) (Bilici \& Pala, 2009). Por esta razón, es importante señalar que en ciertos procesos se puede optimizar la remoción de arsénico mediante la pre-oxidación y el ajuste de $\mathrm{pH}$. El cloro, permanganato, ozono y dióxido de manganeso son agentes oxidantes efectivos para el proceso de pre-oxidación (National Electronic Publications Information System, 2005).

Tabla 5.1

Mejores tecnologías disponibles para la remoción de arsénico de agua potable

\begin{tabular}{l|c}
\hline Tecnología de tratamiento & $\begin{array}{c}\text { Eficiencia máxima de } \\
\text { remoción }(\%)\end{array}$ \\
\hline Alúmina activada & 95 \\
Coagulación/Filtración & 95 \\
Intercambio iónico & 95 \\
Ablandamiento con cal & 90 \\
Osmosis inversa & $>95$ \\
Electrodiálisis & 85 \\
Oxidación/Filtración & 80 \\
\hline
\end{tabular}

Fuente: Bilici Baskan, Meltem (2009)

A continuación, se incluye una descripción general de los diversos procesos y tecnologías de tratamiento. 


\subsubsection{Alúmina activada}

Implica un proceso de sorción que utiliza material granular poroso con propiedades de intercambio iónico. En el tratamiento del agua potable, la adsorción en alúmina activada empacada en lechos se usa comúnmente para eliminar la materia orgánica natural y el fluoruro. La eliminación de $\mathrm{As}(\mathrm{V})$ por adsorción puede lograrse pasando agua continuamente bajo presión a través de una o más camas. La alúmina agotada puede regenerarse o eliminarse y reemplazarse por una nueva (National Electronic Publications Information System, 2005).

La eficiencia y economía del sistema dependen de factores tales como la preoxidación previa de As(III) a As(V), la interferencia de los iones disueltos con el proceso de adsorción y la necesidad de ajustar el pH a $<6.5$ (National Electronic Publications Information System, 2005).

\subsubsection{Coagulación- Filtración mejorada}

Este proceso puede optimizarse para eliminar el $\mathrm{As}(\mathrm{V})$ inorgánico disuelto del agua. El mecanismo implica adsorción y co-precipitación de $\mathrm{As}(\mathrm{V})$ a un precipitado de aluminio o hidróxido férrico. El As(III) no se elimina de manera efectiva debido a su carga neutral a pH natural; en consecuencia, el As(III) es más difícil de eliminar que el As(V), por lo que suele ser necesaria una etapa de pre-oxidación.

La eficiencia y la economía del sistema dependen de varios factores, incluyendo el tipo y la dosis de coagulante, velocidad de agitación y pH. Algunos sistemas optimizados de coagulación-filtración son capaces de lograr más del 90\% de remoción de $\mathrm{As}(\mathrm{V})$. Aunque los coagulantes de aluminio y hierro pueden eliminar el arsénico, los coagulantes de hierro (cloruro férrico o sulfato férrico) son más efectivos (National Electronic Publications Information System, 2005). En esta investigación se verificó el uso del cloruro férrico como coagulante en los ensayos realizados.

\subsubsection{Intercambio iónico}

El intercambio iónico es un proceso físico-químico en el que los iones se intercambian entre una fase de solución y una fase de resina sólida. Los grupos ionizables se intercambian por iones de carga similar en solución que tienen una afinidad de intercambio más fuerte (selectividad) por la resina. En el tratamiento del agua potable, 
esta tecnología se utiliza comúnmente para el ablandamiento del agua (intercambio de cationes) y la eliminación de nitratos (intercambio de aniones). Es importante tener en cuenta que el intercambio iónico no es efectivo para la eliminación de As(III) (National Electronic Publications Information System, 2005).

\subsubsection{Ablandamiento con cal mejorado}

El ablandamiento con cal es un proceso de precipitación comúnmente utilizado para eliminar los cationes de calcio y magnesio de la solución. Para eliminar el arsénico, se agrega cal para aumentar el $\mathrm{pH}$ por encima de 10.5 para formar hidróxido de magnesio. En este intervalo de $\mathrm{pH}$, el hidróxido de magnesio y el $\mathrm{As}(\mathrm{V})$ se eliminan por coprecipitación (National Electronic Publications Information System, 2005).

\subsubsection{Osmosis inversa}

La ósmosis inversa es un proceso de separación por membrana impulsado por presión, capaz de eliminar el arsénico del agua por medio del tamaño de partícula, características dieléctricas e hidrofilicidad / hidrofobicidad. La ósmosis inversa también elimina eficazmente otros componentes del agua, incluidos el carbono orgánico, las sales, los minerales disueltos y el color. Este proceso de tratamiento es relativamente insensible al $\mathrm{pH}$, aunque puede ser necesario ajustar el $\mathrm{pH}$ para proteger la membrana de incrustaciones (National Electronic Publications Information System, 2005).

\subsubsection{Remoción biológica}

Como alternativa a la oxidación química, la oxidación bacteriana de As(III) es aplicable para el tratamiento de agua contaminada con arsénico. La aplicación de la oxidación bacteriana de As(III) da como resultado la formación de As(V), que puede eliminarse fácilmente del agua utilizando métodos de tratamiento convencionales (Ike, Miyazaki, Yamamoto, Sei, \& Soda, 2008). La oxidación biológica del hierro por dos bacterias, Gallionella ferruginea y Leptothrix ochracea, ha demostrado ser una tecnología prometedora para la eliminación efectiva del arsénico de las aguas subterráneas. Esta tecnología elimina eficazmente el arsénico del agua y una de las ventajas que ofrece frente a los procesos de tratamiento físico-químico convencionales es que evita la incorporación 
de reactivos químicos para la oxidación del arsénico trivalente (Shankar, Shanker, \& Shikha, 2014).

\subsubsection{Selección de la tecnología}

Como criterios para la selección de la tecnología se tendrá en cuenta el bajo costo, la durabilidad y el mínimo impacto ambiental.

Al ser un proyecto nuevo se utilizará la tecnología semiautomática, ya que la tecnología automatizada requiere de una gran inversión económica y volúmenes de producción muy altos para justificar la inversión.

De esta manera, procesos como la producción de ferrato será realizado empleando una tecnología automatizada, es decir, las operaciones contarán con máquinas que no requieren la supervisión permanente de un operario. Mientras que proceso como la oxidación/coagulación y la microfiltración serán realizados serán realizados empleando una tecnología semi-automatizada. Por otra parte, la operación de ensamblaje del reactor de ferrato se realizará de forma manual.

\subsection{Proceso de producción}

\subsubsection{Proceso de producción del ferrato}

El proceso de producción de ferrato inicia con el ensamble del reactor electroquímico. Para armar el reactor se procede a colocar una pieza de grafito en el espacio central de la placa gruesa de polimetilmetacrilato (PMMA). Verificar que tenga conductividad y se repite este paso con la pieza de acero. Luego, encima de la plancha gruesa de PMMA con grafito se coloca una pieza de nitrilo, seguida de una plancha delgada de PMMA y una lámina adicional de nitrilo, encima se coloca la membrana, verificando el sentido de intercambio. Se vuelve a colocar una lámina de nitrilo, una pieza de PMMA delgada y otra lámina de nitrilo. Finalmente, se pone la pieza de PMMA gruesa que tiene en su centro la pieza de acero. Para unir las piezas del reactor, se hacen pasar los pernos, arandelas y tuercas por los 7 orificios. El diagrama de operaciones y procesos que detalla las actividades correspondientes al ensamble se muestra en la Figura 5.1.

Luego se bombea la solución hidróxido de sodio al 50\% desde un dispensador hacia el reactor. La solución de hidróxido de sodio al 50\% será usada como electrolito para el proceso de electrólisis. Primero se llena la cámara catódica $(120 \mathrm{~mL})$ y en seguida 
la cámara anódica $(120 \mathrm{~mL})$. El ferrato será producido en la cámara anódica por descomposición del electrodo de hierro (Barışçı, Ulu, Särkkä, Dimoglo, \& Sillanpää, 2014). Cuando ambas cámaras estén llenas, se conecta la fuente de poder al reactor y se fija la corriente a usar (250 mA). Luego la fuente de poder es encendida y da inicio la electrólisis. Al término de cuatro horas, la solución de ferrato que se ha formado en la cámara anódica es bombeada a un dispensador a la espera de ser utilizado en el tratamiento de agua. Para dar inicio al siguiente ciclo de producción, el hidróxido de sodio que se encuentra en la cámara catódica (catolito) es bombeado a la cámara anódica para ser usado como anolito, mientras otra bomba alimenta la cámara catódica con nuevo hidróxido de sodio al $50 \%$ desde el dispensador. 


\section{Figura 5.1}

Diagrama de operaciones y procesos para el armado del reactor electroquímico productor de ferrato(VI)

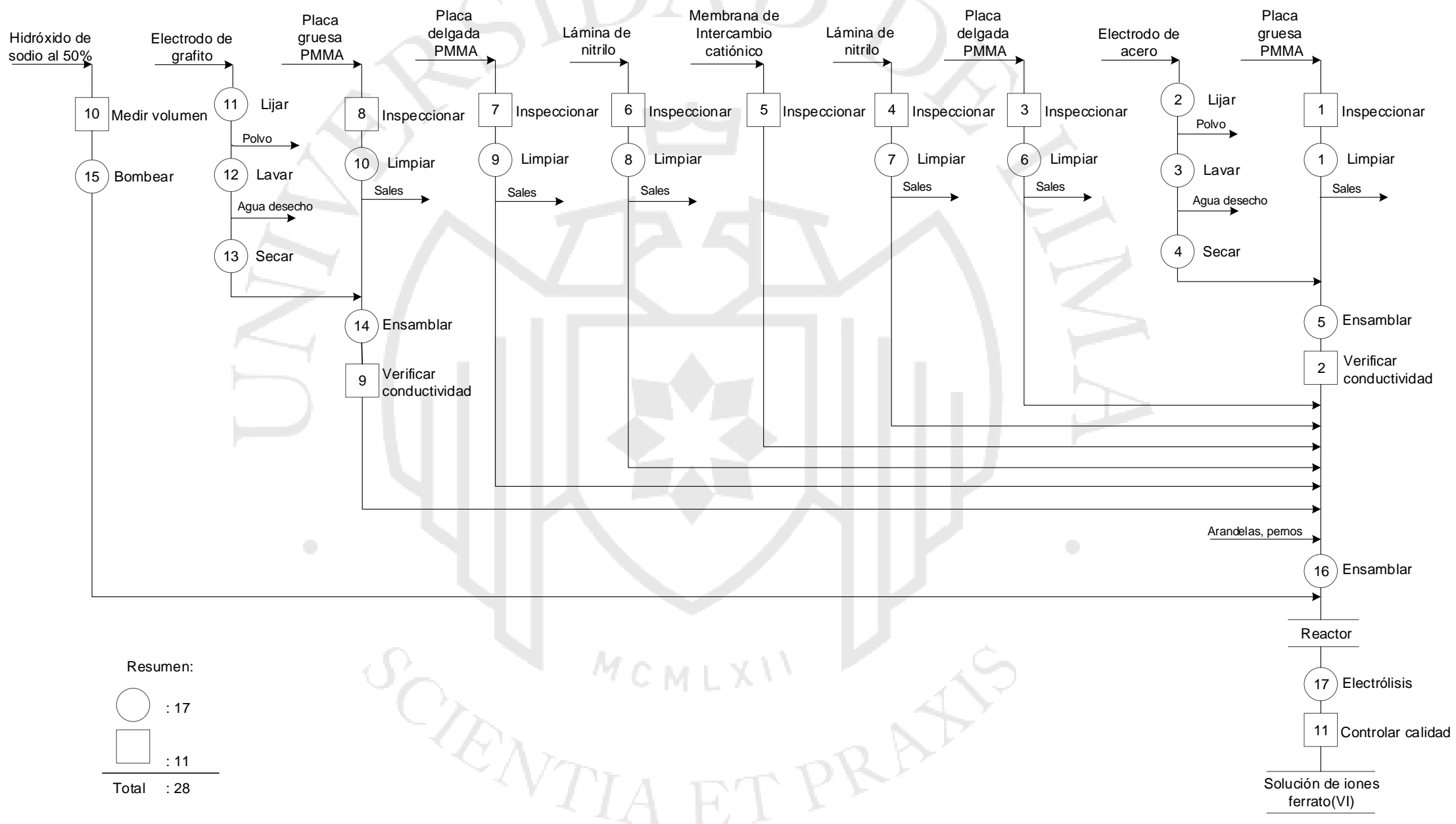




\subsubsection{Sistema de control}

El sistema de control está conformado por un controlador lógico programable (PLC, por sus siglas en inglés) el cual será programado para controlar a las fuentes de poder que energizan los reactores de ferrato, las bombas peristálticas y las electrobombas. Sus entradas serán la lectura de $\mathrm{pH}$ del sensor ubicado en el separador de fases y las lecturas de los sensores de nivel de los tanques.

\subsubsection{Proceso propuesto de tratamiento de agua para riego}

El agua que ingresa al proceso es agua del rio Rímac que ha tenido un pre-tratamiento. Actualmente, el Instituto Nacional de Innovación Agraria - Centro Experimental La Molina cuenta con la infraestructura para el pre-tratamiento conformado por un filtro de rejas, dos sedimentadores y un reservorio. Al ingresar el agua por la bocatoma (Figura 5.2), se inunda una canaleta que colinda con un filtro de rejas (Figura 5.3), en el que se retiran los materiales flotantes que pueden ser ramas, botellas, bolsas, etc. En el filtro de rejas se separa el $0.5 \%$ en masa (sólidos grandes). Luego, se utiliza un sedimentador de tipo abierto y flujo por lote para retener la arena que arrastra el agua, en el que se separa un $3 \%$ de la masa que ingresa. Un segundo sedimentador es empleado para retener partículas finas y separarlas por decantación (Figura 5.4). En esta operación se separa los lodos y arcillas que confieren color marrón al agua, y que constituyen el $2 \%$.

Figura 5.2

Bocatoma

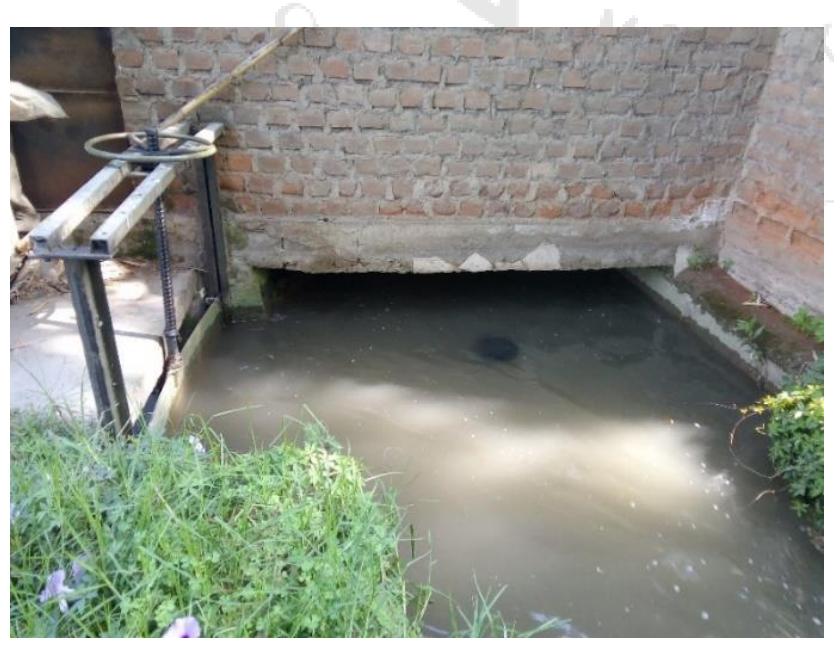

Elaboración propia 
Figura 5.3

Filtro de rejas y sistema de inundación

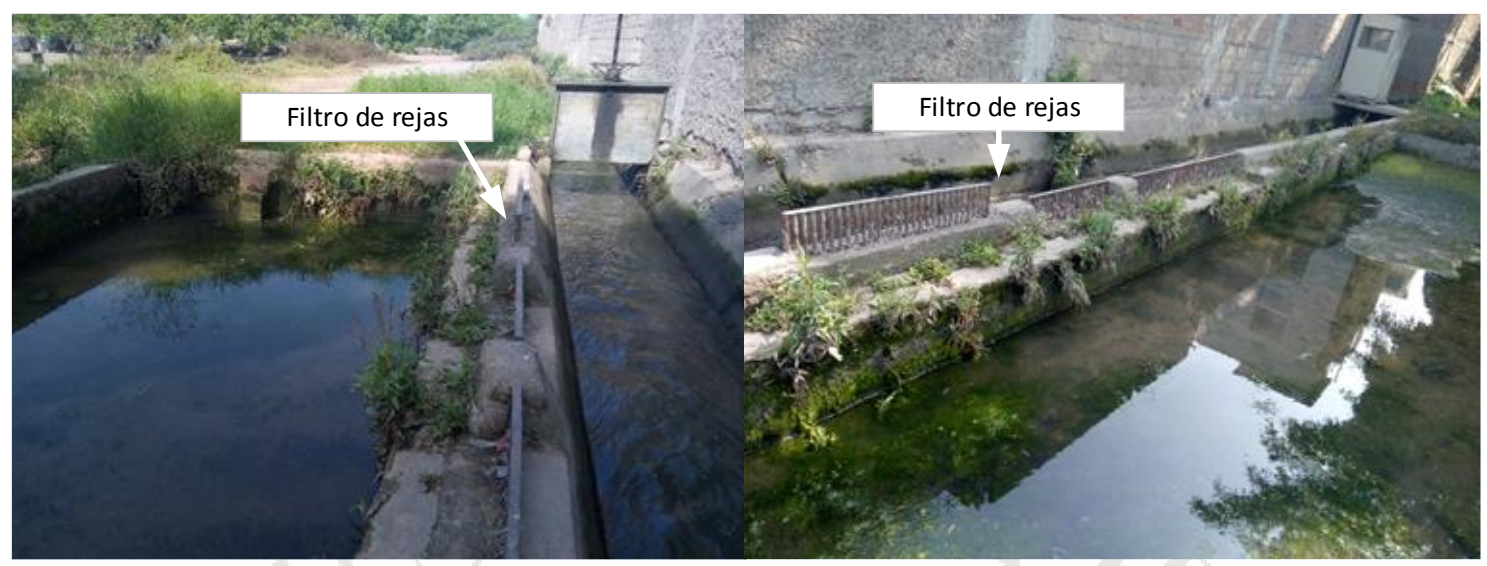

Elaboración propia

Figura 5.4

Sedimentadores

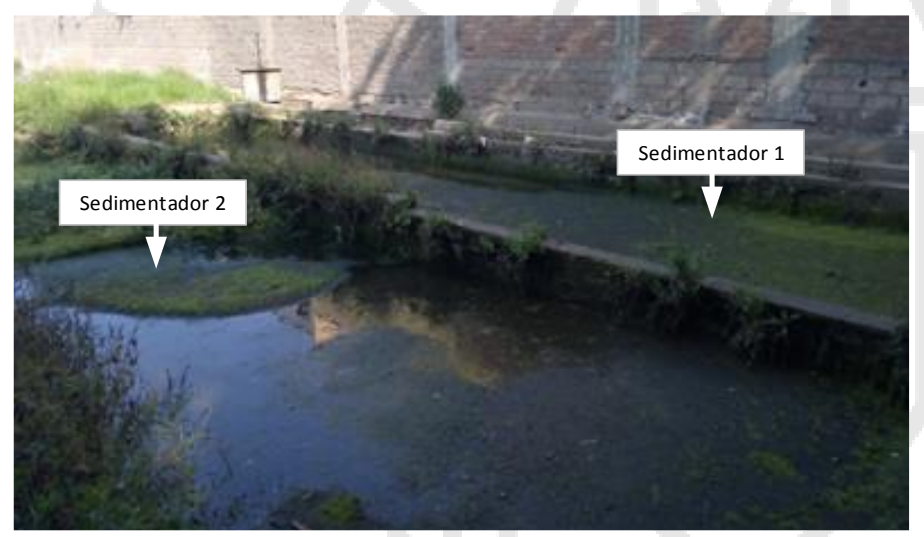

Elaboración propia

Luego de pasar por los sedimentadores, el agua es almacenada en un reservorio abierto. La carga de nutrientes que trae el agua de rio y la recepción de energía solar mientras está en el reservorio favorecen el crecimiento de algas.

A partir de este punto, se considera el sistema de tratamiento propuesto, que comprende el uso del ferrato, los iones férricos y la microfiltracion. El agua que es bombeada del reservorio ingresa a un mezclador estático, con la finalidad de generar turbulencia que permita una mezcla rápida del agua con el oxidante (ferrato) y el coagulante (cloruro férrico). La solución de ferrato de sodio es bombeada desde el dispensador hacia el mezclador estático con una bomba peristáltica. Del mismo modo, el cloruro férrico es bombeado desde el dispensador hacia el mezclador estático. Si el controlador recibe la señal de que el pH es mayor a 8 , mandará la señal a la bomba 
peristáltica del cloruro férrico para seguir dosificando la sal hasta llegar a un $\mathrm{pH}$ de $7 \pm$ 0,5 .

Luego de pasar por el mezclador estático, el agua llega a un separador de fases, que es el punto donde recircula el agua que alimenta a la unidad de filtración tangencial. En el separador de fases, se separa el lodo retenido luego de la recirculación. Según ensayos realizados en laboratorio se determinó que el volumen de lodos húmedos generados es de $1.9 \%$ de la masa total que sale del mezclador estático.

En seguida, el agua es bombeada desde el separador de lodos hasta la unidad de filtración tangencial que emplea filtros de $0.45 \mu \mathrm{m}$. En la unidad de filtración tangencial, la presión es monitoreada con dos manómetros, uno ubicado en la línea de alimentación de la membrana y el otro en la línea del retenido. El valor promedio de la diferencia de las lecturas de estos dos manómetros se toma como la presión aplicada sobre la membrana. A través de los manómetros se registran los cambios en la presión a través de la membrana (TMP, por sus siglas en inglés).

La membrana de microfiltración es instalada verticalmente en la unidad de filtración tangencial como se muestra en la Figura 5.5.

\section{Figura 5.5}

Disposición de filtros en la unidad de filtración tangencial

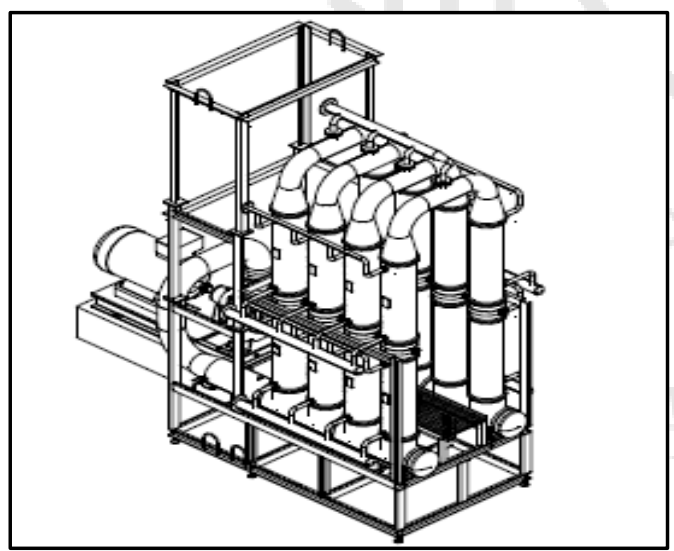

Fuente: Novasep (s.f)

El producto retenido que sale del módulo de membrana se recicla al separador de fases, mientras que el flujo de permeado se colecta en otro tanque, de donde será bombeado para ser usado como agua tratada para riego.

El diagrama de flujo para el proceso descrito se muestra en la Figura 5.6. 
Figura 5.6

Diagrama de flujo del proceso de tratamiento de agua para riego

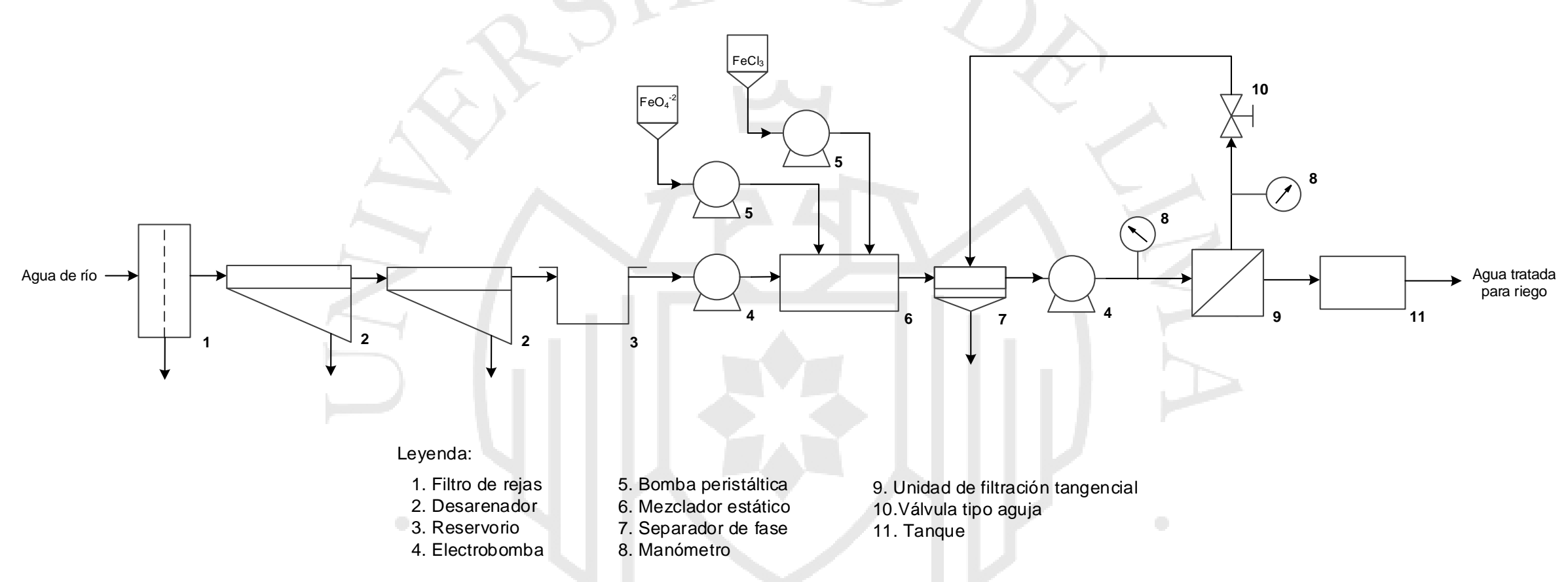

Elaboración propia 


\subsection{Balance de materia}

El balance de materia para el proceso de tratamiento de agua será realizado en base a la cantidad de agua tratada requerida en un año. El Instituto Nacional de Innovación Agraria - Centro Experimental La Molina emplea 5,500 $\mathrm{m}^{3}$ de agua por campaña y cada campaña dura 15 semanas (Rojas Meza, 2016). Se realizan dos campañas por año.

$$
\text { Volumen de agua requerido }=\frac{5500 \mathrm{~m}^{3}}{\operatorname{campa\tilde {n}a}} \times \frac{2 \text { campañ } a s}{a \tilde{\mathrm{n}} o}=11000 \frac{\mathrm{m}^{3}}{a \tilde{\mathrm{n}} o}
$$

De acuerdo a los ensayos de laboratorio realizados, se tiene que, para las condiciones de estudio, las mejores dosis para reducir la concentración de arsénico a los estándares de calidad para Agua, categoría 3- subcategoría D1, son de $1 \mathrm{mg}$ de ferrato(VI) seguido de $3 \mathrm{mg}$ de hierro como cloruro férrico y microfiltración.

Para añadir $1 \mathrm{mg}$ de ferrato(VI) a un litro de agua, se debe tener en cuenta que los iones ferrato se encuentran en la forma $\mathrm{Na}_{2} \mathrm{FeO}_{4}$ en una solución concentrada de $\mathrm{NaOH}$. De acuerdo a los ensayos realizados, para dosificar $1 \mathrm{mg}$ de ferrato(VI) a un litro de agua a partir de una solución de concentración $0.384 \mathrm{M}$, es necesario añadir $0.0217 \mathrm{~mL}$. Se midió experimentalmente la densidad del ferrato y se obtuvo un valor de $1.2007 \mathrm{~g} / \mathrm{mL}$.

$1 \times 10^{-3} \mathrm{~g} \mathrm{FeO}_{4}^{2-} \times \frac{1 \mathrm{~mol} \mathrm{FeO}_{4}^{2-}}{119.843 \mathrm{~g} \mathrm{FeO}_{4}^{2-}} \times \frac{1 \mathrm{~L}_{\text {solución }}}{0.384 \mathrm{~mol} \mathrm{FeO}_{4}^{2-}} \times \frac{10^{3} \mathrm{~mL}}{1 \mathrm{~L}}=0.0217 \mathrm{~mL}_{\text {solución }}$

$0.0217 \times 10^{-3} L$ solución $\times \frac{1.2007 \mathrm{~g}}{10^{-3} \mathrm{~L}}=0.0261 \mathrm{~g}$ de solución de ferrato

De forma análoga, se calculó, para un litro, el volumen a añadir de una solución de cloruro férrico $\left(\mathrm{FeCl}_{3}\right)$ al $40 \%$ (presentación comercial), el cual tiene una densidad de $1.43 \mathrm{~g} / \mathrm{mL}$.

$3 \times 10^{-3} \mathrm{~g} \mathrm{Fe} \times \frac{1 \mathrm{~mol} \mathrm{Fe}}{55.845 \mathrm{~g} \mathrm{Fe}} \times \frac{162.24 \mathrm{~g} \mathrm{FeCl}_{3}}{1 \mathrm{~mol} \mathrm{FeCl}_{3}} \times \frac{10^{-3} \mathrm{~L}}{1.43 \mathrm{~g}} \times \frac{100}{40}=1.524 \times 10^{-5} \mathrm{~L} \mathrm{FeCl}_{3}$ al $40 \%$

$1.524 \times 10^{-5} \mathrm{LFeCl}_{3}$ al $40 \% \times \frac{1.43 \mathrm{~g}}{10^{-3} \mathrm{~L}}=0.0218 \mathrm{~g} \mathrm{FeCl}_{3}$ al $40 \%$ 
Con esta información se calcularán las cantidades requeridas de solución de ferrato y cloruro férrico para abastecer con $11000 \mathrm{~m}^{3}$ de agua tratada. El balance de materia del proceso de tratamiento de agua se muestra en la Figura 5.7.

A partir del balance de materia para el tratamiento de agua se calcula la cantidad de solución de ferrato requerida en un año. El balance de materia del proceso de producción de ferrato se muestra en la Figura 5.8.

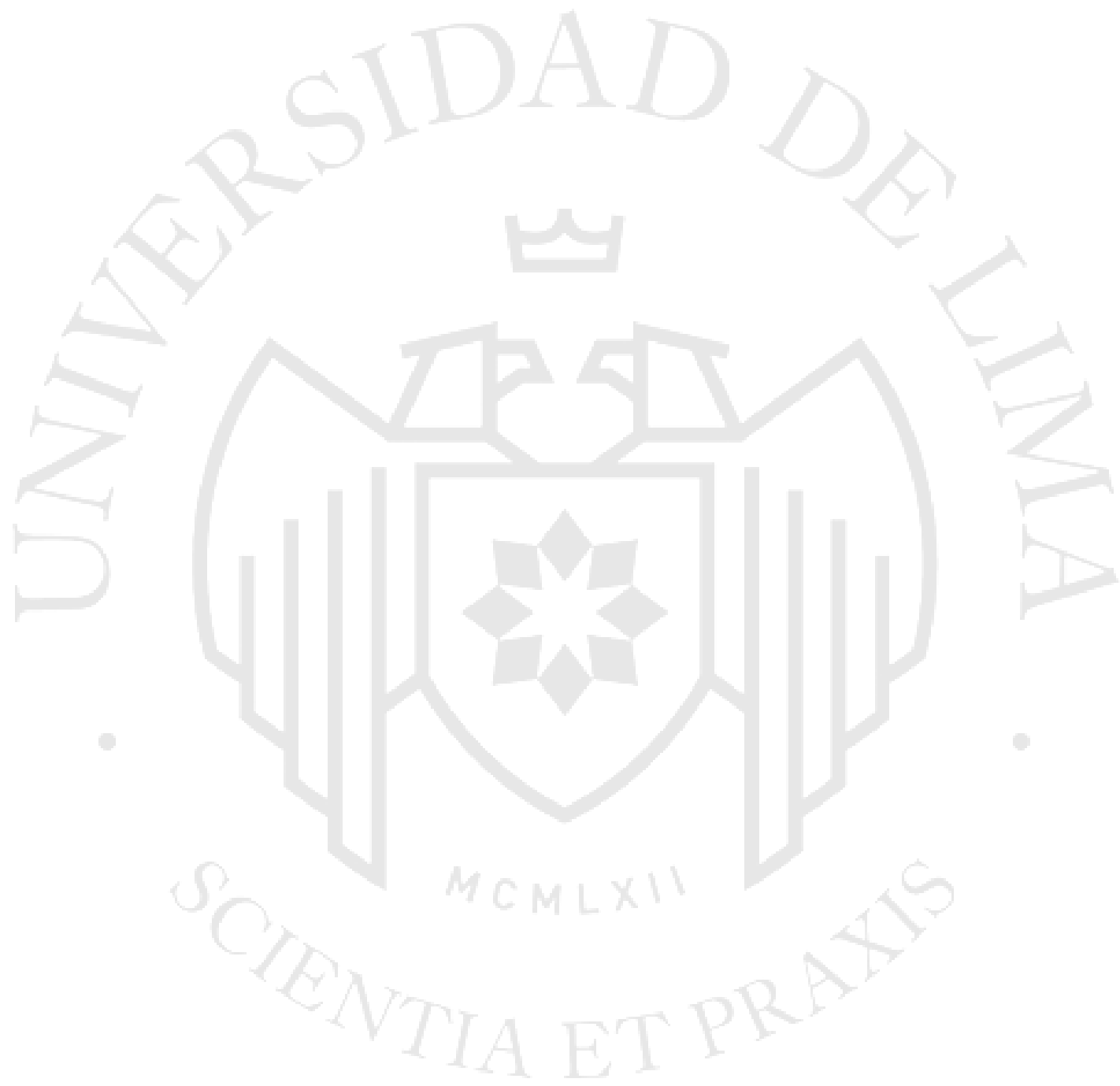




\section{Figura 5.7}

Balance de materia del proceso de tratamiento de agua para riego

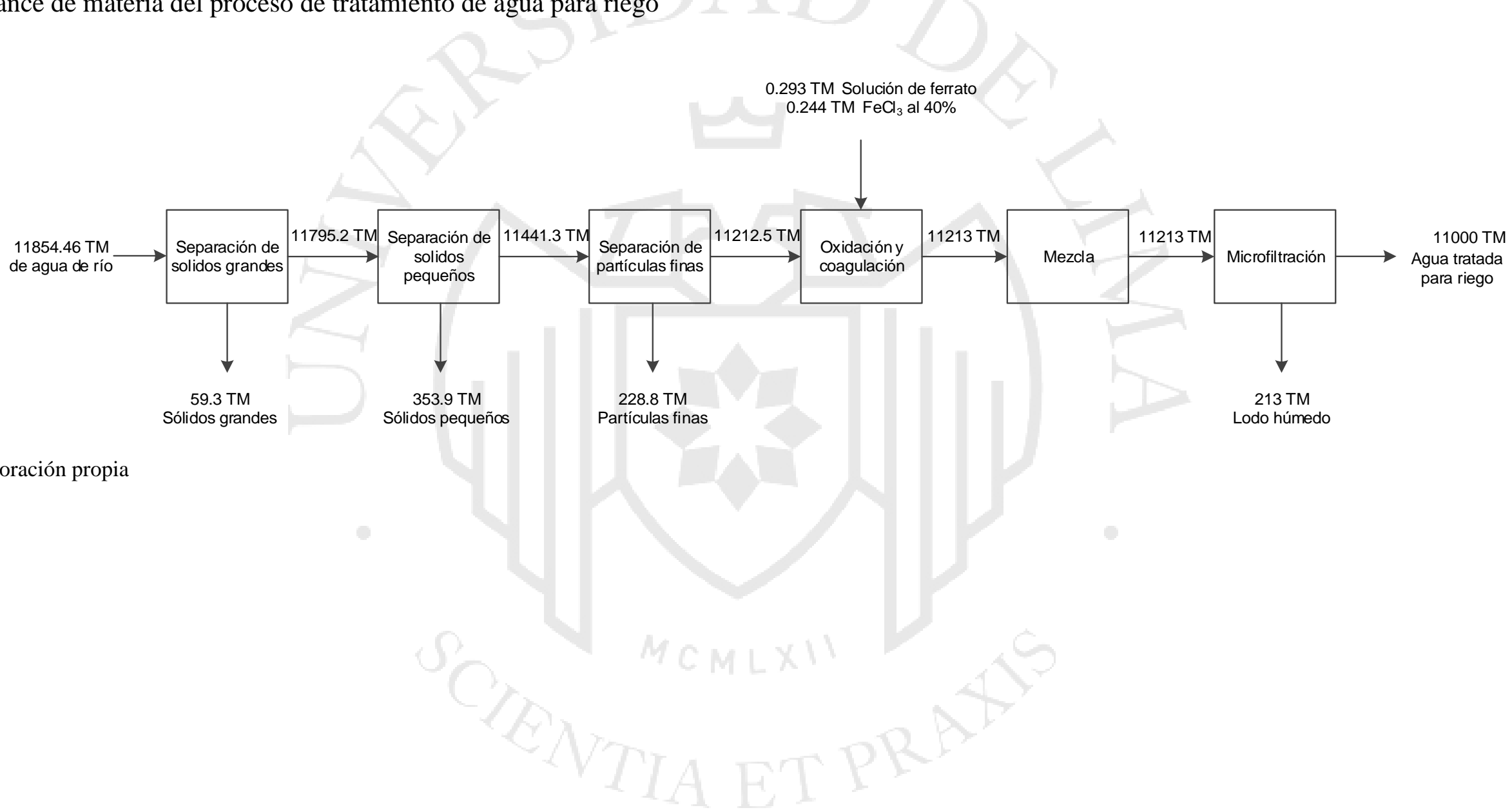


Figura 5.8

Balance de materia del proceso de producción de ferrato

áminas de nitrilo

Placa de hierro

Placa de grafito

Membrana

Pernos, tuercas y

arandelas

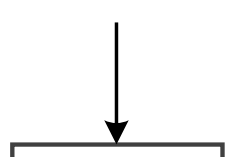

Ensamble de

Reactor reactor

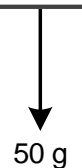

Polvos ensamblado
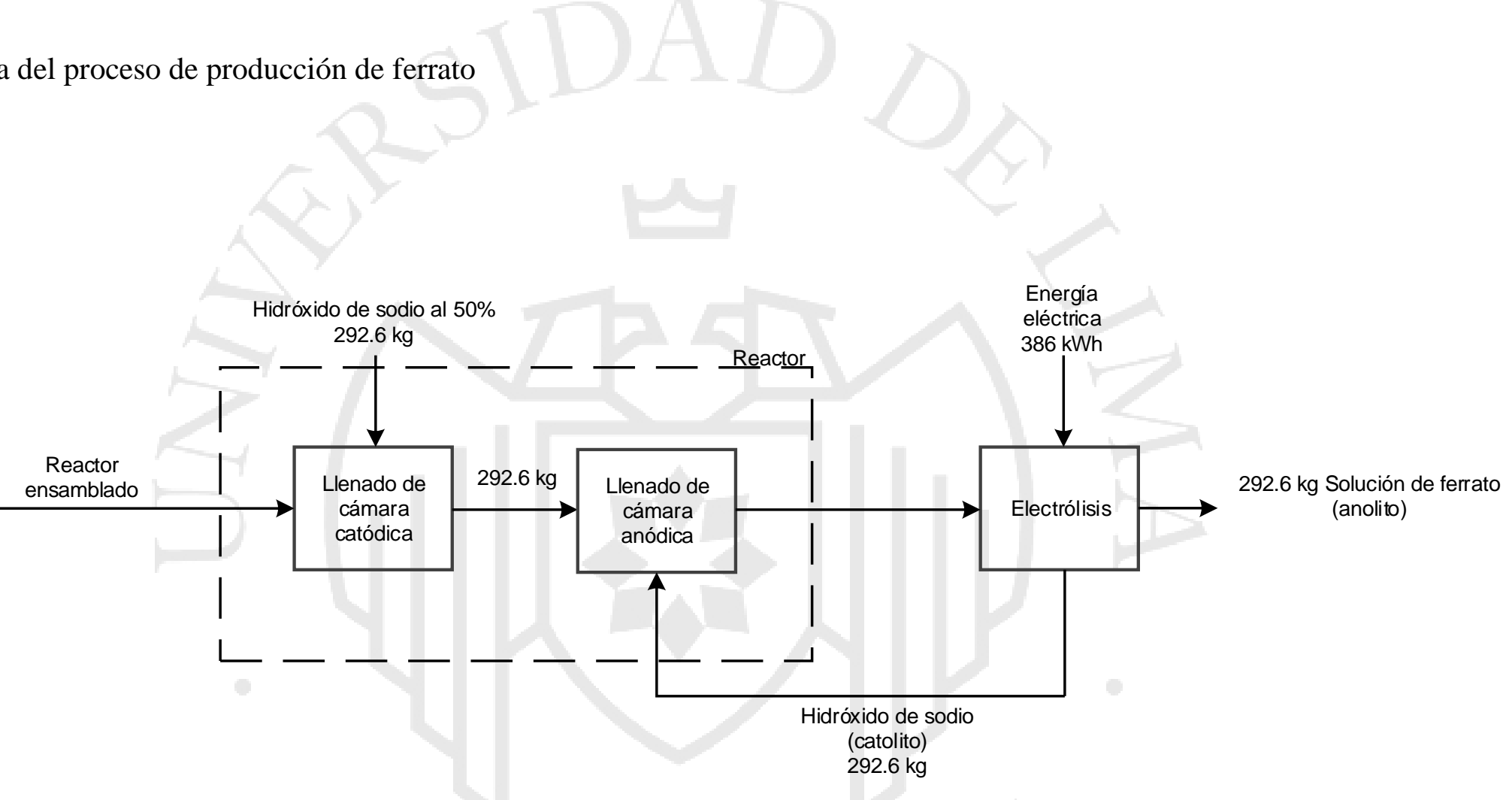

Elaboración propia 


\subsection{Características de los equipos}

De acuerdo al proceso descrito en el punto anterior, se muestran las especificaciones de equipos e instrumentos a usar en el proceso de producción de ferrato (Tabla 5.2) y en el proceso de tratamiento de agua (Tabla 5.3).

\section{Tabla 5.2}

Especificaciones de los equipos y dispositivos para la producción de ferrato

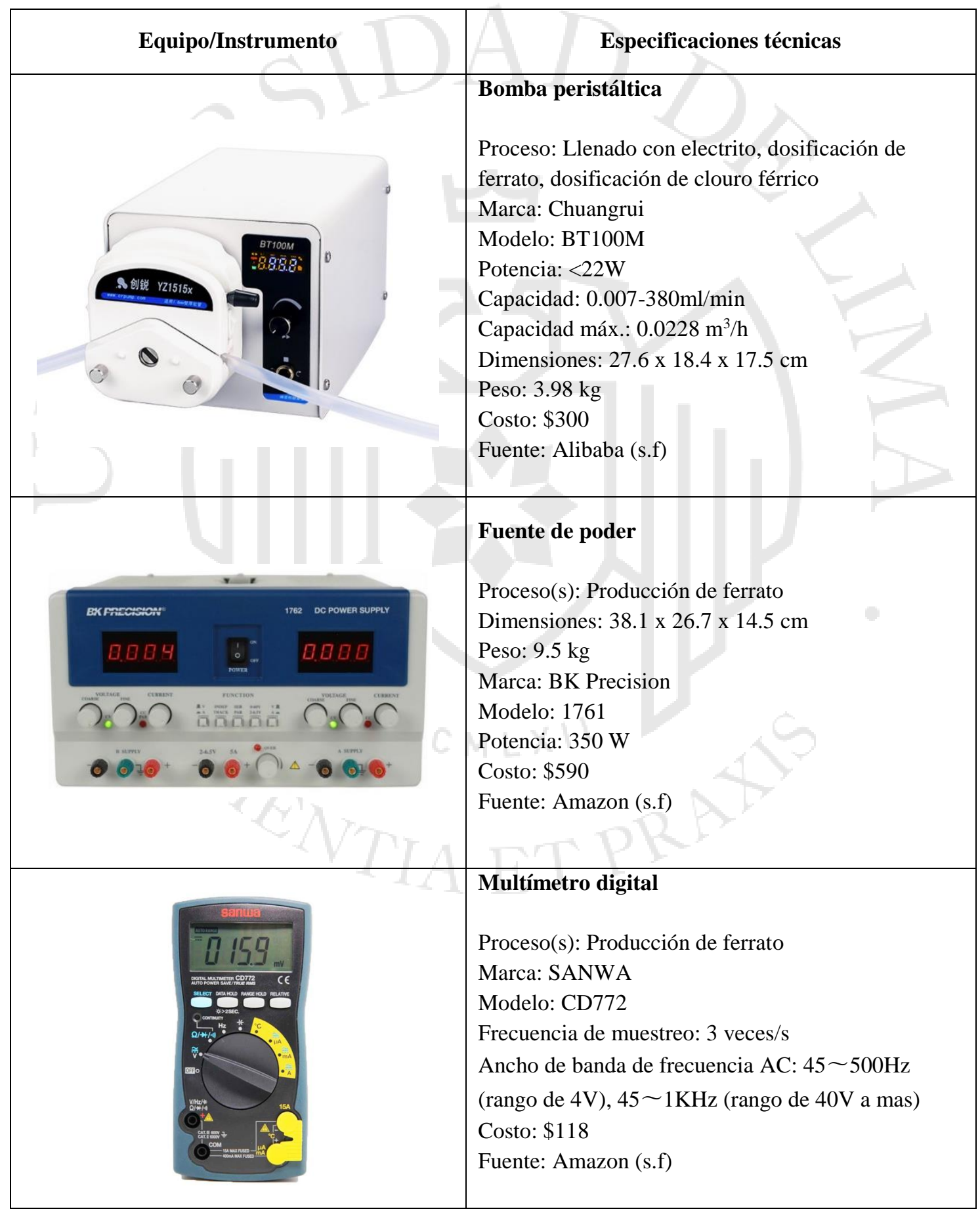


Tabla 5.3

Especificaciones de los equipos e instrumentos para el tratamiento de agua para riego

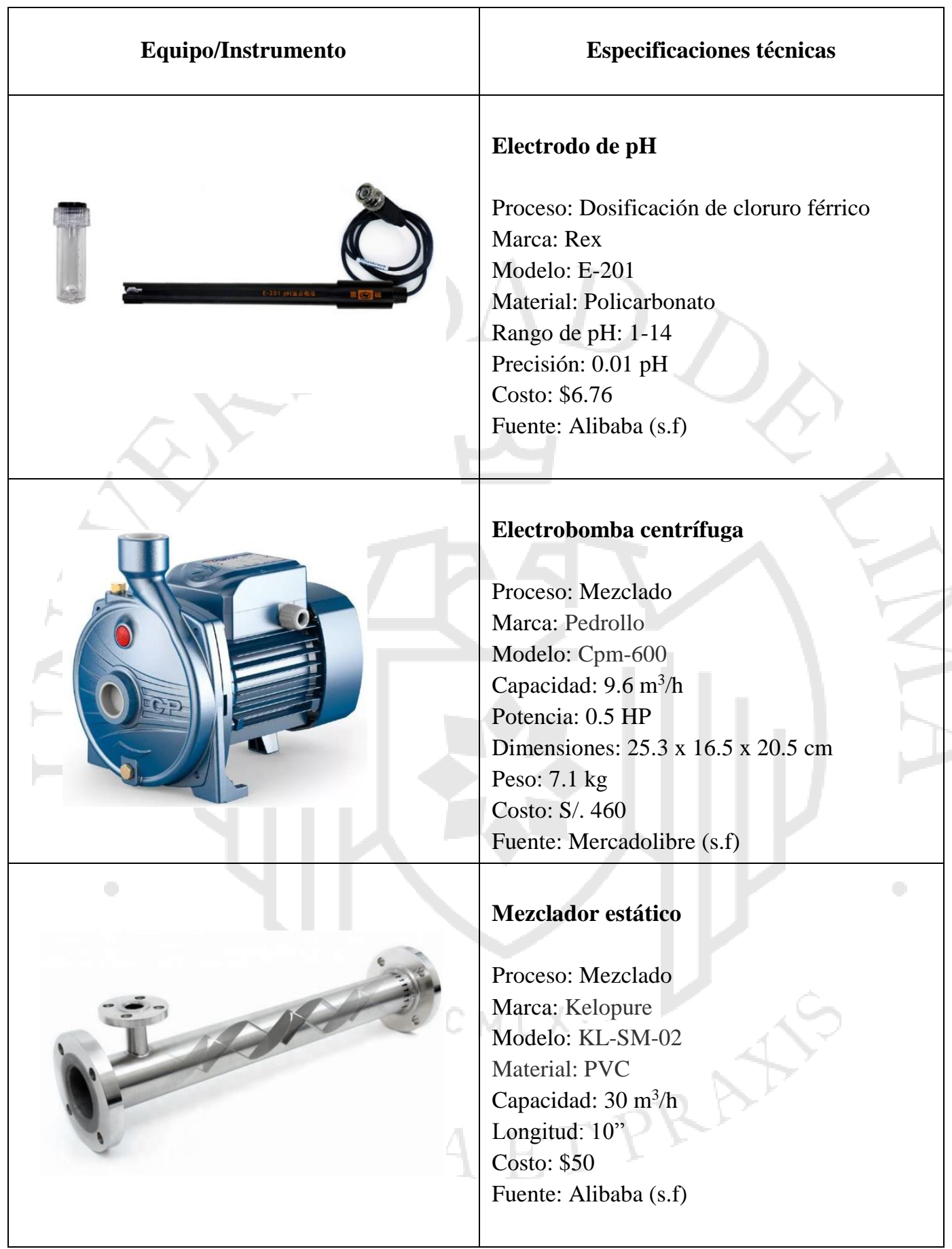

(continúa) 


\section{(continuación)}

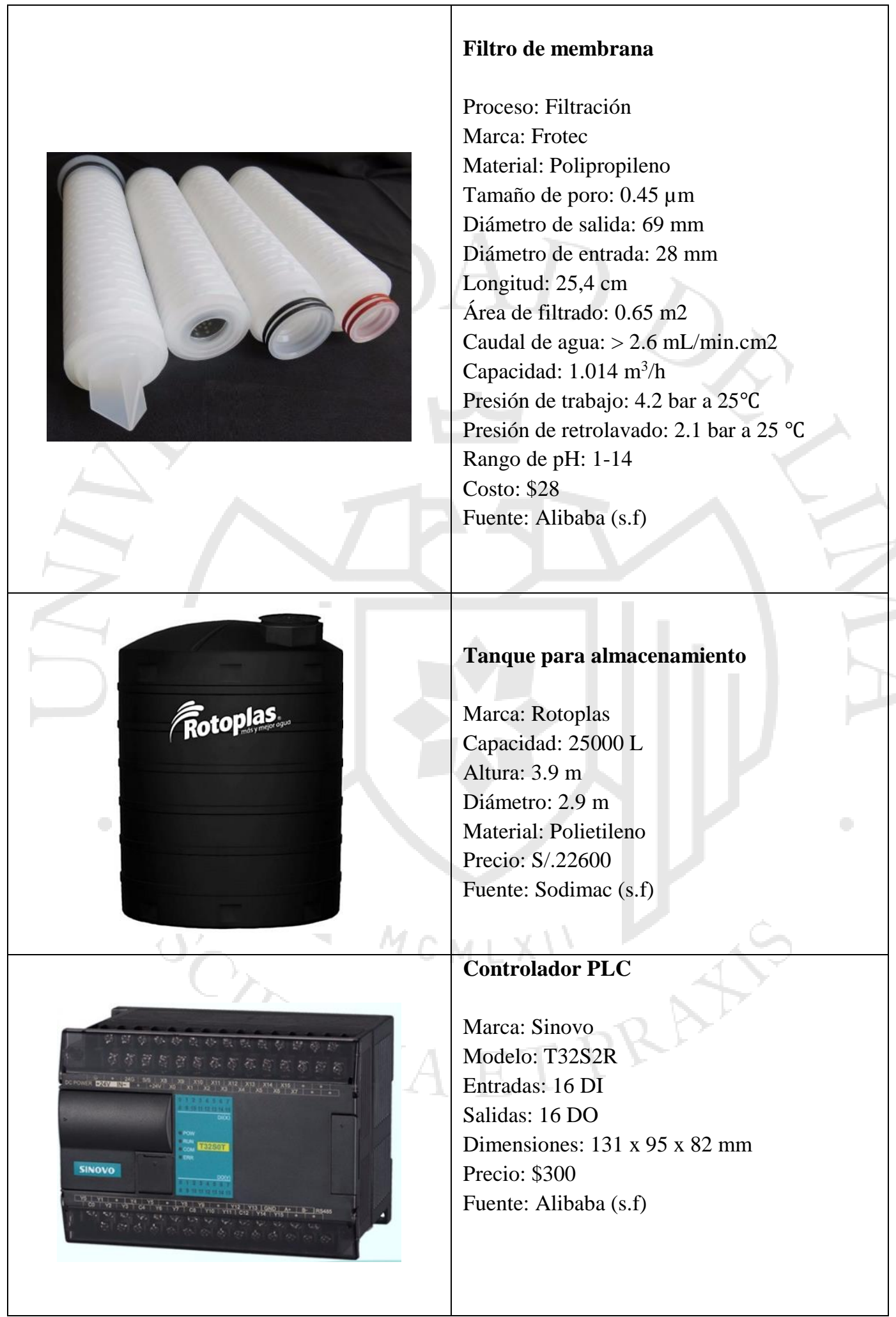

(continúa) 
(continuación)

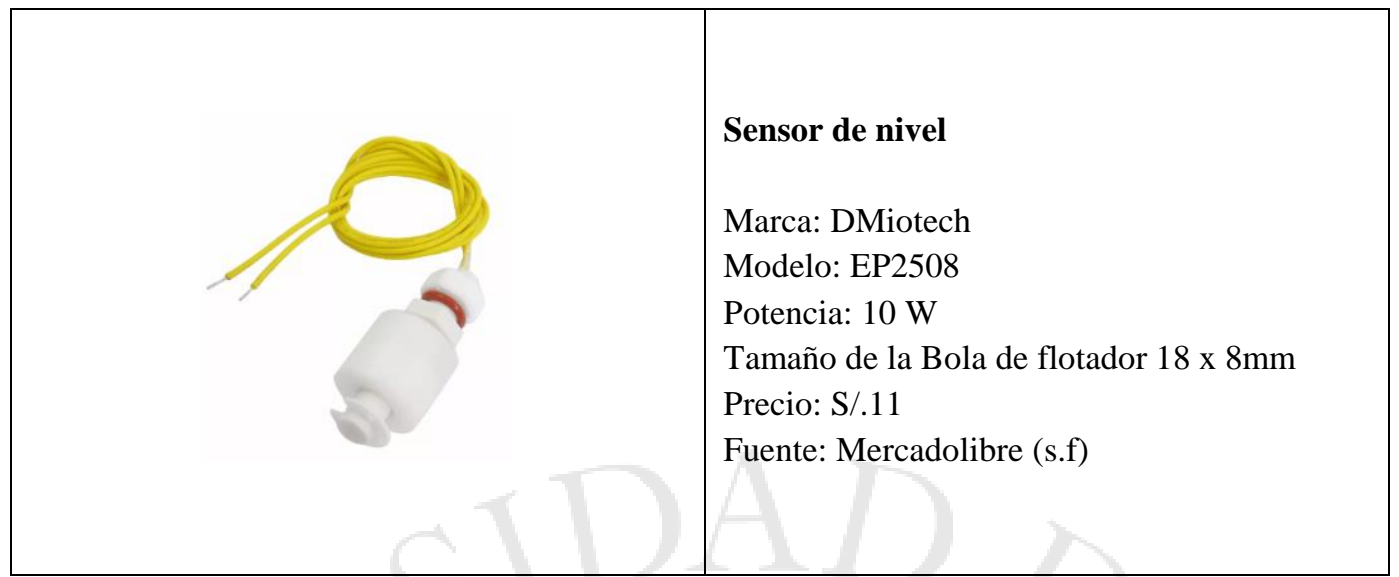

Elaboración propia

\subsection{Capacidad instalada}

\subsubsection{Cálculo del número de equipos y operarios requeridos}

El cálculo para determinar la cantidad de equipos necesarios está en base al requerimiento anual de agua en metros cúbicos. Se calcula el número de equipos para cada proceso, con este fin se emplea la información de la Figura 5.7 y Figura 5.8 y que detallan las cantidades entrantes y salientes en cada etapa de la producción de ferrato y tratamiento de agua, respectivamente.

Para el cálculo de la capacidad instalada es necesario señalar que los equipos no necesitan ser supervisados permanentemente durante su funcionamiento, por lo tanto, el factor de utilización será igual a 1 .

La Tabla 5.4, muestra el número de equipos para el tratamiento de agua, mientras que la Tabla 5.5 muestra el número de equipos para la producción de ferrato.

Tabla 5.4

Número de equipos requeridos para el tratamiento de agua

\begin{tabular}{c|cccccc}
\hline & \multicolumn{3}{c}{ Tiempo } \\
Etapa & $\begin{array}{c}\text { Procesa } \\
\text { (TM/año) }\end{array}$ & $\begin{array}{c}\text { Factor de } \\
\text { unidad } \\
\text { (h/ TM) }\end{array}$ & $\begin{array}{c}\text { Factor de } \\
\text { Utilización } \\
\text { Eficiencia }\end{array}$ & $\begin{array}{c}\text { Tiempo } \\
\text { del } \\
\text { periodo } \\
\text { (h/año) }\end{array}$ & $\begin{array}{c}\text { Equipos } \\
\text { Eqund }\end{array}$ \\
\hline $\begin{array}{c}\text { Dosificación de } \\
\mathrm{Na}_{2} \mathrm{FeO}_{4}\end{array}$ & 0.2 & 43.86 & 1 & 0.7 & 2080 & 1 \\
Dosificación de $\mathrm{FeCl}_{3}$ & 0.2 & 43.86 & 1 & 0.7 & 2080 & 1 \\
\hline
\end{tabular}


(continuación)

\begin{tabular}{c|cccccc}
\hline $\begin{array}{c}\text { Alimentación de } \\
\text { mezclador }\end{array}$ & $11,212.5$ & 0.10 & 1 & 0.7 & 2080 & 1 \\
Mezclado & $11,213.0$ & 0.03 & 1 & 0.7 & 2080 & 1 \\
Microfiltrado & $11,213.0$ & 0.99 & 1 & 0.7 & 2080 & 8 \\
\hline
\end{tabular}

Elaboración propia

Se tiene que serán necesarios 8 filtros de $0.45 \mu \mathrm{m}$. Estos filtros conformarán la unidad de filtración tangencial.

Tabla 5.5

Número de equipos requeridos para la producción de ferrato

\begin{tabular}{c|cccccc}
\hline Etapa & $\begin{array}{c}\text { Procesa } \\
\text { (kg/año) }\end{array}$ & $\begin{array}{c}\text { Tiempo } \\
\text { por } \\
\text { unidad } \\
\text { (h/kg) }\end{array}$ & $\begin{array}{c}\text { Factor de } \\
\text { Utilización }\end{array}$ & $\begin{array}{c}\text { Factor de } \\
\text { Eficiencia }\end{array}$ & $\begin{array}{c}\text { Tiempo } \\
\text { del } \\
\text { periodo } \\
\text { (h/año) }\end{array}$ & \#Equipos \\
\hline $\begin{array}{c}\text { Bombeo de } \\
\text { catolito }\end{array}$ & 292.6 & 0.04 & 1 & 0.7 & 6240 & 1 \\
$\begin{array}{c}\text { Electrólisis } \\
\text { (anolito) }\end{array}$ & 292.6 & 33.33 & 1 & 0.8 & 6240 & 2 \\
\hline
\end{tabular}

Elaboración propia

De la Tabla 5.5 se tiene que serán necesarios dos reactores electroquímicos de 120 $\mathrm{mL}$ de volumen de cámara anódica con la finalidad de suministrar la cantidad requerida de ferrato para el tratamiento del agua.

\section{Cálculo de número de operarios para el ensamblaje del reactor}

El tiempo estándar para el armado del reactor electroquímico es 30 minutos. Por lo que para el armado de los dos reactores necesarios para el proceso de electrólisis solo es necesario un operario.

El operario que realiza la actividad de ensamblado será el mismo que supervisa el funcionamiento del sistema de producción. 


\subsubsection{Cálculo de la capacidad instalada}

Para el cálculo de la capacidad instalada, es necesario conocer la cantidad de horas que se trabajan al año, para ello se considera el horario de trabajo en el Instituto Nacional de Innovación Agraria - Centro Experimental La Molina que es de lunes a viernes de 8:00 a 17:00 horas, que incluye una hora de refrigerio.

\section{Capacidad instalada para la producción de ferrato}

Para calcular el tiempo del periodo en horas por año para la producción de ferrato, se tiene en cuenta que, al ser un proceso automático, este puede funcionar las 24 horas del día. El cálculo es como sigue:

$$
\frac{24 h}{\text { día }} \times \frac{5 \text { días }}{\text { semana }} \times \frac{52 \text { semanas }}{a \tilde{n} o}=6240 \frac{h}{a \tilde{\text { ño }}}
$$

La Tabla 5.6 muestra la capacidad de producción del ferrato, en kilogramos por año.

Tabla 5.6

Capacidad instalada para la producción de ferrato

\begin{tabular}{c|cccccc}
\hline Operación & $\begin{array}{c}\text { Capacidad } \\
\text { de } \\
\text { producción } \\
\text { kg /hora }\end{array}$ & $\begin{array}{c}\mathbf{N}^{\circ} \text { de } \\
\text { equipos }\end{array}$ & $\begin{array}{c}\text { Factor de } \\
\text { Utilización }\end{array}$ & $\begin{array}{c}\text { Factor de } \\
\text { Eficiencia }\end{array}$ & $\begin{array}{c}\text { Tiempo } \\
\text { del } \\
\text { periodo } \\
\text { (h/año) }\end{array}$ & $\begin{array}{c}\text { Capacidad } \\
\text { de } \\
\text { producción } \\
\text { kg/año }\end{array}$ \\
\hline Electrólisis (anolito) & 0.03 & 2 & 1 & 0.8 & 6240 & 299.52 \\
\hline
\end{tabular}

Elaboración propia

\section{Capacidad instalada para el tratamiento de agua}

Para calcular el tiempo del periodo en horas por año para el tratamiento de agua, se tiene en cuenta que se requieren de operaciones automáticas con la supervisión de un operario, por lo que se calcula como sigue:

$$
\frac{8 h}{\text { día }} \times \frac{5 \text { días }}{\text { semana }} \times \frac{52 \text { semanas }}{a \tilde{n} o}=2080 \frac{h}{a \tilde{n} o}
$$


La Tabla 5.7 muestra la capacidad del producción de agua para riego tratada, en toneladas métricas (TM) por año.

Tabla 5.7

Capacidad instalada para el tratamiento de agua

\begin{tabular}{c|cccccc}
\hline Operación & $\begin{array}{c}\text { Capacidad de } \\
\text { producción } \\
\text { TM/hora }\end{array}$ & $\begin{array}{c}\mathbf{N}^{\circ} \mathbf{d e} \\
\text { equipos / } \\
\text { operarios }\end{array}$ & $\begin{array}{c}\text { Factor de } \\
\text { Utilización }\end{array}$ & $\begin{array}{c}\text { Factor de } \\
\text { Eficiencia }\end{array}$ & $\begin{array}{c}\text { Tiempo } \\
\text { del } \\
\text { periodo } \\
\text { (h/año) }\end{array}$ & $\begin{array}{c}\text { Capacidad } \\
\text { de } \\
\text { producción } \\
\text { TM/año }\end{array}$ \\
\hline $\begin{array}{c}\text { Alimentación de } \\
\text { mezclador } \\
\text { Mezclado }\end{array}$ & 9.6 & 1 & 1 & 0.7 & 2080 & $13,977.60$ \\
Microfiltrado & 30 & 1 & 1 & 0.7 & 2080 & $43,680.00$ \\
\hline
\end{tabular}

Elaboración propia

Se observa que la estación cuello de botella es la unidad de filtración tangencial, sin embargo, sí se produce la cantidad requerida por el INIA.

\subsection{Identificación de los aspectos e impactos en el proceso}

La matriz de caracterización fue empleada para identificar los aspectos e impactos de los procesos. Así, la Tabla 5.8 muestra los aspectos e impactos identificados en la producción de ferrato, mientras que la Tabla 5.9 muestra la información análoga para el tratamiento de agua. 
Tabla 5.8

Matriz de caracterización para la producción de ferrato

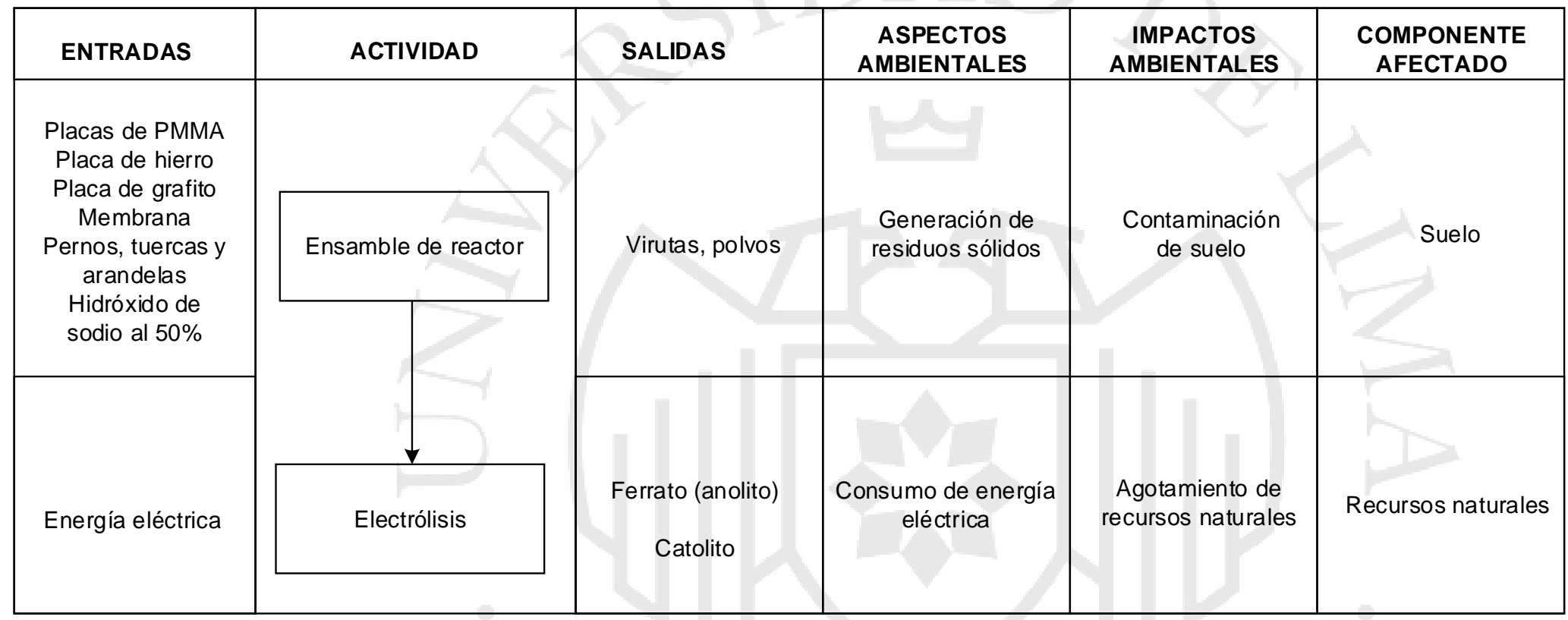

Elaboración propia 
Tabla 5.9

Matriz de caracterización para el proceso de tratamiento de agua

\begin{tabular}{|c|c|c|c|c|c|}
\hline ENTRADAS & ACTIVIDAD & SALIDAS & $\begin{array}{c}\text { ASPECTOS } \\
\text { AMBIENTALES }\end{array}$ & $\begin{array}{c}\text { IMPACTOS } \\
\text { AMBIENTALES }\end{array}$ & $\begin{array}{c}\text { COMPONENTE } \\
\text { AFECTADO }\end{array}$ \\
\hline Agua de río & $\begin{array}{c}\text { Separación de solidos } \\
\text { grandes }\end{array}$ & $\begin{array}{c}\text { Materiales flotantes } \\
\text { (ramas, botellas, } \\
\text { bolsas, etc.) }\end{array}$ & $\begin{array}{l}\text { Generación de } \\
\text { residuos sólidos }\end{array}$ & $\begin{array}{l}\text { Contaminación } \\
\text { de suelo }\end{array}$ & Suelo \\
\hline $\begin{array}{c}\text { Agua con } \\
\text { partículas } \\
\text { pequeñas y finas }\end{array}$ & $\begin{array}{l}\text { Separación de sólidos } \\
\text { pequeños }\end{array}$ & Arena & $\begin{array}{l}\text { Generación de } \\
\text { residuos sólidos }\end{array}$ & $\begin{array}{c}\text { Contaminación } \\
\text { de suelo }\end{array}$ & o \\
\hline $\begin{array}{c}\text { Agua con } \\
\text { partículas finas }\end{array}$ & $\begin{array}{l}\text { Separación de } \\
\text { partículas finas }\end{array}$ & Arcilla, lodos & $\begin{array}{l}\text { Generación de } \\
\text { residuos sólidos }\end{array}$ & $\begin{array}{c}\text { Contaminación } \\
\text { de suelo }\end{array}$ & Suelo \\
\hline $\begin{array}{c}\text { Agua de reservorio } \\
\text { Energía eléctrica } \\
\text { Ferrato } \\
\text { Cloruro férrico }\end{array}$ & Oxidación y coagulación & Agua con flocs & $\begin{array}{c}\text { Consumo de energía } \\
\text { eléctrica }\end{array}$ & $\begin{array}{l}\text { Agotamiento de } \\
\text { recursos naturales }\end{array}$ & Recursos naturales \\
\hline $\begin{array}{l}\text { Agua con flocs } \\
\text { Energía eléctrica }\end{array}$ & Microfiltración & dos & $\begin{array}{c}\text { Generación de } \\
\text { residuos sólidos } \\
\text { Consumo de energía } \\
\text { eléctrica }\end{array}$ & $\begin{array}{l}\text { Contaminación de } \\
\text { suelo } \\
\text { Agotamiento de } \\
\text { recursos naturales }\end{array}$ & $\begin{array}{c}\text { Suelo } \\
\text { Recursos naturales }\end{array}$ \\
\hline
\end{tabular}

Elaboración propia 


\subsection{Disposición de planta}

\subsubsection{Características físicas del proyecto}

Como se mencionó previamente, el Instituto Nacional de Innovación Agraria - Centro Experimental La Molina dispone de infraestructura que comprende un filtro de rejas, dos sedimentadores y un reservorio. A esta infraestructura se le añadirá los equipos necesarios para el tratamiento que propone esta investigación, y para estos equipos adicionales se realizará el cálculo de requerimiento de áreas correspondiente.

\subsubsection{Determinación de las zonas físicas requeridas}

Para el cálculo de las zonas físicas requeridas se empleará el método Guerchet. Es importante señalar que el método Guerchet a desarrollar permite calcular los requerimientos mínimos aproximados del área de producción (Diaz Garay, Jarufe, \& Noriega, 2014). Las zonas requeridas son el área de ensamble, el área de producción de ferrato y el área de tratamiento de agua.

Para la producción de ferrato se requieren varios equipos y una mesa de trabajo que constituirán elementos estáticos, pues requieren de un área fija. Como elemento móvil, solamente el operario ha sido considerado.

El tratamiento de agua, también cuenta con elementos estáticos. Además, todo el proceso requiere un transporte a través de bombas.

\subsubsection{Cálculo de áreas para cada zona}

Luego de haber identificado los elementos estáticos y móviles que se muestran en la Tabla 5.10 y haber definido el número de lados $(\mathrm{N})$ a partir de los cuales el mueble o la máquina deben ser utilizados se calculó la superficie estática (Ss), la superficie de gravitación ( $\mathrm{Sg}$ ) y superficie de evolución (Se). Mediante el producto de las tres superficies se obtiene la superficie total $(\mathrm{St})$ requerida para cada elemento.

Según el método aplicado, el valor del coeficiente de evolución (K) permite establecer una relación entre los elementos estáticos y móviles; y permite calcular la superficie de evolución. Para su cálculo es necesario hallar la altura ponderada de los elementos móviles y la de los elementos estáticos (Diaz et al., 2014). 
Tabla 5.10

Método de Guerchet

\begin{tabular}{|c|c|c|c|c|c|c|c|c|c|c|c|}
\hline Etapa & Elementos & $\begin{array}{l}\mathbf{L} \\
(\mathbf{m})\end{array}$ & $\begin{array}{l}\text { A } \\
(\mathbf{m})\end{array}$ & $\begin{array}{l}\text { D } \\
(\mathbf{m})\end{array}$ & $\begin{array}{l}\mathbf{H} \\
(\mathbf{m})\end{array}$ & $\mathbf{n}$ & $\mathbf{N}$ & Ss & Sg & Se & St \\
\hline & ESTÁTICOS & & & & & & & & & & \\
\hline Ensamble & Mesa de trabajo & 1,20 & 0,60 & & 0,90 & 1 & 1,00 & 0,72 & 0,72 & 0,35 & 1,79 \\
\hline \multirow[t]{3}{*}{ Almacenado } & Dosificador & 0,20 & 0,15 & & 0,20 & 1 & 1,00 & 0,03 & 0,03 & 0,01 & 0,07 \\
\hline & Bomba peristáltica & 0,28 & 0,18 & & 0,18 & 1 & & 0,05 & - & 0,01 & 0,06 \\
\hline & Fuente de poder & 0,38 & 0,27 & & 0,15 & 1 & 1,00 & 0,10 & 0,10 & 0,05 & 0,25 \\
\hline \multirow[t]{2}{*}{ Electrólisis } & Reactor electroquímico & 0,19 & 0,08 & & 0,19 & 2 & 1,00 & 0,01 & 0,01 & 0,01 & 0,07 \\
\hline & Bomba peristáltica & 0,28 & 0,18 & & 0,18 & 1 & & 0,05 & - & 0,01 & 0,06 \\
\hline \multirow[t]{2}{*}{ Almacenado } & Dosificador & 0,20 & 0,15 & & 0,20 & 1 & & 0,03 & - & 0,01 & 0,04 \\
\hline & Bomba peristáltica & 0,28 & 0,18 & & 0,18 & 1 & & 0,05 & - & 0,01 & 0,06 \\
\hline \multirow[t]{3}{*}{ Almacenado } & Dosificador & 0,20 & 0,15 & & 0,20 & 1 & 1,00 & 0,03 & 0,03 & 0,01 & 0,07 \\
\hline & Bomba peristáltica & 0,28 & 0,18 & & 0,18 & 1 & & 0,05 & - & 0,01 & 0,06 \\
\hline & Electrobomba & 0,25 & 0,17 & & 0,21 & 1 & & 0,04 & - & 0,01 & 0,05 \\
\hline \multirow[t]{3}{*}{ Mezclado } & Mezclador estático & 0,25 & 0,10 & & 0,10 & 1 & & 0,03 & - & 0,01 & 0,03 \\
\hline & Separador de fase & 1,50 & 1,50 & 1,50 & 1,50 & 1 & & 2,25 & - & 0,55 & 2,80 \\
\hline & Electrobomba & 0,25 & 0,17 & & 0,21 & 1 & & 0,04 & & 0,01 & 0,05 \\
\hline Filtración & $\begin{array}{l}\text { Unidad de filtración } \\
\text { tangencial }\end{array}$ & 0,69 & 0,37 & & 0,65 & 1 & & 0,25 & - & 0,06 & 0,31 \\
\hline \multirow[t]{4}{*}{ Almacenado } & Tanque & 2,90 & 2,90 & 2,90 & 3,90 & 2 & & 8,41 & - & 2,05 & 20,91 \\
\hline & Electrobomba & 0,25 & 0,17 & & 0,21 & 1 & & 0,04 & - & 0,01 & 0,05 \\
\hline & MÓVILES & & & & & & & & & & \\
\hline & Operario & & & & 1,65 & 1 & & 0,50 & & & \\
\hline Área mínima requerida $\left(\mathrm{m}^{2}\right)$ & & & & & & & & & & & 26,77 \\
\hline
\end{tabular}


Para el cálculo del coeficiente de evolución (K) se tiene que:

$\begin{aligned} \text { Altura ponderada de los elementos móviles } & =1.65 \\ \text { Altura ponderada de los elementos estáticos } & =3.389\end{aligned}$

$$
K=\frac{1.65}{2 * 3.389}=0.2434
$$

Asimismo, de la Tabla 5.10 se tiene que la superficie total mínima para el área de producción es de $26.8 \mathrm{~m}^{2}$, repartidos en las siguientes proporciones:

- $\quad$ Área de ensamble: $1.8 \mathrm{~m}^{2}$

- Área de producción de ferrato: $0.52 \mathrm{~m}^{2}$

- Área de tratamiento de agua: $24.45 \mathrm{~m}^{2}$

Adicionalmente, debido a que se emplean insumos concentrados, es pertinente implementar un área que sea exclusiva para el almacenamiento de insumos. En este punto se considera un área de $2.25 \mathrm{~m}^{2}$.

Finalmente, el área total requerida sería de $29 \mathrm{~m}^{2}$. En la Figura 5.9 se muestra cómo sería la forma del terreno a utilizar, siendo L el valor de $76 \approx 8$ metros y $\mathrm{L} / 2 \mathrm{el}$ valor $3.8 \approx 4$ metros.

Figura 5.9

Área total de terreno requerido

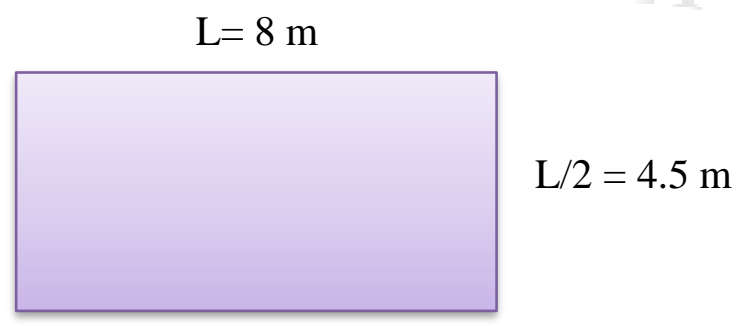

Elaboración propia 


\subsubsection{Disposición general}

Luego de definir las zonas requeridas y su área respectiva, una propuesta de plano ha sido elaborada, y se muestra en la Figura 5.10.

Figura 5.10.

Plano de planta propuesto

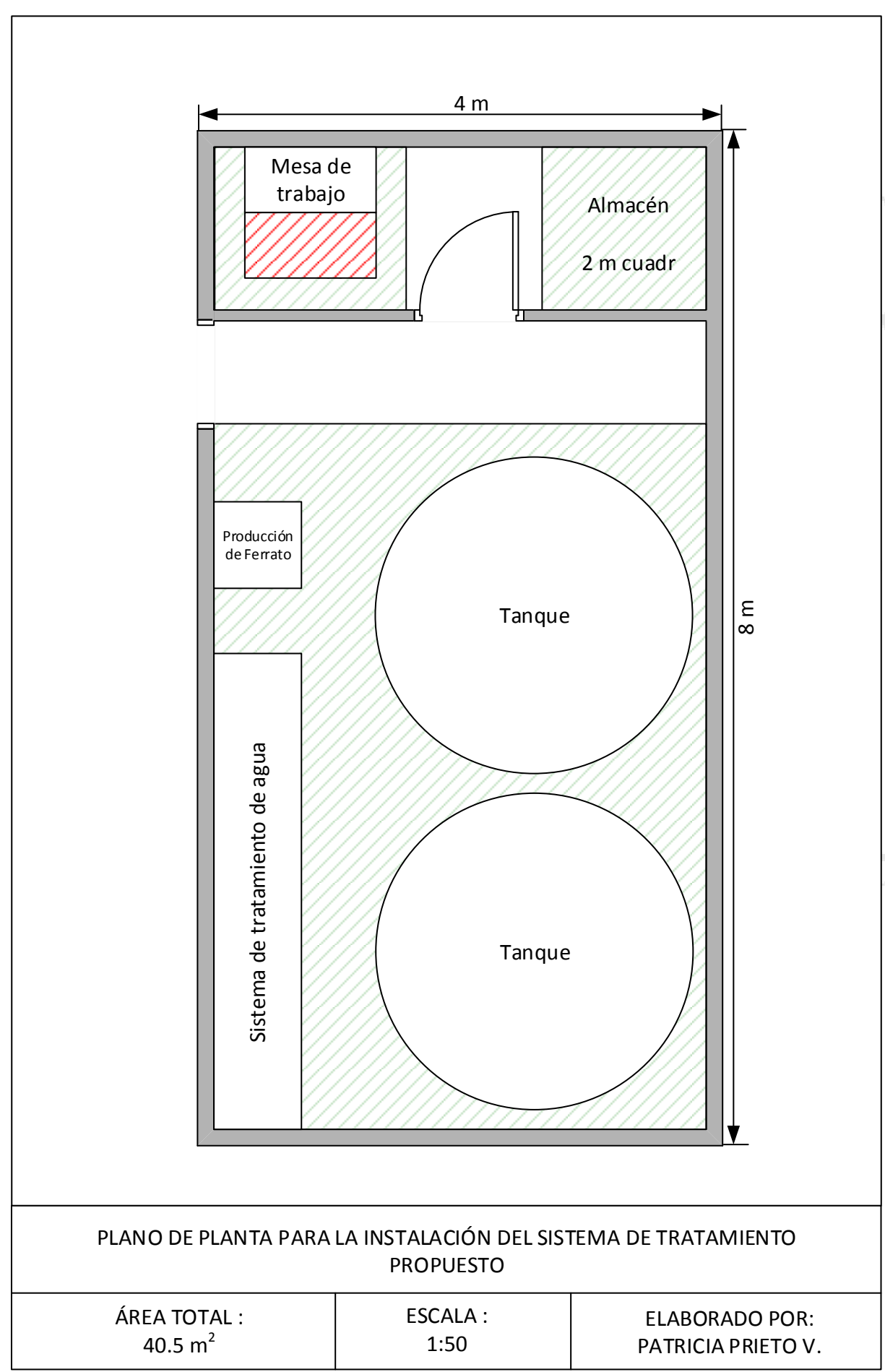

Elaboración propia 


\section{CONCLUSIONES}

- La producción electroquímica del ferrato(VI), con la configuración empleada, no permite obtener una concentración mayor a $0.5 \mathrm{~mol} / \mathrm{L}$, pues la solución que se obtiene es muy viscosa, lo que dificulta su dosificación.

- Al realizar los experimentos empleando diferentes concentraciones de iones ferrato(VI), no se logró reducir la concentración de arsénico por debajo de los $100 \mu \mathrm{g} / \mathrm{L}$ que establece el Estándar Nacional de Calidad Ambiental-ECA para Agua, categoría 3, subcategoría D1. Sin embargo, se tiene evidencia de que existe una mayor remoción de arsénico a medida que se incrementa la concentración de iones ferrato(VI), aunque, en la práctica no es posible incrementar indefinidamente la concentración de iones ferrato(VI) en el agua que se quiere tratar, pues se podría incrementar demasiado el $\mathrm{pH}$ del agua tratada; ya que el ferrato(VI) se encuentra en una solución alcalina. Por otro lado, se evidenció que el empleo de los iones ferrato(VI) permite reducir la cantidad de iones férricos $\left(\mathrm{Fe}^{3+}\right)$ y alcanzar una concentración de arsénico que cumple con el Estándar de Calidad Ambiental para agua de riego. Esta reducción de la cantidad de iones férricos requeridos implica reducir la cantidad de iones totales que se añaden al agua durante el tratamiento.

- El empleo de una concentración de iones ferrato(VI) igual a $1 \mathrm{mg} / \mathrm{L}$, seguido de una solución de $\mathrm{FeCl}_{3}$ (coagulante) de concentración igual a $3 \mathrm{mg} / \mathrm{L}$ y posterior microfiltración, en las condiciones de estudio evaluadas, permite reducir la concentración del arsénico desde $500 \mu \mathrm{g} / \mathrm{L}$ hasta $31.1 \pm 1.6 \mu \mathrm{g} / \mathrm{L}$. Esta concentración de arsénico remanente cumple con el ECA para agua de riego.

- Considerando las concentraciones de cloruro férrico y ferrato(VI) mencionadas en el punto anterior, se podría ahorrar un valor económico de S/.2199 al año. Este ahorro se debe a que la suma del costo de los consumibles cloruro férrico y ferrato asciende a S/.1944 por año. Mientras que, cuando solamente se emplean iones férricos seguidos de microfiltración, es necesario 
emplear $15 \mathrm{mg} / \mathrm{L}$ de Fe como cloruro férrico para obtener una concentración de arsénico remanente comparable $(32 \mu \mathrm{g} / \mathrm{L} \mathrm{As})$; en este caso, el costo del consumible cloruro férrico ascendería a S/.4143 por año. En consecuencia, no solo se consigue reducir la cantidad de iones que se añaden al agua, sino que también se reduce el costo de los consumibles aproximadamente en un $53 \%$. 


\section{RECOMENDACIONES}

A continuación, se indican las recomendaciones:

- Mayores concentraciones de la solución de ferrato(VI) no fueron evaluadas debido al incremento del $\mathrm{pH}$ del agua; considerando además que el $\mathrm{pH}$ inicial del agua ya era alcalino ( $\mathrm{pH}$ 8.9). Se recomendaría realizar ensayos a este valor de $\mathrm{pH}$ para evaluar el desempeño del ferrato(VI).

- Evaluar la remoción de otros contaminantes inorgánicos del agua, tales como sulfatos, fosfatos, nitratos y nitritos.

- Evaluar la efectividad del ferrato en la remoción de algas, ya que se encontró que el crecimiento de algas es un problema recurrente cuando se trata de agua almacenada en reservorios. 


\section{REFERENCIAS}

Al-Mashharawi, S. (2011). King Abdullah University of Science and Technology. Recuperado el 01 de Julio de 2018, de Evaluating the Efficiency of Different Microfiltration and Ultrafiltration Membranes: http://repository.kaust.edu.sa/kaust/bitstream/10754/209401/1/SamerMashharaw iThesis.pdf

Alsheyab, M., Jiang, J.-Q., y Stanford, C. (2010). Electrochemical generation of ferrate (VI): determination of optimum conditions. Desalination, 254(2010) 175-178 DOI: 10.1016/j.desal.2009.11.035.

American Public Health Association. (1998). Standard methods for the examination of water and wastewater. Washington: American Public Health Association.

American Society for Testing and Materials (2013). Standard Practice for Coagulation-Flocculation Jar Test of Water. Recuperado de ASTM D2035-13: http://www.astm.org/cgi-bin/resolver.cgi?D2035

American Water Works Association. (2011). Operational control of coagulation and filtration processes. AWWA manual M37. Denver: American Water Works Association.

Arora, M., Kiran, B., Rani, S., Rani, A., Kaur, B., y Mittal, N. (2008). Heavy metal accumulation in vegetables irrigated with water from different sources. Food Chemistry 111(4), 811-815.

Arroyo, V. (2012). Recuperado de Nutrientes y gases: Oxígeno disuelto: http://repositorio.imta.mx/bitstream/handle/20.500.12013/1499/HC-1209.1.pdf

Autoridad Nacional del Agua (2009). Recuperado el 02 de 08 de 2017, de Informe País del V Foro Mundial del Agua:

http://www.ana.gob.pe/media/442806/informe\%20pais\%20v\%20foro\%20mundi al\%20del\%20agua.pdf

Barışçı, S., Ulu, F., Särkkä, H., Dimoglo, A., y Sillanpää, M. (2014). Electrosynthesis of Ferrate (VI) ion Using High Purity Iron Electrodes: Optimization of Influencing Parameters on the Process and Investigating Its Stability. International Journal of Electrochemical Science, 9(2014) 3099 - 3117.

Bauder, T., Waskom, R., y Davis, J. (2007). University of Wyoming. Recuperado de http://www.uwyo.edu/soilfert/pubs/irrigation\%20water\%20quality\%20csu.pdf

Bernex, N. (2015). Aguas y Arsénico natural en Perú. Lima.

Bilici Baskan, M., y Pala, A. (2009). Determination of arsenic removal efficiency by ferric ions using response surface methodology. Journal of Hazardous Materials, 166 (2009) 796-801. DOI: 10.1016/j.jhazmat.2008.11.131. 
Cabezas, C. (2014). Enfermedades asociadas al agua en el Perú. La Salud Ambiental en el Perú: Impacto de la Contaminación del Agua, del Aire y del Cambio Climático.

Castro de Esparza, M. (2006). Presencia de arsénico en el agua de bebida en América Latina y su efecto en la salud pública. International Congress: Natural arsenic in groundwaters of Latin America. Ciudad de Mexico.

Castro de Esparza, M. L. (2015). El arsénico en los recursos hídricos del Perú. En Aguas y arsénico natural en Perú. Lima.

Chávez, P. D. (2015). La información y su gestión como herramienta para enfrentar la contaminación del agua con arsénico. En Aguas y Arsénico natural en Perú (págs. 27-34). Lima.

Chavez, M. (2009). Evaluación de dos técnicas analìticas para la especiación de arsénico en aguas superficiales del sur del Perú. Revista Peruana de Medicina Experimental y Salud Pública, 26(1):20-26. Recuperado el 10 de 02 de 17, de http://www.scielo.org.pe/pdf/rins/v26n1/a05v26n1

Departament of Water. (2009). Government of Western Australia. Recuperado de www.water.wa.gov.au

Diaz Garay, B., Jarufe, B., y Noriega, M. T. (2014). Disposición de planta. Lima: Fondo Editorial de la Universidad de Lima.

DPI Agriculture Water and Irrigation Unit. (2016). Recuperado de Interpreting water quality test results: www.dpi.nsw.gov.au

Driscoll, D., Carter, J., Williamson, J., y Putnam, L. (2002). U.S. Geological Survey. Recuperado de U.S. Geological Survey Web site: https://pubs.usgs.gov/wri/wri024094/pdf/mainbodyofreport-3.pdf

Duan, J., y Gregory, J. (2003). Coagulation by hydrolysig metal salts. Advances in colloid and interface science, 100-102 (2003) 475 - 502.

Grasshoff, K., Kremling, K., Ehrhardt, M., y Wiley, J. (2009). Methods of seawater analysis. Pag. 278.

Grupo de hidrología subterránea. (2018). Grupo de hidrología subterránea. Recuperado de www.h2ogeo.upc.edu/es/salinizacion

Hach Company. (2013). Recuperado de DR/890 Colorimeter Procedures Manual: https://www.hach.com/asset-get.download.jsa?id=7639982259

Hach Company. (2013). Digital Titrator, model 16900.

Halder, D., Lin, J., Essilfie-Dughan, J., Das, S., y Robertson, J. (2018). Implications of the iron(II/III)-arsenic ratio on the precipitation of iron-arsenic minerals from $\mathrm{pH} 2.5$ to 10.5. Applied Geochemistry. 
Han, Q., Wang, H., Dong, W., Liu, T., y Yin, Y. (2013). Formation and inhibition of bromate during ferrate(VI) - Ozone oxidation process. Separation and Purification Technology, 118(2013) 653-658

DOI:10.1016/j.seppur.2013.07.042.

Henke, K. (2009). Arsenic. Environmental chemistry, health threats and waste treatment. Wiley.

Howe, K., Hand, D., Crittenden, J., Trussell, R., y Tchobanoglous, G. (2016). Principios de tratamiento de aguas. México: Cengage Learning.

Ike, M., Miyazaki, T., Yamamoto, N., Sei, K., y Soda, S. (2008). Removal of arsenic from groundwater by arsenite-oxidizing bacteria. Water Science \& TechnologyWST , 1095-1100.

Instituto de Hidrología, Meteorología y Estudios Ambientales (2 de Agosto de 2007). Instituto de Hidrología, Meteorología y Estudios Ambientales - IDEAM. Recuperado de http://www.ideam.gov.co/documents/14691/38155/S\%C3\%B3lidos+Suspendid os+Totales+en+aguas.pdf/f02b4c7f-5b8b-4b0a-803a-1958aac1179c

Instituto Nacional de Estadística e Informática. (2015). Perú: anuario de estadísticas ambientales 2014. Recuperado de www.inei.gob.pe/media/MenuRecursivo/publicaciones_digitales/Est/Lib1197/li bro.pdf

Jian, J.-Q., y Lloyd, B. (2002). Progress in the development and use of ferrate(VI) salt as an oxidant and coagulant for water and wastewater treatment. Water Research, 36(2002) 1397 - 1408.

Jiang, J.-Q., Durai, H., Winzenbacher, M., Petri, M., y Seitz, W. (2014). Drinking water treatment by in situ generated ferrate(VI). Desalination and Water Treatment, 19.

Khan, S., Cao, Q., Zheng, Y., Huang, Y., y Zhu, Y. (2008). Health risks of heavy metals in contaminated soils and food crops irrigated with wastewater in Beijing, China. Environmental pollution (Barking, Essex: 1987), 152(3): 68692.

Konieczny, K., Sąkol, D., Płonka, J., Rajca, M., y Bodzek, M. (2009). Coagulationultrafiltration system for river water treatment. Desalination, 240 (2009) 151159, DOI: 10.1016/j.desal.2007.11.072.

Lee, Y., Um, I.-H., y Yoon, J. (2003). Arsenic(III) Oxidation by Iron(VI) (Ferrate) and Subsequent Removal of Arsenic(V) by Iron(III) Coagulation. Environmental Science \& Technology, 37, 5750-5756.

Light, S., y Yu, X. (2005). Electrochemical Alkaline Fe(VI) Water Purification and Remediation. Envioronmental Science and Technology, 39(2005), 8071 - 8076 DOI: 10.1021/es051084k. 
Lillo, J. (Enero de 2008). Peligros geoquímicos: arsénico de origen natural en las aguas. Recuperado el 07 de Julio de 2018, de Universidad Complutense de Madrid: https://www.ucm.es/data/cont/media/www/pag15564/Peligros\%20geoqu\%C3\%ADmicos\%20del\%20ars\%C3\%A9nico\%20\%20Javier\%20Lillo.pdf

Liviac, D., Creus, A., y Marcos, R. (2009). Genotoxicity analysis of two halonitromethanes, a novel group of disinfection by-products (DBPs), in human cells treated in vitro. Environmental Research, 109(2009) 232-238 DOI: 10.1016/j.envres.2008.12.009.

Ma, J., y Liu, W. (2002). Effectiveness and mechanism of potassium ferrate(VI) preoxidation for algae removal by coagulation. Water Research, 36 (2002) 871878.

Mácová, Z., Bouzek, K., y Sharma, V. (2009). The influence of electrolyte composition on electrochemical ferrate(VI) synthesis. Part I: anodic dissolution kinetics of pure iron. Journal of Applied Electrochemistry, 40(5) 1019-1028 DOI: 10.1007/s10800-009-0051-8.

Mácová, Z., Bouzek, K., Híves, J., Sharma, V., Terryn, R., y Baum, C. (2009). Research progress in the electrochemical synthesis of ferrate(VI). Electrochimica Acta, 54(2009) 2673 - 2683.

McClintock, T., Chen, Y., Bundschuh, J., Oliver, J., Navoni, J., Olmos, V., Parvez, F. (2012). Review Arsenic exposure in Latin America: Biomarkers, risk assessments and related effects. Science of the Total Environment 429, 76-91 DOI: 10.1016/j.scitotenv.2011.08.051.

Ministerio de Economía y Finanzas. (2011). Análisis funcional: Inversión pública en agricultura - riego. Recuperado el 28 de Abril de 2016, de www.snip.gob.pe/contenidos/politicas/difusion/boletin/boletin4/analisis_funcion al.pdf

Ministerio del Ambiente (2017). DS N 004-2017-MINAM : Aprueban Estándares de Calidad Ambiental (ECA) para Agua y establecen Disposiciones Complementarias.

Moreno, P. M. (2009). Arsénico en aguas subterráneas y su transferencia al suelo y a la planta. Tesis doctoral. Universidad de Valladolid.

National Electronic Publications Information System (2005). Treatment Technologies For Arsenic Removal . Recuperado de National Service Center for Environmental Publications (NSCEP): https://nepis.epa.gov/Exe/ZyPURL.cgi?Dockey=20017IDW.txt

Organización de las Naciones Unidas para la agricultura y la alimentación. (2002). Alimentos inocuos y nutritivos para los consumidores. Recuperado de Fao.org: http://www.fao.org/worldfoodsummit/sideevents/papers/y6656s.htm

Organización Mundial de la Salud (2011). Arsenic in drinking water. Recuperado el 14 de Julio de 2018, de World Health Organization: 
http://www.who.int/water_sanitation_health/water-

quality/guidelines/chemicals/arsenic.pdf

Prucek, R., Tuček, J., Kolařík, J., Filip, J., Marušák, Z., Sharma, V., y Zbořil, R. (2013). Ferrate(VI)-Induced Arsenite and Arsenate Removal by In Situ Structural Incorporation into Magnetic Iron(III) Oxide Nanoparticles. Environmental Science and Technology, 47(7) 3283-3292 DOI: 10.1021/es3042719.

Quino-Favero, J., Eyzaguirre, R., Mogrovejo, P., Prieto, P., y Del Pino, L. F. (2018). Electrochemical synthesis of ferrate(VI): Optimization of parameters and evaluation of their impact in production cost. Desalination and Water Treatment, 113, 179-186. DOI:10.5004/dwt.2018.22262.

Rojas Meza, M. E. (2016). Los experimentos demostrativos como metodología de transferencia de tecnología agronómica en un marco de investigación participativa. Perú.

Seimer, R., Reinhart, D., Sharma, V., y Austin, G. (2007). The application of the Green oxidant ferrate for Wastewter disinfection and reuse to be utilized for wetland restoration, irrigation and groundwater recharge. Desinfection.

Serrano, M., Montesinos, I., Cardador, M., Silva, M., y Gallego, M. (2015). Seasonal evaluation of the presence of 46 disinfection by-products throughout a drinking water treatment plant. Science of the Total Environment, 517(2015) 246 - 258 DOI: 10.1016/j.scitotenv.2015.02.070.

Shankar, S., Shanker, U., y Shikha. (2014). Arsenic Contamination of Groundwater: A Review of Sources, Prevalence, Health Risks, and Strategies for Mitigation Review Article. The Scientific World Journal, DOI: 10.1155/2014/304524.

Sharma, V. K., Chen, L., y Zboril, R. (2016). Review on High Valent FeVI (Ferrate): A Sustainable Green Oxidant in Organic Chemistry and Transformation of Pharmaceuticals. ACS Sustainable Chemistry \& Engineering, 4 (1), 18-34.

Sharma, V., Anquandah, G., Kim, H., Jiang, J.-Q., y Zboril, R. (2013). Ferrate(VI): A Green Chemistry Oxidant for Removal of Antibiotics in Water. Novel Solutions to Water Pollution, 31-44 DOI: 10.1021/bk-2013-1123.ch003.

Stanford, C., Jiang, J., y Alsheyab, M. (2009). Electrochemical Production of Ferrate (Iron VI): Application to the Wastewater Treatment on a Laboratory Scale and Comparison with Iron (III) Coagulant. Water, Air, \& Soil Pollution, 209(1-4), 483-488.

Sterlitech Corporation. (2018). GE JX MICROFILTRATION (MF) MEMBRANE. Recuperado el 06 de Agosto de 2018, de Sterlitech Corporation: https://www.sterlitech.com/microfiltration-mf-membrane-ymjxsp3001.html

The National Institute of Environmental Health Sciences. (2005). Report on carcinogens 11 ed. 
Tiwari, D., y Lee, S.-M. (2011). Ferrate(VI) in the Treatment of Wastewaters: A New Generation Green Chemical. Waste Water - Treatment And Reutilization, DOI: $10.5772 / 15500$.

Organización de las Naciones Unidas para la Educación, la Ciencia y la Cultura UNESCO. (2003). La inercia política exacerba la crisis del agua, según el informe mundial sobre recursos hídricos. Recuperado el 28 de Abril de 2016, de Portal.unesco.org: http://portal.unesco.org/es/ev.phpurl_id=10064\&url_do=do_topic\&url_section=201.html

World Health Organization. (2001). United Nations synthesis report on arsenic in drinking water. Geneva.

Yates, B., Zboril, R., y Sharma, V. (2014). Engineering aspects of ferrate in water and wastewater treatment - a review. Journal of Environmental Science and Health, Part A(2014)49, 1603-1614 DOI: 10.1080/10934529.2014.950924.

Yoon, S.-H. (2015). Membrane Bioreactor Processes: Processes and Applications. Taylor \& Francis Group. Recuperado el 27 de Julio de 2018, de http://onlinembr.info/membrane-process/classification-of-membranesaccording-to-pore-size/

Yunho Lee, M. C. (2004). Chemistry of Ferrate (Fe(VI)) in aqueous solution and its applications as a green chemical. J. Ind. Eng. Chem. Vol. 10, No 1, 161-171. 


\section{BIBLIOGRAFÍA}

Amy, G. (2000). Arsenic treatability options and evaluation of residuals management issues. Denver, Colo.: AWWA Research Foundation and American Water Works Association.

Boerschk, R. (2002). Evaluation of Arsenic Mitigation Technologies for Use in Bangladesh. Recuperado de http://archive.unu.edu/env/Arsenic/Boerschke.pdf

Diaz Garay, B., Jarufe, B., y Noriega, M. T. (2014). Disposición de planta. Lima: Fondo Editorial de la Universidad de Lima.

Eaton, A., Hsaio, C., y Northington, J. (1998). Analytical chemistry of arsenic in drinking water. Denver, CO: AWWA Research Foundation.

Henke, K. (2009). Arsenic. Environmental chemistry, health threats and waste treatment. Wiley.

Howe, K., Hand, D., Crittenden, J., Trussell, R., y Tchobanoglous, G. (2016). Principios de tratamiento de aguas. México: Cengage Learning.

Hwang, S. (2002). Point-of-use arsenic removal from drinking water in Nepal using coagulation and filtration. Massachusetts Institute of Technology. 


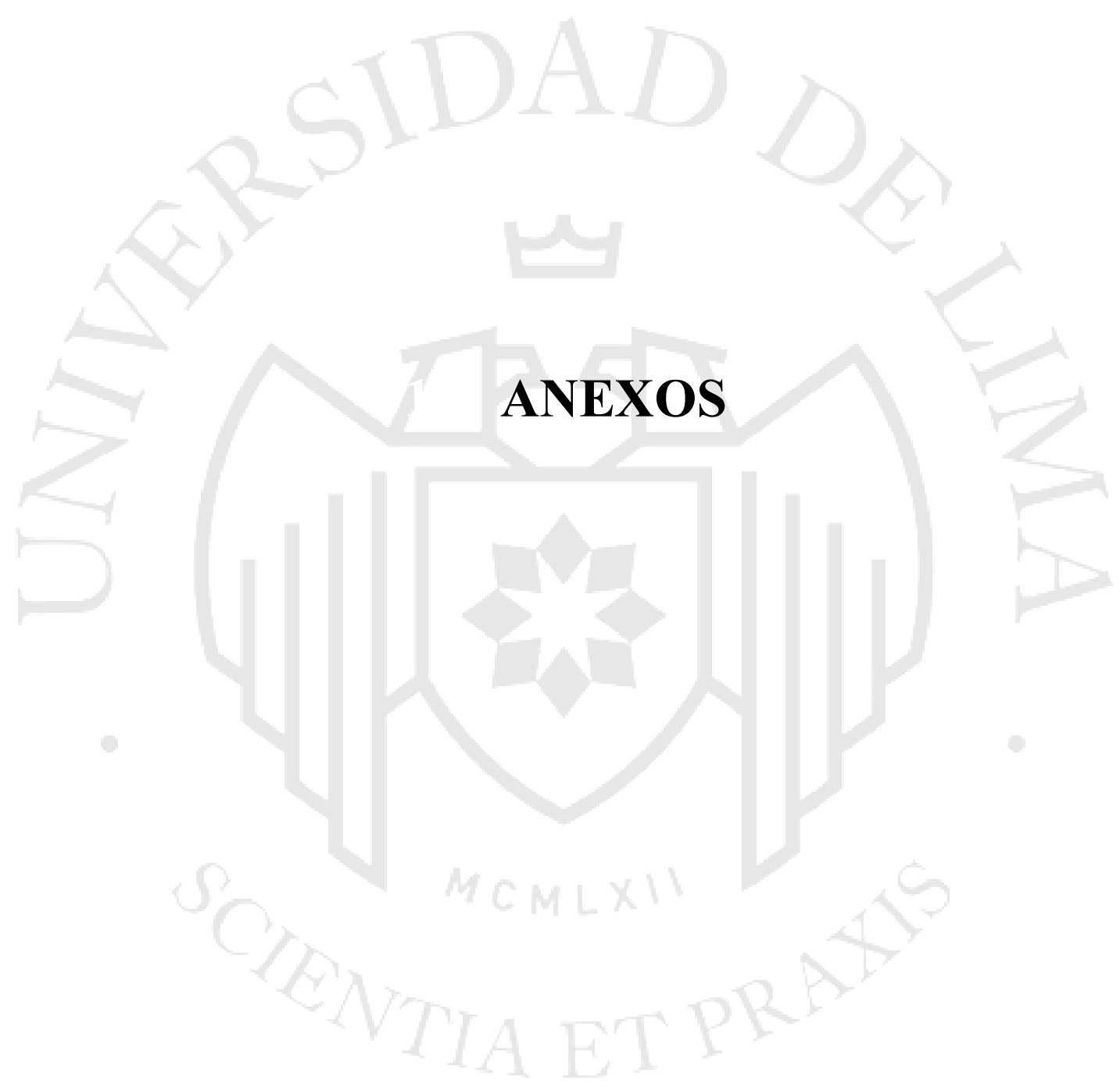




\section{Anexo 1: Decreto supremo N$^{\circ}$ 004-2017-MINAM Estándares de calidad ambiental (ECA) para agua}

Rigl El Peruano/ Miércoles 7 de junio de 20

NORMAS LEGALES

17

Tabla N 0 1: Estándar de calidad de Amoniaco Total en función de $\mathrm{pH}$ y temperatura para la protección de la vida acuática en agua dulce $\left(\mathrm{mg} / \mathrm{L}\right.$ de $\mathrm{NH}_{3}$ )

\begin{tabular}{|c|c|c|c|c|c|c|c|c|}
\hline $\begin{array}{c}\text { Temperatura } \\
\left({ }^{\circ} \mathbf{C}\right)\end{array}$ & \multicolumn{70}{|c|}{$\mathrm{pH}$} \\
\hline & $\mathbf{6}$ & $\mathbf{6 , 5}$ & 7,0 & 7,5 & $\mathbf{8 , 0}$ & $\mathbf{8 , 5}$ & $\mathbf{9 , 0}$ & $\mathbf{1 0 , 0}$ \\
\hline $\mathbf{0}$ & 231 & 73,0 & 23,1 & 7,32 & 2,33 & 0,749 & 0,250 & 0,042 \\
\hline $\mathbf{5}$ & 153 & 48,3 & 15,3 & 4,84 & 1,54 & 0,502 & 0,172 & 0,034 \\
\hline $\mathbf{1 0}$ & 102 & 32,4 & 10,3 & 3,26 & 1,04 & 0,343 & 0,121 & 0,029 \\
\hline 15 & 69,7 & 22,0 & 6,98 & 2,22 & 0,715 & 0,239 & 0,089 & 0,026 \\
\hline $\mathbf{2 0}$ & 48,0 & 15,2 & 4,82 & 1,54 & 0,499 & 0,171 & 0,067 & 0,024 \\
\hline $\mathbf{2 5}$ & 33,5 & 10,6 & 3,37 & 1,08 & 0,354 & 0,125 & 0,053 & 0,022 \\
\hline $\mathbf{3 0}$ & 23,7 & 7,50 & 2,39 & 0,767 & 0,256 & 0,094 & 0,043 & 0,021 \\
\hline
\end{tabular}

\section{Nota:}

$\left({ }^{\star}\right)$ El estándar de calidad de Amoniaco total en función de $\mathrm{pH}$ y temperatura para la protección de la vida acuática en agua dulce, presentan una tabla de valores para rangos de $\mathrm{pH}$ de 6 a 10 y Temperatura de 0 a $30^{\circ} \mathrm{C}$. Para comparar la temperatura y $\mathrm{pH}$ de las muestras de agua superficial, se deben tomar la temperatura y $\mathrm{pH}$ próximo superior al valor obtenido en campo, ya que la condición más extrema se da a mayor temperatura y $\mathrm{pH}$. En tal sentido, no es necesario establecer rangos.

$\left({ }^{*}\right)$ En caso las técnicas analíticas determinen la concentración en unidades de Amoniaco-N $\left(\mathrm{NH}_{3}-\mathrm{N}\right)$, multiplicar el resultado por el factor 1,22 para expresarlo en las unidades de Amoniaco $\left(\mathrm{NH}_{3}\right)$.

Categoría 3: Riego de vegetales y bebida de animales

\begin{tabular}{|c|c|c|c|c|}
\hline \multirow[b]{2}{*}{ Parámetros } & \multirow[b]{2}{*}{$\begin{array}{c}\text { Unidad de } \\
\text { medida }\end{array}$} & \multicolumn{2}{|c|}{ D1: Riego de vegetales } & \multirow{2}{*}{$\begin{array}{c}\text { D2: Bebida de } \\
\text { animales }\end{array}$} \\
\hline & & $\begin{array}{c}\text { Agua para } \\
\text { riego no } \\
\text { restringido } \\
\text { (c) }\end{array}$ & $\begin{array}{c}\text { Agua } \\
\text { para riego } \\
\text { restringido }\end{array}$ & \\
\hline \multicolumn{5}{|c|}{ Físıcos- Químicos } \\
\hline Aceites y Grasas & $\mathrm{mg} / \mathrm{L}$ & \multicolumn{2}{|c|}{5} & 10 \\
\hline Bicarbonatos & $\mathrm{mg} / \mathrm{L}$ & \multicolumn{2}{|c|}{518} & $*$ \\
\hline Cianuro Wad & $\mathrm{mg} / \mathrm{L}$ & \multicolumn{2}{|c|}{0,1} & 0,1 \\
\hline Cloruros & $\mathrm{mg} / \mathrm{L}$ & \multicolumn{2}{|c|}{500} & $*$ \\
\hline Color (b) & $\begin{array}{c}\text { Color } \\
\text { verdadero } \\
\text { Escala Pt } \\
\text { Co }\end{array}$ & \multicolumn{2}{|c|}{$100(a)$} & 100 (a) \\
\hline Conductividad & $(\mu \mathrm{S} / \mathrm{cm})$ & \multicolumn{2}{|c|}{2500} & 5000 \\
\hline \begin{tabular}{|l|} 
Demanda \\
Bioquimica de \\
Oxígeno $\left(\mathrm{DBO}_{5}\right)$ \\
\end{tabular} & $\mathrm{mg} / \mathrm{L}$ & \multicolumn{2}{|c|}{15} & 15 \\
\hline $\begin{array}{l}\text { Demanda Química } \\
\text { de Oxigeno (DQO) }\end{array}$ & $\mathrm{mg} / \mathrm{L}$ & \multicolumn{2}{|c|}{40} & 40 \\
\hline $\begin{array}{l}\begin{array}{l}\text { Detergentes } \\
\text { (SAAM) }\end{array} \\
\end{array}$ & $\mathrm{mg} / \mathrm{L}$ & \multicolumn{2}{|c|}{0,2} & 0,5 \\
\hline Fenoles & $\mathrm{mg} / \mathrm{L}$ & \multicolumn{2}{|c|}{0,002} & 0,01 \\
\hline Fluoruros & $\mathrm{mg} / \mathrm{L}$ & \multicolumn{2}{|c|}{1} & $*$ \\
\hline $\begin{array}{l}\text { Nitratos }\left(\mathrm{NO}_{3}^{-}-\mathrm{N}\right)+ \\
\text { Nitritos }\left(\mathrm{NO}_{2}^{-}-\mathrm{N}\right)\end{array}$ & $\mathrm{mg} / \mathrm{L}$ & \multicolumn{2}{|c|}{100} & 100 \\
\hline Nitritos $\left(\mathrm{NO}_{2}^{-}-\mathrm{N}\right)$ & $\mathrm{mg} / \mathrm{L}$ & \multicolumn{2}{|c|}{10} & 10 \\
\hline $\begin{array}{l}\text { Oxigeno Disuelto } \\
\text { (valor minimo) }\end{array}$ & $\mathrm{mg} / \mathrm{L}$ & \multicolumn{2}{|c|}{$\geq 4$} & $\geq 5$ \\
\hline \begin{tabular}{|l} 
Potencial de \\
Hidrógeno $(\mathrm{pH})$
\end{tabular} & $\begin{array}{c}\text { Unidad de } \\
\mathrm{pH}\end{array}$ & \multicolumn{2}{|c|}{$6,5-8,5$} & $6,5-8,4$ \\
\hline Sulfatos & $\mathrm{mg} / \mathrm{L}$ & \multicolumn{2}{|c|}{1000} & 1000 \\
\hline Temperatura & ${ }^{\circ} \mathrm{C}$ & \multicolumn{2}{|c|}{$\Delta 3$} & $\Delta 3$ \\
\hline \multicolumn{5}{|l|}{ INORGÁNICOS } \\
\hline Aluminio & $\mathrm{mg} / \mathrm{L}$ & & 5 & 5 \\
\hline
\end{tabular}

\begin{tabular}{|c|c|c|c|c|}
\hline \multirow[b]{2}{*}{ Parámetros } & \multirow[b]{2}{*}{$\begin{array}{l}\text { Unidad de } \\
\text { medida }\end{array}$} & \multicolumn{2}{|c|}{ D1: Riego de vegetales } & \multirow{2}{*}{$\begin{array}{c}\text { D2: Bebida de } \\
\text { animales }\end{array}$} \\
\hline & & $\begin{array}{l}\text { Agua para } \\
\text { riego no } \\
\text { restringido } \\
\text { (c) }\end{array}$ & \begin{tabular}{|c|} 
Agua \\
para riego \\
restringido
\end{tabular} & \\
\hline Arsénico & $\mathrm{mg} / \mathrm{L}$ & \multicolumn{2}{|c|}{$\begin{array}{l}0,1 \\
\end{array}$} & 0,2 \\
\hline Bario & $\mathrm{mg} / \mathrm{L}$ & \multicolumn{2}{|c|}{0,7} & $*$ \\
\hline Berilio & $\mathrm{mg} / \mathrm{L}$ & \multicolumn{2}{|c|}{0,1} & 0,1 \\
\hline Boro & $\mathrm{mg} / \mathrm{L}$ & \multicolumn{2}{|c|}{1} & 5 \\
\hline Cadmio & $\mathrm{mg} / \mathrm{L}$ & \multicolumn{2}{|c|}{0,01} & 0,05 \\
\hline Cobre & $\mathrm{mg} / \mathrm{L}$ & \multicolumn{2}{|c|}{0,2} & 0,5 \\
\hline Cobalto & $\mathrm{mg} / \mathrm{L}$ & \multicolumn{2}{|c|}{0,05} & 1 \\
\hline Cromo Total & $\mathrm{mg} / \mathrm{L}$ & \multicolumn{2}{|c|}{0,1} & 1 \\
\hline Hierro & $\mathrm{mg} / \mathrm{L}$ & \multicolumn{2}{|c|}{5} & $*$ \\
\hline Litio & $\mathrm{mg} / \mathrm{L}$ & \multicolumn{2}{|c|}{2,5} & 2,5 \\
\hline Magnesio & $\mathrm{mg} / \mathrm{L}$ & \multicolumn{2}{|c|}{$* *$} & 250 \\
\hline Manganeso & $\mathrm{mg} / \mathrm{L}$ & \multicolumn{2}{|c|}{0,2} & 0,2 \\
\hline Mercurio & $\mathrm{mg} / \mathrm{L}$ & \multicolumn{2}{|c|}{0,001} & 0,01 \\
\hline Niquel & $\mathrm{mg} / \mathrm{L}$ & \multicolumn{2}{|c|}{0,2} & 1 \\
\hline Plomo & $\mathrm{mg} / \mathrm{L}$ & \multicolumn{2}{|c|}{0,05} & 0,05 \\
\hline Selenio & $\mathrm{mg} / \mathrm{L}$ & \multicolumn{2}{|c|}{0,02} & 0,05 \\
\hline Zinc & $\mathrm{mg} / \mathrm{L}$ & \multicolumn{2}{|c|}{2} & 24 \\
\hline \multicolumn{5}{|l|}{ ORGÁNICO } \\
\hline \multicolumn{5}{|c|}{ Bifenilos Policlorados } \\
\hline \begin{tabular}{|l|} 
Bifenilos \\
Policlorados (PCB)
\end{tabular} & $\mu g / L$ & \multicolumn{2}{|c|}{0,04} & 0,045 \\
\hline \multicolumn{5}{|l|}{ PLAGUICIDAS } \\
\hline Paratión & $\mu g / L$ & \multicolumn{2}{|c|}{35} & 35 \\
\hline \multicolumn{5}{|l|}{ Organoclorados } \\
\hline Aldrin & $\mu g / L$ & & 004 & 0,7 \\
\hline Clordano & $\mu g / L$ & & 006 & 7 \\
\hline \begin{tabular}{|l} 
Dicloro Difenil \\
Tricloroetano \\
(DDT)
\end{tabular} & $\mu g / L$ & & 001 & 30 \\
\hline Dieldrin & $\mu g / L$ & & 0,5 & 0,5 \\
\hline Endosulfán & $\mu g / L$ & &, 01 & 0,01 \\
\hline Endrin & $\mu g / L$ & & 004 & 0,2 \\
\hline $\begin{array}{l}\text { Heptacloro y } \\
\text { Heptacloro } \\
\text { Epóxido }\end{array}$ & $\mu g / L$ & &, 01 & 0,03 \\
\hline Lindano & $\mu g / \mathrm{L}$ & & 4 & 4 \\
\hline Carbamato & & & & \\
\hline Aldicarb & $\mu g / \mathrm{L}$ & & 1 & 11 \\
\hline MICROBIOLÓGICO & S Y PARAS & ITOLÓGICO & & \\
\hline $\begin{array}{l}\text { Coliformes } \\
\text { Termotolerantes }\end{array}$ & $\begin{array}{c}\text { NMP/100 } \\
\mathrm{ml}\end{array}$ & 1000 & 2000 & 1000 \\
\hline Escherichia coli & $\begin{array}{c}\text { NMP/100 } \\
\mathrm{ml}\end{array}$ & 1000 & $*$ & $*$ \\
\hline $\begin{array}{l}\text { Huevos de } \\
\text { Helmintos }\end{array}$ & Huevo/L & 1 & 1 & $*$ \\
\hline
\end{tabular}

(a): Para aguas claras. Sin cambio anormal (para aguas que presentan coloración natural).

(b): Después de filtración simple.

(c): Para el riego de parques públicos, campos deportivos, áreas verdes y plantas ornamentales, sólo aplican los parámetros microbiológicos y parasitológicos del tipo de riego no restringido.

$\Delta 3$ : significa variación de 3 grados Celsius respecto al promedio mensual multianual del área evaluada.

\section{Nota 4:}

- El símbolo ** dentro de la tabla significa que el parámetro no aplica para esta Subcategoría.

- Los valores de los parámetros se encuentran en concentraciones totales, salvo que se indique lo contrario. 


\section{Anexo 2: Instrumentos, equipos materiales y reactivos}

\section{Especificaciones de instrumentos/equipos}

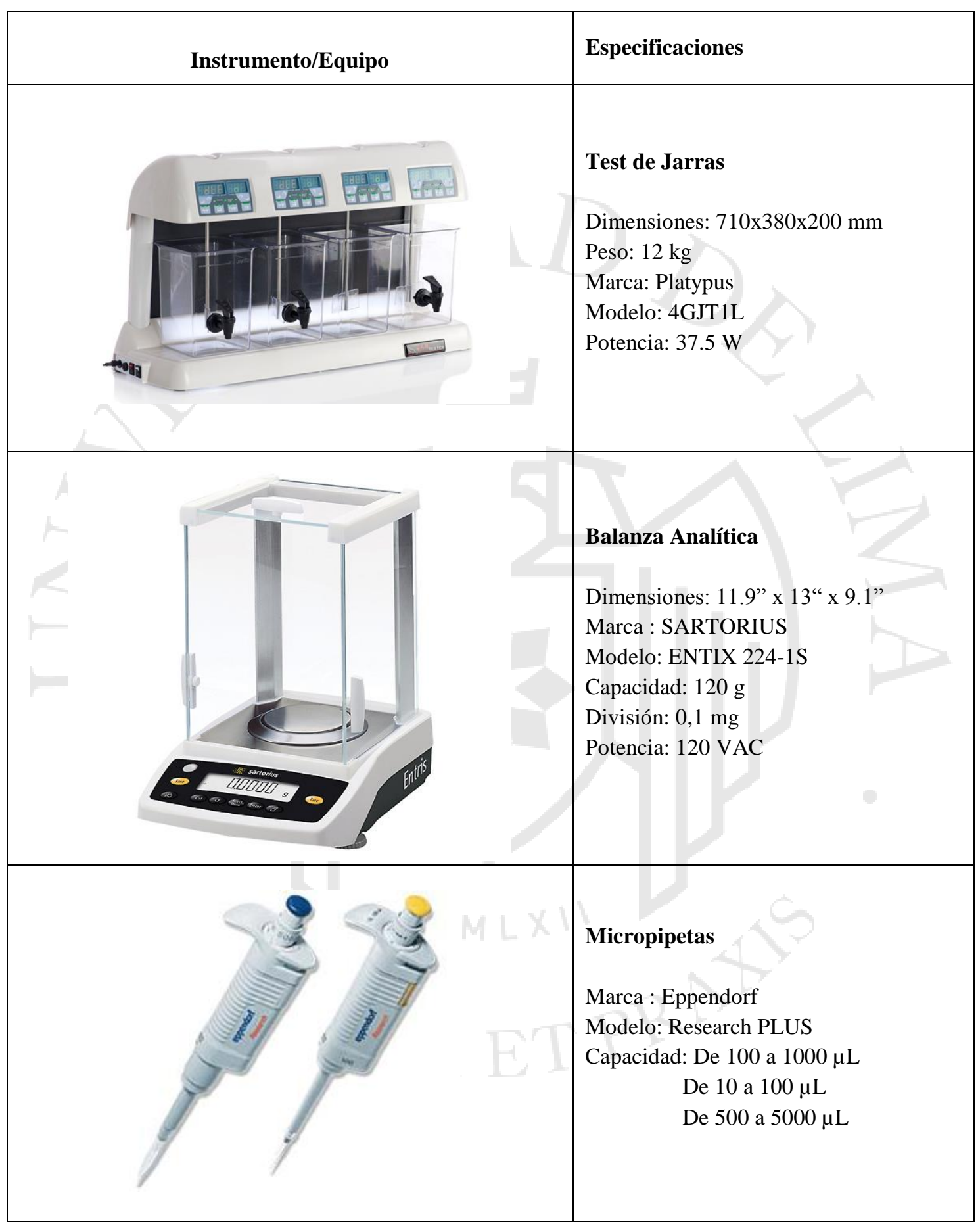

(continúa) 


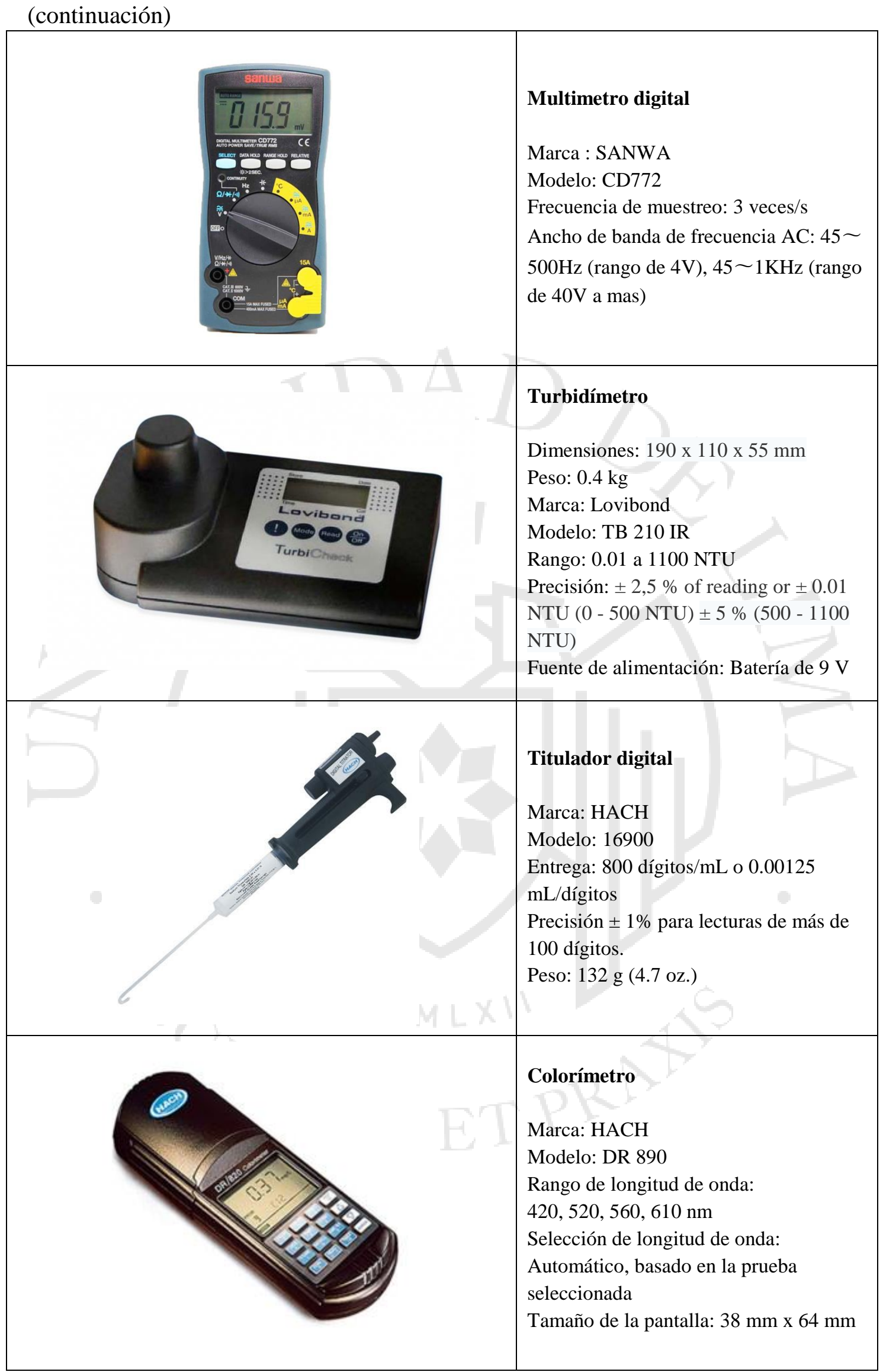

(continúa) 


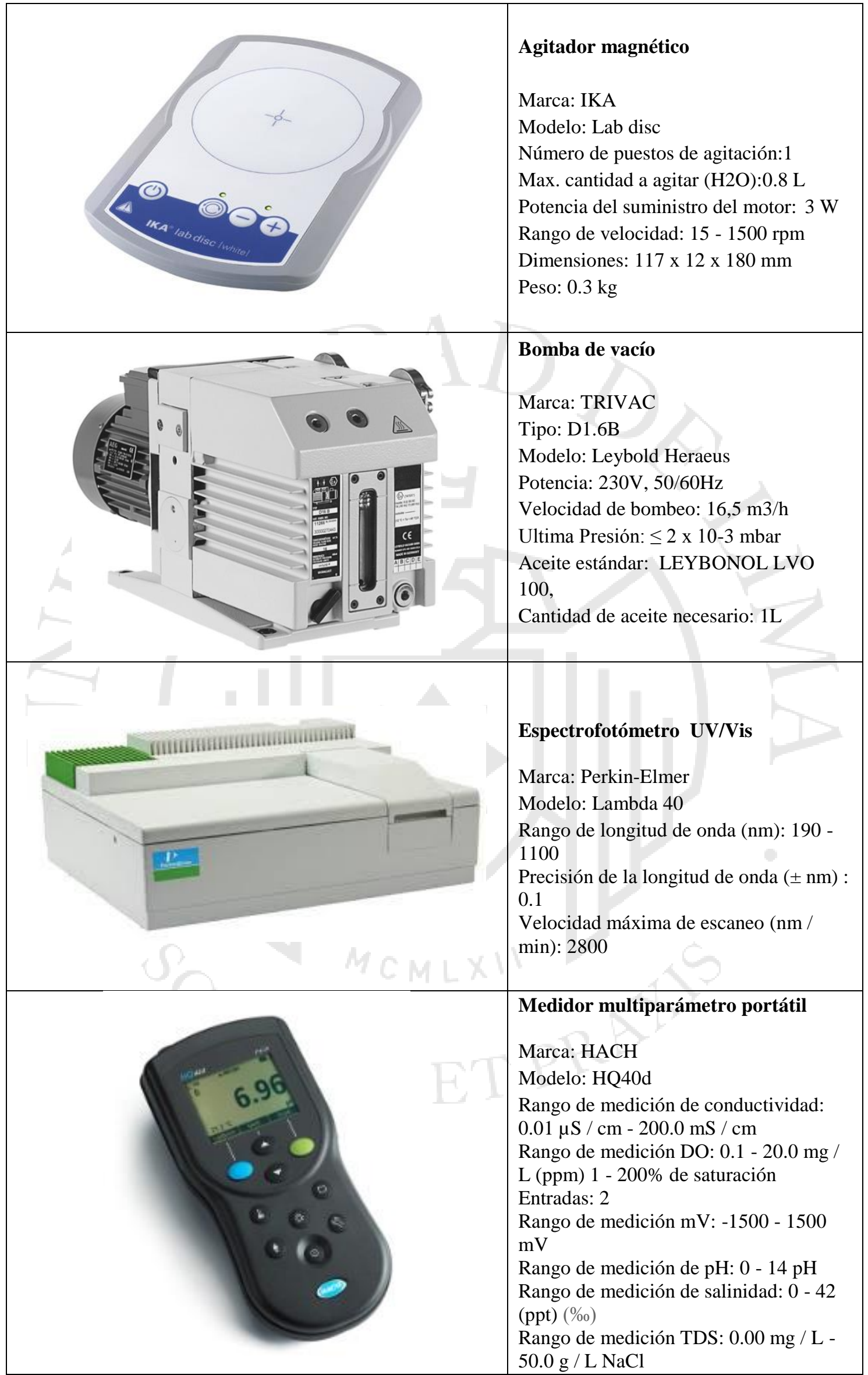




\section{Anexo 3: Datos de ensayos de prueba de jarras}

Remoción de arsénico empleando 1, 2 y3 mg/L de ferrato(VI) con 3, 6 y $9 \mathrm{mg} / \mathrm{L}$ de $\mathrm{Fe}(\mathrm{III})$, seguido de microfiltración en $0.45 \mu \mathrm{m}$.

\begin{tabular}{|c|c|c|c|c|c|c|c|}
\hline $\mathrm{Fe}(\mathrm{VI})$ & $\mathrm{Fe}(\mathrm{III})$ & \multicolumn{4}{|c|}{ Arsénico remanente (mg/L) } & As Total & \multirow{2}{*}{ pH } \\
\hline $\mathrm{mg} / \mathrm{L}$ & $\mathrm{mg} / \mathrm{L}$ & R1 & $\mathbf{R 2}$ & $\mathbf{R 3}$ & R4 & $\mu g / L$ & \\
\hline \multicolumn{2}{|c|}{ Blanco } & 493.6 & 499.3 & 518.4 & 520.8 & $508 \pm 13.6$ & \\
\hline 0 & 0 & 472.1 & 472.8 & 480.7 & 465.8 & $472.8 \pm 6.1$ & $7.1 \pm 0.1$ \\
\hline 1 & 0 & 392.9 & 389.9 & 377.2 & 377.8 & $384.4 \pm 8.2$ & $7 \pm 0$ \\
\hline 2 & 0 & 286.2 & 290.1 & 278.4 & 270.6 & $281.3 \pm 8.6$ & $7.1 \pm 0.3$ \\
\hline 3 & 0 & 201.1 & 199.9 & 248.4 & 249.8 & $224.8 \pm 28.1$ & $7 \pm 0.3$ \\
\hline 0 & 3 & 219.6 & 216.8 & 204.3 & 205.7 & $211.6 \pm 7.7$ & $7 \pm 0.1$ \\
\hline 1 & 3 & 31.3 & 33.1 & 29.3 & 30.6 & $31.1 \pm 1.6$ & $6.9 \pm 0$ \\
\hline 2 & 3 & 18.2 & 17.7 & 22.3 & 22.3 & $20.1 \pm 2.5$ & $6.9 \pm 0.1$ \\
\hline 3 & 3 & 12.6 & 13.6 & 14.4 & 15.4 & $14 \pm 1.2$ & $7 \pm 0.2$ \\
\hline 0 & 6 & 146.3 & 143.7 & 153.9 & 149.5 & $148.4 \pm 4.4$ & $7 \pm 0$ \\
\hline 1 & 6 & 6.6 & 6.9 & 2.6 & 4.0 & $5 \pm 2.1$ & $6.8 \pm 0.2$ \\
\hline 2 & 6 & 3.6 & 4.4 & 7.3 & 6.9 & $5.5 \pm 1.8$ & $6.9 \pm 0.1$ \\
\hline 3 & 6 & 3.9 & 3.6 & 4.7 & 4.7 & $4.2 \pm 0.6$ & $7 \pm 0$ \\
\hline 0 & 9 & 116.5 & 114.0 & 106.1 & 102.8 & $109.8 \pm 6.5$ & $6.8 \pm 0.1$ \\
\hline 1 & 9 & 4.6 & 4.5 & 1.2 & 0.4 & $2.7 \pm 2.2$ & $6.8 \pm 0.4$ \\
\hline 2 & 9 & 2.1 & 2.1 & 1.3 & 1.2 & $1.7 \pm 0.5$ & $6.7 \pm 0.3$ \\
\hline 3 & 9 & 3.5 & 3.6 & 0.9 & 1.4 & $2.3 \pm 1.4$ & $6.8 \pm 0.5$ \\
\hline
\end{tabular}




\section{Anexo 4: Datos de ensayos con otras dosis $\mathrm{Fe}(\mathrm{VI}) / \mathrm{Fe}(\mathrm{III})$}

Remoción de arsénico empleando 0.5 y $1 \mathrm{mg} / \mathrm{L}$ de ferrato(VI) con 10 y $15 \mathrm{mg} / \mathrm{L}$ de $\mathrm{Fe}(\mathrm{III})$, seguido de microfiltración en $0.45 \mu \mathrm{m}$.

\begin{tabular}{|c|c|c|c|}
\hline $\mathrm{Fe}(\mathrm{VI})$ & $\mathrm{Fe}(\mathrm{III})$ & $\begin{array}{c}\text { As Total } \\
\text { remanente }\end{array}$ & \multirow{2}{*}{ pH } \\
\hline $\mathrm{mg} / \mathrm{L}$ & $\mathrm{mg} / \mathrm{L}$ & $\mathrm{mg} / \mathrm{L}$ & \\
\hline \multicolumn{2}{|c|}{ Blanco } & 0,512 & 7,55 \\
\hline 0 & 10 & 0,044 & 6,81 \\
\hline 0 & 10 & 0,061 & 6,80 \\
\hline 0,5 & 10 & 0,010 & 7,06 \\
\hline 0,5 & 10 & 0,010 & 7,07 \\
\hline 1 & 10 & 0,009 & 7,58 \\
\hline & 10 & 0,010 & 7,62 \\
\hline 0 & 15 & 0,032 & 6,66 \\
\hline 0 & 15 & 0,033 & 6,70 \\
\hline 0,5 & 15 & 0,008 & 6,89 \\
\hline 0,5 & 15 & 0,007 & 6,83 \\
\hline 1 & 15 & 0,007 & 7,17 \\
\hline 1 & 15 & 0,008 & 7,16 \\
\hline
\end{tabular}

Elaboración propia 


\section{Anexo 5: Cotización para el Hidróxido de sodio al 50\%}

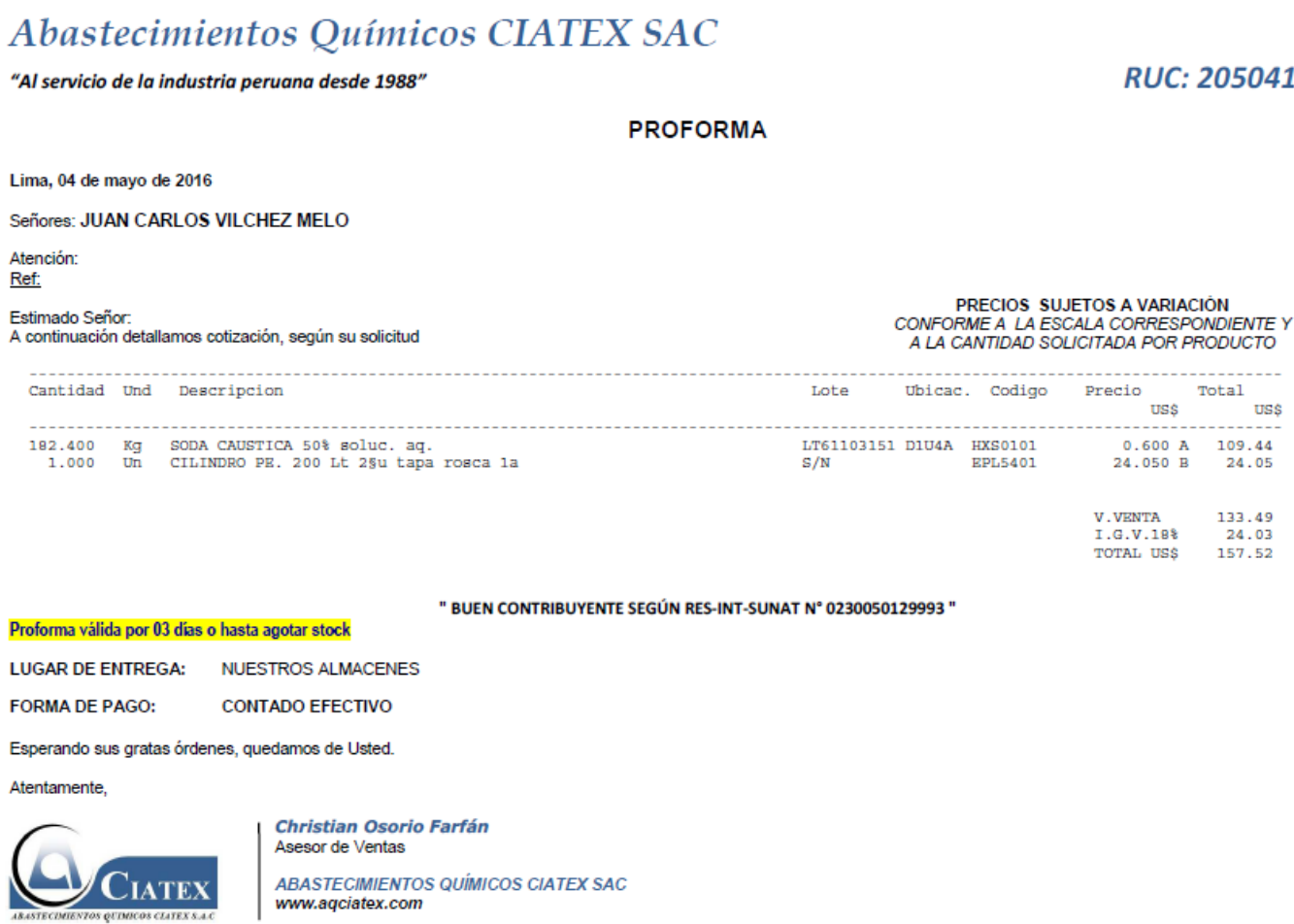

PROFORMA

Lima, 04 de mayo de 2016

Señores: JUAN CARLOS VILCHEZ MELO

Atención:

Estimado Señor:

A continuación detallamos cotización, según su solicitud CONFORME A LA ESCALA CORRESPONDIENTEY

Ubicac. Codigo Precio USS Total USS

$182.400 \quad \mathrm{Kg} \quad$ SODA CAUSTICA 508 Boluc. aq

$\begin{array}{llll}\text { LT61103151 D1U4A } & \text { HXS0101 } & 0.600 \mathrm{~A} & 109.44 \\ \mathrm{~S} / \mathrm{N} & \mathrm{EPL} 5401 & 24.050 \mathrm{~B} & 24.05\end{array}$

$\begin{array}{lr}\text { V.VENTA } & 133.49 \\ \text { I.G.V.18\& } & 24.03 \\ \text { TOTAL USS } & 157.52\end{array}$

Proforma valida por 03 dias o hasta agotar stock

" BUEN CONTRIBUYENTE SEGÚN RES-INT-SUNAT Nº 0230050129993 "

LUGAR DE ENTREGA: NUESTROS ALMACENES

FORMA DE PAGO: CONTADO EFECTIVO

Esperando sus gratas órdenes, quedamos de Usted.

Atentamente,

Christian Osorio Farfán

Asesor de Ventas

ABASTECIMIENTOS QUIMICOS CIATEX SAC

www.aqciatex.com

Ventas: 3320164 - 3325695 - 3326252 - 423264 RPC: $989-001-691$ Horario: L-V : 8:10 am - 12:30 pm / 2:00 pm - 5:30 pm // Sab: 8:20 am - 12:30 pm 


\section{Anexo 6: Cotización para el cloruro férrico al $40 \%$}

QUIMICOS GOICOCHEA S.A.C.

qgventas@quimicosgoicochea.com

Av. Nestor Gambetta 150 - Callao

VENTAS TEL.: $614-4400$

NEXTEL: $101^{*} 4338-833^{*} 8757$

RPM : \#525791

\begin{tabular}{|l|ll|}
\hline CLIENTE & COTIZACION N ${ }^{\circ}$ & 000174898 \\
\hline PROGRAMA NACIONAL DE INNOVACION AGRARIA & TELEFONO : & (511) 3444109 \\
& FAX : & \\
\hline
\end{tabular}

\begin{tabular}{|c|c|c|c|c|c|c|}
\hline FECHA & Banco Continental & $:$ S/.0362-01-0000-6188 & Banco Scotiabank & $: \mathrm{S} / 0004551966$ & FORMA DE PAGO & MONEDA \\
\hline $13 / 09 / 2018$ & $\begin{array}{l}\text { Cta. Cte.: } \\
\text { Banco de Credito } \\
\text { Cta. Cte.: }\end{array}$ & $\begin{array}{c}\$ 0362-01-0000-5513 \\
: \text { S/.194-1057-807-0-17 } \\
\$ 192-1147717-1-09\end{array}$ & $\begin{array}{l}\text { Cta. Cte.: } \\
\text { Banco Interbank } \\
\text { Cta. Cte.: }\end{array}$ & $\begin{array}{l}\$ 0002797331 \\
: \text { S/.041-3000302546 } \\
\$ 041-3000302553\end{array}$ & Depósito en cuenta adelantado & NUEVOS SOLES \\
\hline
\end{tabular}

\begin{tabular}{|c|c|c|c|c|c|c|}
\hline \hline$N^{\circ}$ & UND. & DESCRIPCIÓN & CANT. & $\begin{array}{c}\text { PRECIO UNIT. } \\
\text { SIN IGV. }\end{array}$ & $\begin{array}{c}\text { PREC. TOT. } \\
\text { SIN IGV }\end{array}$ & $\begin{array}{c}\text { PREC. TOT. } \\
\text { INC. IGV }\end{array}$ \\
\hline 1 & UND & CLORURO FERRICO EN SOLUCION AL 40\% (BIDON 40KG) & 1 & 115.000000 & $115.0 \mathrm{C}$ & 135.70 \\
\hline
\end{tabular}




\title{
Anexo 7: Tarifario de energía eléctrica
}

\author{
EMPRESA DE DISTRIBUCION ELECTRICA LUZ DEL SUR S.A.A \\ PRECIOS PARA LA VENTA DE ENERGIA ELECTRICA (incluye IGV)
}

PLIEGO TARIFARIO RETROACTIVO : 04 NOVIEMBRE 2018 (/1)

LDS2018-11

\begin{tabular}{|c|c|c|c|}
\hline & & Sistema Lim & \\
\hline MEDICION DOBLE DE ENERGIA Y CONTRATACION O MEDICION DE DOS POTE & Unidad & MT2 & BT2 \\
\hline Cargo Fijo mensual & $\mathrm{S} / . /$ Usuario & 6,34 & 6,34 \\
\hline Cargo por Energía en punta & cent S/./kW.h & 28,39 & 30,87 \\
\hline Cargo por Energía fuera de punta & cent S/./kW.h & 23,85 & 25,92 \\
\hline Cargo por potencia activa de generación en horas punta & $\mathrm{S} / . / \mathrm{kW}$-mes & 64,96 & 68,51 \\
\hline Cargo por potencia activa por uso redes de distribución en horas punta & $\mathrm{S} / . / \mathrm{kW}$-mes & 10,29 & 51,35 \\
\hline Cargo por exceso de potencia por uso redes distribución en horas fuera de pul & $\mathrm{S} / . / \mathrm{kW}$-mes & 11,15 & 42,59 \\
\hline Cargo por energía reactiva que exceda del $30 \%$ del total de la energía activa & cent S/./kvarh & 5,44 & 5,44 \\
\hline MEDICION DOBLE DE ENERGIA Y UNA POTENCIA CONTRATADA (2E1P) & Unidad & MT3 & BT3 \\
\hline Cargo Fijo mensual & S/./Usuario & 6,32 & 6,32 \\
\hline Cargo por Energía en punta & cent S/./kW.h & 28,39 & 30,87 \\
\hline Cargo por Energía fuera de punta & cent S/./kW.h & 23,85 & 25,92 \\
\hline Cargo por potencia activa de generación para calificación "Presentes punta" & $\mathrm{S} / . / \mathrm{kW}$-mes & 56,73 & 60,60 \\
\hline Cargo por potencia activa de generación para calificación "Fuera punta" & $\mathrm{S} / . / \mathrm{kW}$-mes & 37,22 & 40,06 \\
\hline Cargo por potencia activa por uso redes de distribución para calificación "Pres & $\mathrm{S} / . / \mathrm{kW}$-mes & 11,20 & 53,30 \\
\hline Cargo por potencia activa por uso redes de distribución para calificación "Fuer & $\mathrm{S} / . / \mathrm{kW}$-mes & 11,17 & 49,11 \\
\hline Cargo por energía reactiva que exceda del $30 \%$ del total de la energía activa & cent S/./kvarh & 5,44 & 5,44 \\
\hline SIMPLE MEDICION DE ENERGIA Y UNA POTENCIA CONTRATADA (1E1P) & Unidad & MT4 & BT4 \\
\hline Cargo Fijo mensual & S/./Usuario & 6,32 & 6,32 \\
\hline Cargo por Energía & cent S/./kW.h & 24,87 & 27,05 \\
\hline Cargo por potencia activa de generación para calificación "Presentes punta" & $\mathrm{S} / . / \mathrm{kW}$-mes & 56,73 & 60,60 \\
\hline Cargo por potencia activa de generación para calificación "Fuera punta" & $\mathrm{S} / . / \mathrm{kW}$-mes & 37,22 & 40,06 \\
\hline Cargo por potencia activa por uso redes de distribución para calificación "Pres & $\mathrm{S} / . / \mathrm{kW}-\mathrm{mes}$ & 11,20 & 53,30 \\
\hline Cargo por potencia activa por uso redes de distribución para calificación "Fuer & $\mathrm{S} / . / \mathrm{kW}$-mes & 11,17 & 49,11 \\
\hline Cargo por Energía Reactiva que exceda el $30 \%$ del total de la Energía Activa & cent $\mathrm{S} / . / \mathrm{kvarh}$ & 5,44 & 5,44 \\
\hline DOBLE MEDICION DE ENERGIA (2E) & Unidad & & BT5A \\
\hline Cargo Fijo mensual & S/./Usuario & & 6,32 \\
\hline Cargo por Energía en punta para demandas hasta $20 \mathrm{~kW}$ en horas punta y fue & cent $\mathrm{S} / . / \mathrm{kW} \cdot \mathrm{h}$ & & 213,04 \\
\hline Cargo por Energía en punta para demandas hasta $20 \mathrm{~kW}$ en hor.punta y $50 \mathrm{~kW}$ & cent S/./kW.h & & 184,39 \\
\hline Cargo por Energía fuera de punta & cent S/./kW.h & & 25,92 \\
\hline Cargo por exceso de potencia en horas fuera de punta & $\mathrm{S} / . / \mathrm{kW}$-mes & & 46,16 \\
\hline Cargo por exceso de potencia en horas de punta & $\mathrm{S} / . / \mathrm{kW}$-mes & & 46,16 \\
\hline SIMPLE MEDICION DE ENERGIA (1E) & Unidad & & BT5C-AP \\
\hline Cargo Fijo mensual & S/./Usuario & & 3,50 \\
\hline Cargo por Energía & cent S/./kW.h & & 62,61 \\
\hline CLIENTES A PENSION FIJA & Unidad & & BT6 \\
\hline Cargo Fijo mensual & S/./Usuario & & 3,27 \\
\hline Cargo mensual por Potencia & cent S/./Watt & & 25,20 \\
\hline
\end{tabular}

